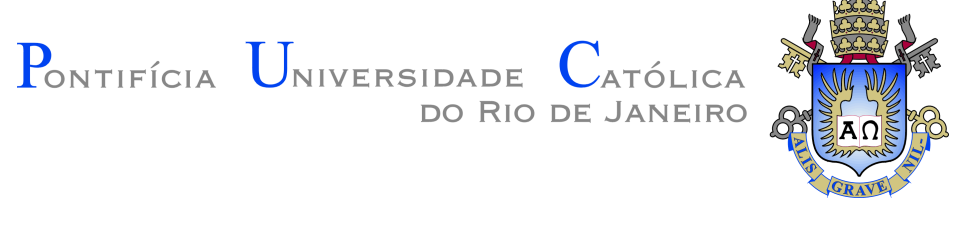

Lorena Rodrigues da Costa Moraes

\title{
Rheology of functionalized graphene suspensions in a model yield stress fluid
}

Tese de Doutorado

Thesis presented to the Programa de Pós-graduação em Engenharia Mecânica, do Departamento de Engenharia Mecânica da PUC-Rio in partial fulfillment of the requirements for the degree of Doutor em Engenharia Mecânica.

Advisor : $\quad$ Profa. Mônica Feijó Naccache Co-advisor: Prof. Ricardo Jorge Espanhol Andrade 

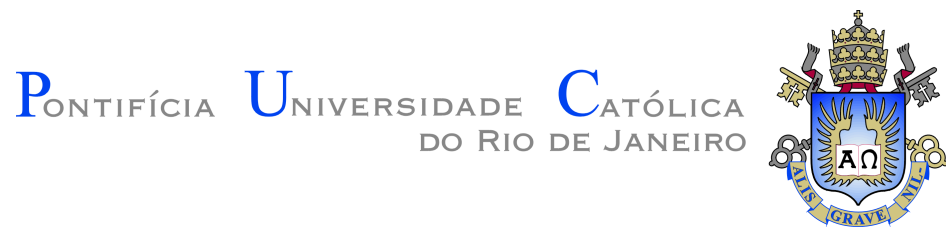

Lorena Rodrigues da Costa Moraes

\author{
Rheology of functionalized graphene \\ suspensions in a model yield stress fluid
}

Thesis presented to the Programa de Pós-graduação em Engenharia Mecânica of PUC-Rio in partial fulfillment of the requirements for the degree of Doutor em Engenharia Mecânica. Approved by the Examination Committee.

Profa. Mônica Feijó Naccache

Advisor

Departamento de Engenharia Mecânica - PUC-Rio

Prof. Ricardo Jorge Espanhol Andrade

Co-advisor

Mackgraphe - Universidade Presbiteriana Mackenzie

Profa. Nicole Raymonde Demarquette

École de Technologie Supérieure - Université du Québec

Prof. Francisco J. Galindo-Rosales

Faculdade de Engenharia - Universidade do Porto

Prof. Sergio Humberto Domingues Mackgraphe - Instituto Presbiteriano Mackenzie

Profa. Aurora Pérez Gramatges

Departamento de Química - PUC-Rio

Rio de Janeiro, June the 7th, 2021 
All rights reserved.

\section{Lorena Rodrigues da Costa Moraes}

Graduated in Mechanical Engineering from the State University of Rio de Janeiro (UERJ) in 2011, she obtained a M.Sc. Degree in Materials Science and Technology also from UERJ in 2015, emphasizing the study of polymeric materials.

Bibliographic data

Rodrigues da Costa Moraes, Lorena

Rheology of functionalized graphene suspensions in a model yield stress fluid / Lorena Rodrigues da Costa Moraes; advisor: Mônica Feijó Naccache; co-advisor: Ricardo Jorge Espanhol Andrade. - Rio de janeiro: PUC-Rio, Departamento de Engenharia Mecânica, 2021.

v., 101 f: il. color. ; $30 \mathrm{~cm}$

Tese (doutorado) - Pontifícia Universidade Católica do Rio de Janeiro, Departamento de Engenharia Mecânica.

Inclui bibliografia

1. Engenharia Mecânica - Teses.

2. Grafeno;. 3. Óxido de Grafeno;. 4. Grafeno Funcionalizado;. 5. Reologia;. 6. Fluido Viscoplástico;. 7. Suspensão;. 8. Hidrogel;. 9. Carbopol.. I. Naccache, Mônica. II. Andrade, Ricardo. III. Pontifícia Universidade Católica do Rio de Janeiro. Departamento de Engenharia Mecânica. IV. Título. 


\section{Acknowledgments}

First of all, I thank God for the gift of life and for the opportunities that I have found along the way. Nothing would be possible without Him. I thank Our Lady, the mother who take the lead, whenever I pray to Mary I feel love, patience and courage to live life. I am also grateful to my saints, Santa Rita and Santa Teresinha, in the difficult moments of my doctorate I prayed, asked for support, and was always answered. Finally, I express my thanks to the divine forces, I believe that they exist.

My gratitude to my advisors Monica Feijó Naccache and Ricardo Jorge Espanhol Andrade. I thank Monica for trusting me and bringing me to the GReo group. More than guiding research and teaching fluid mechanics, heat transfer and rheology (which is no small feat), Professor Monica has affection for her students and is always concerned with our well-being and committed to our personal and professional growth, I always say that I was very lucky to have her as an advisor. Professor Ricardo introduced me to a completely new and exciting world, the nano world, and was fundamental in the development of this thesis. In addition to teaching me about graphene, characterization techniques and rheology, he was always enthusiastic and encouraged research to go further, giving advice and words of encouragement when situations got more difficult.

I also thank Professor Helio Ribeiro, who I consider to be my third advisor. At the end of 2019, Professor Helio joined the research team, bringing a deeper chemical analysis. In addition to synthesizing the amine-functionalized graphene oxide and providing the XPS characterization with the CDTN group, he helped a lot in the interpretation of the chemical characterizations. There were many remote meetings. Thank you very much for your patience, disposal to teach and encouragement.

I am very grateful to the friends of the GReo group: Ricardo, Isabela, Eliana, Roberta, Elias, João Naccache, Daniel, Behbood, João Cunha, Erika, Bruno, Alexandre, Monica Netto, Gustavo, Angela, Ana Carolina, Marina, Márcio, William and especially to my dear Pedro, Camila, Tatiana and Priscilla, for the days shared, conversations, discussions, exchange of ideas and happy hours. What a wonderful group to work with!

I would also like to thank the Mechanical Engineering department of the Pontifical Catholic University of Rio de Janeiro, especially Carina Beline for helping with the administrative procedures inherent to the doctorate.

I thank the institution and colleagues at Mackgraphe, especially Dr. Leice Amurin for advising on the synthesis of graphene oxide, Dr. Fernanda Valim and Elyff Cargnin for the GO characterization tests. 
I am grateful to the Center for the Development of Nuclear Technology (CDTN) for enabling the synthesis of amine-functionalized graphene oxide and to Dr. Wellington Marcos da Silva for conducting X-ray photoelectron spectroscopy.

I am grateful to the Laboratory of Microhydrodynamics and Flow in Porous Media (LMMP) group for the space so that graphene oxide synthesis could be performed and for the zeta potential tests. I would like to especially thank Felicle Lopez and Leonardo Moreira, for their friendly reception and for always being helpful, and Anthony Hutin who helped a lot in conducting the tests.

For my previous training, I am grateful to the University of the State of Rio de Janeiro (UERJ), in particular to Professor Marisa Cristina Guimarães Rocha, who made me develop a taste for research and polymeric materials, and to Professor Norberto Cella, who encouraged me to look for new opportunities and whom I admire a lot. I am also thankful to UERJ for giving me the opportunity to meet great people and form strong friendships, in particular Ranna Silveira, Peterson Heringer and Jorge Futigami who are always cheering for me and encouraging me to grow. I extend my thanks to William Korzan, my first boss and mentor in the industry, thank you for the confidence, advices, and encouragement that have helped me get this far.

I thank my family with all my heart for all the strength, love and affection. To my parents Paulo and Aneliesse, all my love, everything is for you. To my brother Leonardo, my nephew Marcelo and sister-in-law Jessica, you inspire me to be better. To Helenise, Josemeire, Jorge Luís, Isabel, Moisés, Christian, João Vitor, Antônio, Pierre and Ailton, I love you. I include here a thanks to the brothers Cândida Marly and Luzio, who took care of me during the time I lived in Rio de Janeiro as if I were a daughter.

This study was financed in part by the Coordenação de Aperfeiçoamento de Pessoal de Nível Superior - Brasil (CAPES) - Finance Code 001. I would like to thank also the Petrobras for the scholarship and financial support; and the Conselho Nacional de Desenvolvimento Científico e Tecnológico (CNPq, Project Number: 409917/2018-4), the Fundação de Amparo à Pesquisa do Estado do Rio de Janeiro (FAPERJ), the Fundação de Amparo à Pesquisa do Estado do São Paulo (FAPESP), and the Fundo Mackenzie de Pesquisa (MackPesquisa, Project Number 181009) for supporting the research. 


\section{Abstract}

Rodrigues da Costa Moraes, Lorena; Naccache, Mônica (Advisor); Andrade, Ricardo (Co-Advisor). Rheology of functionalized graphene suspensions in a model yield stress fluid. Rio de Janeiro, 2021. 101p. Tese de doutorado - Departamento de Engenharia Mecânica, Pontifícia Universidade Católica do Rio de Janeiro.

This work investigates the impact of functionalized graphene suspensions on the rheology of a Carbopol aqueous dispersion. The graphene derivatives used were graphene oxide (GO) and amino-functionalized graphene oxide (AFGO). The variation of the functionalized graphene concentration and oxidation was evaluated and related with the suspensions rheology. GO nanosheets were produced from synthesis of graphite oxide by modified Hummers method, and they were characterized by XRD, Raman,TGA, FTIR, XPS, TEM and AFM techniques. The GO was functionalized with triethylenetetramine by microwave assisted reaction to produce the AFGO, which was characterized by TGA and XPS techiniques. The suspensions were characterized by zeta potential experiments and rheological tests through steady-state and oscillatory flow. The GO characterization shows that oxygenated functional groups were incorporated in its graphitical surface. GO oxidized for 96 hours (GO 96 h) showed higher interplanar distance and also presented fewer layers when compared with GO oxidized for 2 hours (GO $2 \mathrm{~h}$ ). The AFGO characterization points out that aminated groups were covalently attached to the GO nanosheets and the GO with a higher oxidation degree produced an AFGO with higher amination level. All synthesized nanosheets are colloidally stable when suspended at neutral media. All suspensions were well modeled by the Hershel-Bulkley equation. The increase of the nanosheets concentration in the suspensions impairs the level of fluid structure and leads to a decrease in viscosity, yield stress, and elasticity. The GO $96 \mathrm{~h}$ promoted a lower decrease in viscosity, yield stress and elasticity than the GO $2 \mathrm{~h}$ suspension. In the case of AFGO, the greater amination degree can lead to a more pronounced drop in the suspension rheological properties. For the suspension with a higher concentration of GO $96 \mathrm{~h}$, it was observed the appearance of hysteresis at low shear rates. These results show that small changes in the graphene functionalized nanosheets surface can influence the rheological responses of a non-Newtonian fluid.

\section{Keywords}

Graphene; Graphene Oxide; Functionalized Graphene; Rheology; Yield Stress Fluid; Suspension; Hydrogel; Carbopol. 


\section{Resumo}

Rodrigues da Costa Moraes, Lorena; Naccache, Mônica; Andrade, Ricardo. Reologia de suspensões de grafeno funcionalizado num fluido modelo com tensão limite de escoamento. Rio de Janeiro, 2021. 101p. Tese de Doutorado - Departamento de Engenharia Mecânica, Pontifícia Universidade Católica do Rio de Janeiro.

Este trabalho investiga o impacto de suspensões de grafeno funcionalizado sobre reologia de uma dispersão aquosa de Carbopol. Os derivados de grafeno usados foram óxido de grafeno (GO) e óxido de grafeno amino funcionalizado (AFGO). A variação da concentração e do grau de oxidação do grafeno funcionalizado foram avaliadas e relacionadas à reologia das suspensões. O GO foi produzido a partir da síntese de óxido de grafite pelo método de Hummers modificado, e caracterizado pelas técnicas de DRX, Raman, TGA, FTIR, XPS, TEM e AFM. O GO foi funcionalizado com trietilenotetramina por reação assistida por microondas para produzir AFGO, caracterizado por TGA e XPS. As suspensões foram caracterizadas por experimentos de potencial zeta e testes reológicos de escoamento em estado estacionário e oscilatório. A caracterização do GO mostra que grupos funcionais oxigenados foram incorporados em sua superfície grafítica. O GO oxidado por 96 horas (GO 96 h) apresentou maior distância interplanar e também apresentou menos camadas quando comparado com GO oxidado por 2 horas (GO $2 \mathrm{~h}$ ). A caracterização do AFGO aponta que grupos aminados foram covalentemente ligados às nanofolhas GO e o GO com maior grau de oxidação produziu AFGO com maior nível de aminação. Todas as nanofolhas sintetizadas são coloidalmente estáveis quando suspensas em meio neutro. Todas as suspensões foram bem modeladas pela equação de Hershel-Bulkley. O aumento da concentração de nanofolhas nas suspensões prejudica a microestrutura do fluido e leva a uma diminuição da viscosidade, tensão de escoamento e elasticidade. O GO 96 h promoveu menor decréscimo na viscosidade, tensão de escoamento e elasticidade do que a suspensão GO 2 h. No caso do AFGO, o maior grau de aminação pode levar a uma queda mais pronunciada nas propriedades reológicas da suspensão. Para a suspensão com maior concentração de GO 96 h, observou-se o aparecimento de histerese em baixas taxas de cisalhamento. Esses resultados mostram que pequenas mudanças na superfície das nanofolhas de grafeno funcionalizado podem influenciar as respostas reológicas de um fluido não newtoniano.

\section{Palavras-chave}

Grafeno; Óxido de Grafeno; Grafeno Funcionalizado; Reologia; Fluido Viscoplástico; Suspensão; Hidrogel; Carbopol. 


\section{Table of contents}

1 Introduction $\quad 14$

$\begin{array}{lll}1.1 & \text { Motivation } & 14\end{array}$

$\begin{array}{lll}1.2 & \text { Objective } & 21\end{array}$

$2 \quad$ Background and Literature Review $\quad 23$

2.1 Graphene: background, structure and properties 23

$\begin{array}{lll}2.1 .1 & \text { Graphene functionalization } & 29\end{array}$

2.1.1.1 Graphene oxide 30

2.1.1.2 Amine-functionalized graphene oxide 35

$\begin{array}{lll}2.2 & \text { Non-Newtonian fluids } & 36\end{array}$

2.2.1 Yield-stress shear-thinning fluids 38

2.2.1.1 Carbopol ${ }^{\circledR}$ aqueous dispersion 41

3 Materials and Methods $\quad 44$

3.1 Graphene functionalizations $\quad 44$

3.1.1 Synthesis of graphene oxide 44

3.1.2 GO amine-functionalization $\quad 45$

3.2 Preparation of the suspensions 46

3.2.1 Graphene oxide suspensions 46

3.2.2 Amine-functionalized graphene oxide suspensions 47

$\begin{array}{lll}3.3 & \text { Characterization of the nanosheets } & 48\end{array}$

$\begin{array}{lll}3.3 .1 & \text { XRD } & 48\end{array}$

$\begin{array}{lll}3.3 .2 & \text { Raman } & 48\end{array}$

$\begin{array}{llr}3.3 .3 & \text { FTIR } & 49\end{array}$

$\begin{array}{lll}3.3 .4 & \text { TEM } & 49\end{array}$

$\begin{array}{lll}3.3 .5 & \text { AFM } & 49\end{array}$

$\begin{array}{lll}3.3 .6 & \text { TGA and DTG } & 50\end{array}$

$\begin{array}{lll}3.3 .7 & \text { XPS } & 50\end{array}$

3.4 Characterization of the suspensions 50

3.4.1 Rheological measurements 50

3.4.2 Zeta potential 52

$4 \quad$ Results and Discussions $\quad 53$

4.1 Physico-chemical aspects of functionalized graphene nanosheets 53

$\begin{array}{lll}4.2 & \text { Rheological and structural aspects of the suspensions } & 62\end{array}$

4.2.1 Graphene oxide suspensions characteristics 62

4.2.2 Amine-functionalized graphene oxide suspensions characteristics 73

$5 \quad$ Final Remarks $\quad 83$

$6 \quad$ Bibliography $\quad 85$ 


\section{List of figures}

Figure 1.1 The influence of gold nanoparticles size and shape on the optical properties of their suspensions 14

$\begin{array}{lll}\text { Figure 1.2 Graphene molecular model. } & 15\end{array}$

$\begin{array}{ll}\text { Figure 1.3 Graphene oxide molecular model. } & 16\end{array}$

$\begin{array}{lll}\text { Figure 1.4 Model of amine-functionalized graphene oxide } & 17\end{array}$

Figure 2.1 Schotch tape method 24

$\begin{array}{lll}\text { Figure 2.2 Precursor of all graphitic forms. } & 25\end{array}$

$\begin{array}{lll}\text { Figure 2.3 Graphene structure. } & 26\end{array}$

Figure 2.4 Circular regions with delocation of electrons. 26

$\begin{array}{lll}\text { Figure 2.5 Examples ofgraphene defects } & 28\end{array}$

Figure 2.6 Synthesis of graphene oxide and sheet structure 32

Figure 2.7 GO amine-functionalization 36

Figure 2.8 Classification of some flow curves behaviors 37

Figure 2.9 Rheological properties $\times$ manufacturing techniques. $\quad 38$

Figure 2.10 Carbopol molecular structure unit 42

Figure 2.11 Carbopol gel formation 42

Figure 3.1 Synthesis of graphite oxide $\quad 45$

$\begin{array}{lll}\text { Figure 3.2 Graphene oxide suspension preparation } & 47\end{array}$

Figure 3.3 Amine-functionalized graphene oxide suspension preparation 48

$\begin{array}{lll}\text { Figure } 3.4 & \text { AR-G2 Rheometer } & 51\end{array}$

Figure 4.1 Graphene oxide XRD patterns 53

Figure 4.2 Raman spectra of GO nanosheets $\quad 54$

Figure 4.3 FTIR spectrum of GO nanosheets $\quad 55$

Figure 4.4 TGA and DTG of GO nanosheets 56

Figure 4.5 TGA and DTG of AFGO nanosheets 57

Figure 4.6 TEM images of GO nanosheets 58

Figure 4.7 AFM image of GO oxidized for 2 hours 59

Figure 4.8 AFM thickness distribution profile for GO 2 and 96h 60

Figure 4.9 XPS spectra for graphite, GO 96h and AFGO 96h 61

Figure 4.10 High-resolution photoemission $\mathrm{C} 1 s$ peaks 61

Figure 4.11 High-resolution photoemission O1s peaks 63

Figure 4.12 High-resolution photoemission O1s peaks for AFGO 63

Figure 4.13 Flow curves of the three different preparation methods 64

Figure 4.14 Stress sweep curves of the three different preparation methods

Figure 4.15 Measurement repeatability for the suspension with 1 $\mathrm{mg} / \mathrm{mL}$ of GO $2 \mathrm{~h}$ in $0.3 \%$ wt Carbopol dispersion

Figure 4.16 Flow curves of suspensions with $0,0.1,1$ and $5 \mathrm{mg} / \mathrm{mL}$ GO 96h concentrations

Figure 4.17 Stress sweep curves of suspensions with 0, 0.1, 1 and 5 $\mathrm{mg} / \mathrm{mL}$ GO $96 \mathrm{~h}$ concentrations 
Figure 4.18 Effect of oxidation degree on suspensions flow curves

Figure 4.19 Effect of oxidation degree on suspensions stress sweep curves

Figure 4.20 Hysteresis curves of the suspensions with $5 \mathrm{mg} / \mathrm{mL}$ of GO oxidized for 2 and 96 hours

Figure 4.21 Flow curve stability of $5 \mathrm{mg} / \mathrm{mL}$ GO 2 h suspension $\quad 72$

Figure 4.22 AFGO directly sonicated in Carbopol dispersion 74

Figure 4.23 Flow curves of suspensions with 0, 0.1, 1 and $5 \mathrm{mg} / \mathrm{mL}$ AFGO 96h concentrations

Figure 4.24 Stress sweep curves of suspensions with $0,0.1,1$ and 5 $\mathrm{mg} / \mathrm{mL}$ AFGO 96h concentrations

Figure 4.25 Effect of amination degree on AFGO suspensions flow curves

Figure 4.26 Effect of amination degree on suspensions stress sweep curves

Figure 4.27 Hysteresis curves of the suspensions with $5 \mathrm{mg} / \mathrm{mL}$ of AFGO $2 \mathrm{~h}$ and $96 \mathrm{~h}$

Figure 4.28 Flow curves stability of AFGO suspensions after one month 80

Figure 4.29 Structure of AFGO Suspensions on Carbopol 


\section{List of tables}

Table 4.1 Herschel-Bulkley fitting parameters and $\mathrm{pH}$ of the 0.15 wt\% of Carbopol suspensions with $1 \mathrm{mg} / \mathrm{ml}$ of GO $2 \mathrm{~h}$

Table 4.2 Herschel-Bulkley fitting parameters of the suspensions of GO oxidized for 2 and 96 hours

Table 4.3 Zeta potential values of Carbopol dispersion and GO $2 \mathrm{~h}$ suspensions

Table 4.4 Herschel-Bulkley fitting parameters of the suspensions of AFGO 2 and 96 hours

Table 4.5 Zeta potential values of Carbopol dispersion and AFGO $2 \mathrm{~h}$ and $96 \mathrm{~h}$ suspensions 
Panta Rhei ("Everything flows")

Heraclitus, 535-475 BC. 


\section{List of Abbreviations}

GO - Graphene Oxide

$\mathrm{GrO}$ - Graphite Oxide

AFGO - Amine-Functionalized Graphene Oxide

TETA - Triethylenetetramine

PEG - Polyethylene Glycol

GOSF - Silica Fume Encapsulated Graphene Oxide

QHE - Quantum Hall Effect

CVD - Chemical Vapor Deposition

XRD - X-ray Difraction

FTIR - Fourier Transform Infrared

TGA - Thermogravimetric Analysis

DTG - Derivative Thermogravimetry

TEM - Transmission Electon Microscopy

AFM - Atomic Force Microscopy

XPS - X-ray Photoelectron Spectroscopy

LVR - Linear Viscoelastic Region 


\section{Introduction}

\section{1}

\section{Motivation}

The understanding that the size of a material affects its behavior was an important milestone for all areas of knowledge, even originating the branches of nanoscience and nanotechnology. When the dimensions of a material are reduced to the nanoscale, its chemical and physical properties significantly differ from those found for the same material in micro and macroscopic scales $[1,2]$. A famous example of such behavior is the coloring of gold colloidal dispersions in water, a phenomenon first observed by Michael Faraday in the 19th century, who managed to prepare an aqueous dispersion of gold particles with an average diameter of $6 \pm 2 \mathrm{~nm}$ [3]. Gold, which on a macromolecular scale has a yellowish color, showed a ruby red color when reduced to such nanoscale dimensions. Later, it was found that, depending on the size and shape of the nanoparticles, there is a variation of the gold dispersions color, that is, the particle dimensions impact its light absorption, an optical property [4,5]. Figure1.1 ilustrates this behavior.

a.

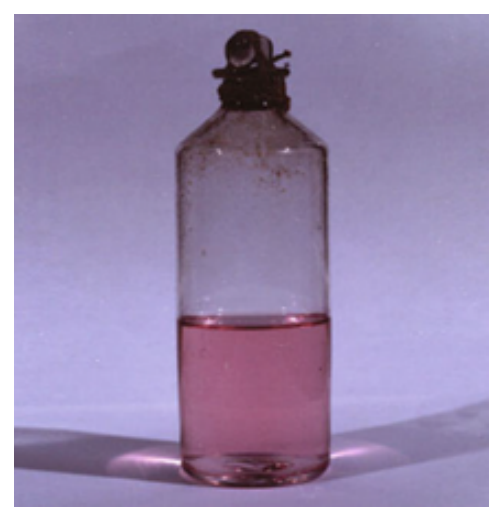

b.

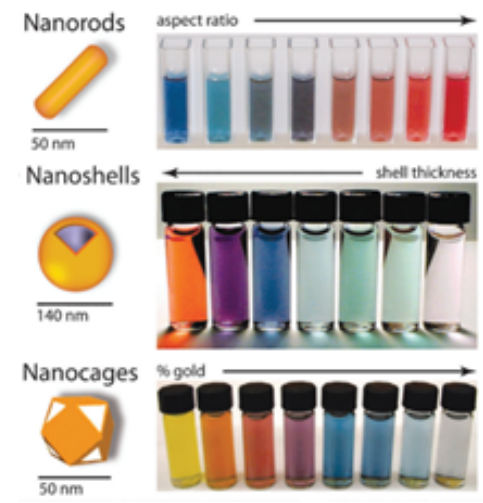

Figure 1.1: a. Faraday's colloidal ruby gold [3] and b. Color dependence of Au NPs on size and shape [5].

Typically, nanomaterials are considered those that have at least one of their dimensions from $100 \mathrm{~nm}$ down to the atomic level (approximately $0.2 \mathrm{~nm}$ ), as it is generally in this range (particularly at the lower end) that materials properties become different or enhanced. The two main reasons 
for this change in behavior are the increased relative surface area, and the dominance of quantum effects [6]. With the progress in nanoscience and nanotechnology, unexpected properties have been discovered for the great variety of nanomaterials synthesized so far. This has brought new and exciting possibilities for future technologies. The era of nanotechnology begins, and it will profoundly impact our economy and Society; it is a modern industrial Revolution [7].

Among all these new nanomaterials, perhaps the most expressive are those generically known as carbon nanomaterials, of which the most famous, and most recent, is graphene [8]. Having been isolated for the first time in 2004 by researchers Andre K. Geim and Konstantin Novoselov [9], graphene has gained great notoriety among other nanomaterials for presenting properties never seen before. It is a material with a very high theoretical specific surface area $\left(2630 \mathrm{~m}^{2} / \mathrm{g}\right)[10]$; it is transparent (optical absorbance $\sim 2.3 \%$ ) [11], waterproof [12], has incomparable thermal conductivity $(\sim 5000 \mathrm{~W} / \mathrm{mK})[13]$ and intrinsic mobility $\left(200000 \mathrm{~cm}^{2} / \mathrm{Vs}\right)$ [14] [15]; very high Young's modulus $(\sim 1.0 \mathrm{TPa})[16]$ [17] and intrinsic strength $(\sim 130 \mathrm{GPa})[16]$. It is no accident that graphene has become a "rising star" [18].

As a two-dimensional (2D) material, or in other words, having the shape of a sheet, graphene is made up of a single layer of carbon atoms, densely packed, linked together in a hexagonal crystalline structure, like a honeycomb, containing $s p^{2}$ bonds [18]. It is from this structure that comes the extraordinary properties of graphene. The sheet morphology is responsible for a very high aspect ratio. Additionally, the $s p^{2}$ bond between carbon atoms is one of the strongest, conferring the material's very high resistance, in addition to resulting in the free movement of electrons, which promotes their high conductivities $[19,20]$. A model of the molecular structure of the graphene sheet is shown in Figure1.2.

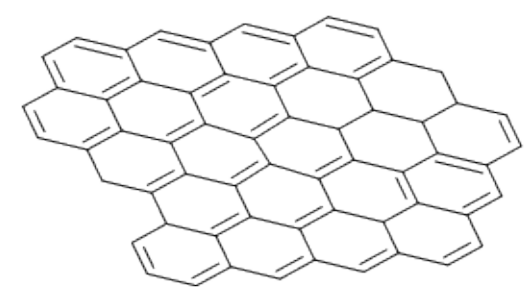

Figure 1.2: Graphene molecular model.

This set of properties makes graphene attractive for a wide variety of applications ranging from high-performance sensors, electronic and opto-electronic devices, conductive and multifunctional inks, nanocomposites with superior properties and insertion of new characteristics, to packaging 
and smart fabrics - such as those used in making protective masks against COVID-19 [21-23], for example. On the other hand, difficulty in large scale synthesis combined with nonreactive surface and poor dispersibility of graphene in water, organic solvents and polymeric systems, due to its hydrophobic nature and the strong cohesive forces between nanosheets, impair its applicability [24]. Chemically modified graphene derivatives have overcome many of impasses associated with graphene's applications and have been continuously investigated.

The chemical functionalization of graphene, which consists of attaching functional groups on its surface, is one of the main methods used to tailor the physical and chemical properties of this nanomaterial, in addition to prevent aggregation between its nanosheets by reducing the cohesive forces $[25,26]$. Consequently, functionalized graphene can be configured to have its interfacial interactions with dispersant improved, which promote more stable and homogeneous dispersions [27-29] besides providing numerous additional functions to graphene nanosheets, hence playing a crucial role in their potential commercial applications [30].

Being the most popular derivative of graphene, graphene oxide (GO) consists of a graphene nanosheet with oxygen-containing functional groups attached to both sides of carbon plane and to the edges [31], as shown in Figure1.3. It is obtained by oxidation of graphite and subsequent exfoliation of graphite oxide, and can also be defined as a single layer of graphite oxide [32]. It is the presence of oxygenated groups that significantly increases the interactions of such nanosheets with water and other dispersants. Graphene oxide is being widely investigated, since it provides a more stable dispersion in several solvents with relatively simpler, cheaper, and more productive synthesis, maintaining the desired characteristics for many applications [10].

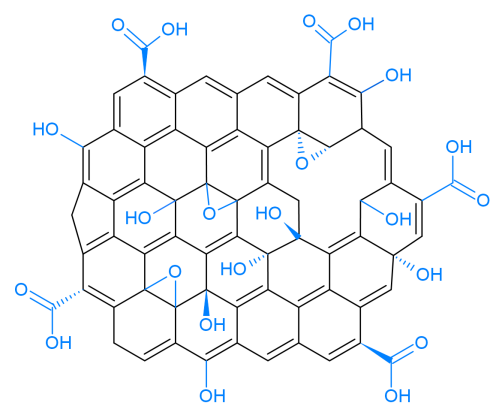

Figure 1.3: Graphene oxide molecular model.

Due to its structure, GO is a 2D amphiphile with a hydrophilic perimeter and largely hydrophobic core [33], also owning an extremely high aspect ratio. This combination of the graphene base structure with the attached oxygenated 
groups makes the GO an versatile material. Under different conditions of synthesis, their properties are adjustable, being intricately linked to the level of oxidation, arrangement and type of oxygenated groups attached on the nanosheet, besides depending on the number of defects and quantity of layers [19]. Depending on the settings, GO can be semiconductor or insulating, for example. Through reduction methods (extraction of oxygenated groups) its properties become closer to those of graphene. Besides, its functional groups act as anchorage sites for various chemical species [34], which additionally turns GO a precursor for others graphene derivatives by further chemical functionalization [35].

Among others, the use of polyamines to modify graphene oxide produces a nanosheet with high solubility, high reactivity with many chemicals, besides to be a useful precursor for further functionalization too [36, 37]. Amine functionalized graphene oxide (AFGO) can be achieved through the amidation reaction of oxygen-containing groups of GO surface without damage of graphene structure [38], a molecular model is illustrated in Figure 1.4. Obviously, because they have different functional groups, there will be applications where the use of AFGO will be more appropriate than that of GO and vice versa. An important difference between these graphene derivatives is that the presence of amino groups promotes an increase in the local density of positive charges on the nanosheet surfaces, while GO behaves like a Lewis acid, that is, it becomes negatively charged when dispersed in water, for example.

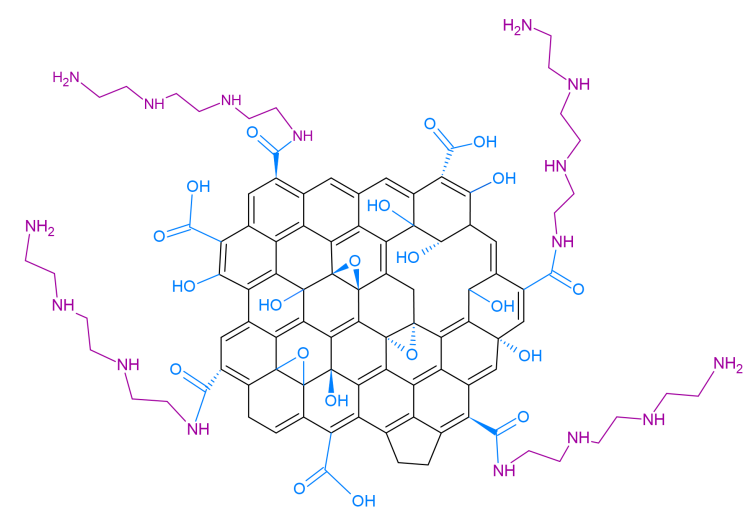

Figure 1.4: Model of graphene oxide functionalized with triethylenetetramine.

GO and its derivatives have also been successfully tested in numerous applications, even for development of biomedical materials due to existence of antibacterial, antifungal and antiviral activities on these nanosheets [3941]. Due to the characteristics of graphene derivatives, it is notorious that interesting possibilities of applications will occur through the suspensions of these nanosheets in fluid dispersants. The introduction of these nanosheets in a 
fluid dispersant can influence, among other properties, the rheological behavior of the dispersion.

It is known that rheological characterization provides essential information for the processing and final application of suspensions. Studies that contemplate the rheology of graphene derivatives suspensions evaluate predominantly the rheological behavior of graphene oxide suspended on Newtonian fluids, such as water (mostly) and polyethylene glycol, for example [42-51]. The studies describe how the rheological properties of the suspensions are established by the microstructures formed through the interaction between GO and the dispersing fluid. The works show a transition to a non-Newtonian behavior due to the formation of clusters as GO concentration increases above a critical value, which in turn depends on the sheet morphology and the oxygenated groups. A shear thinning behavior obtained at higher GO concentrations is associated with the orientation of GO structures, characterizing a typical colloidal isotropic-nematic phase transition $[44,45]$.

Naficy and coworkers [49] found that GO aqueous suspensions exhibit four distinct conditions as the concentration of nanosheets increases: viscoelastic liquid, a transition state consisting of viscoelastic liquid and viscoelastic soft solid, viscoelastic soft solid and viscoelastic gel. At lower GO concentrations, the nanosheets are randomly dispersed in the water, both modules exhibit a frequency dependent behavior, being the loss modulus (G") slightly higher than the elastic modulus $\left(G^{\prime}\right)$, which suggests a viscoelastic liquid-like behavior. Upon increasing the concentration, some nematic ordering starts to appear and G' became greater than $\mathrm{G}$ " for lower oscillatory frequencies (biphasic behavior). Then, when reaching critical concentration, there is the formation of a nematic liquid crystal phase, with G' being greater than G" for higher frequencies too (viscoelastic soft solid). Further increase in GO volume fraction results in higher packing of the nematic phase, which increases simultaneously G' and G", with the elastic modulus increasing much more, until there is no crossover point between G' and G" (viscoelastic gel). The authors also point out that the critical concentration value obtained for the suspension of GO was significantly lower than the values observed for usual colloidal suspensions, this event was attributed to the very high aspect ratio of the nanosheets.

Vallés et al. [43,44] observed that this phase formation is due to two different mechanisms, one related to the repulsion between the graphene oxide nanosheets due to the presence of negatively charged oxygenated groups, and another attractive interaction related to the $\pi-\pi$ and Van der Waals 
interactions between the graphical regions of the GO. For higher concentrations of GO, the proximity between the sheets and the balance between the two types of interaction leads to the formation of a 3D GO gel network. The higher the concentration of GO, the stronger is the structure of the gel formed.

Recently, when compiling and analyzing important findings related to the shear rheology of aqueous GO suspensions, Del Giudice and Shen [42] highlighted that a shear-thinning character becomes more pronounced by increasing the GO concentration and stated that such behavior denotes the existence of a yield stress, a condition reported in various studies [44,45,48-50]. Due to the Brownian diffusion, above the critical concentration the GO nanosheets aggregate. However, by increasing the shear rate, the aggregates disassociate and aligne with the flow direction. Hence, because the drag generated by an oriented sheet is much smaller than that generated by a cluster, the shear viscosity decreases with the increase of the shear rate until reaching a constant value when all the sheets are aligned. The authors also reported that the suspensions can present a thixotropic behavior, especially when subjected to shear stresses close to the yield stress, however there is few studies dedicated to this subject.

Soares et al. [51], have investigated the influence of the GO oxidation degree on the shear rheology of poly(ethylene glycol) (PEG) suspensions and have observed the transition from Newtonian to pseudoplastic behavior on the GO suspensions prepared with the higher oxidation time. They have attributed this behavior to the compatibility improvement between the PEG and GO with the oxidation degree of GO.

There is a lack of information regarding the influence of the characteristics of graphene derivatives on the rheology of their suspensions in non-Newtonian dispersants. To the best of our knowledge, there are still few reports that explore how the morphology of these nanosheets can affect the interactions that govern microstructures in complex dispersing media. However, a significant portion of the base fluids used in industrial and technological applications exhibit complex behavior. Indeed, an important part of the studies that contemplate graphene derivatives applications on fluids are performed with complex dispersants. Once again, research with graphene oxide stands out, but many studies with other graphene functionalizations are also reported. Relevant results are presented for applications of these nanosheets in conductive 3D paints [52-57], drilling fluids [58-60], polymeric composites [61-66], lubricants [67-72], filtration membranes [73-75] cement paste [76-78], among others. However, either the studies do not address the fluids rheological behavior, focusing on other properties, or the base fluid used 
is composed of many additives, as in the case of drilling fluids, which makes it difficult to interpret the cause of rheological responses. So, an attention must be given to the study of the rheological effects of graphene derivatives suspended in complex fluids.

A comparison between the rheological behavior of melted GO/Poly(methyl methacrylate) (PMMA) composites and aqueous GO dispersions was performed by Vallés et al. [43, 44]. As for the aqueous dispersion, the PMMA composites form a gel network as GO concentration increases, with a thixotropic behavior. However, the change in rheological properties is less pronounced than the observed in the aqueous system, probably due to the absence of hydrogen bonding between GO and PMMA. The results also show that above a certain GO concentration the viscosity no longer increases, which may be attributed to aggregation between the GO flakes. It is also pointed that either modifications of the GO surface chemistry or changes on the polymeric matrix can affect $\mathrm{GO} /$ matrix interactions, which can tune the rheological response of the GO dispersion.

Shang et al. [76] analyzed interactions of silica fume, GO and silica fume encapsulated GO (GOSF) dispersed in cement paste. The effects of GO and GO sheets encapsulating silica fume on the rheology of suspended silica fume on cement paste were different. While the addition of GO caused significant increase of rheological parameters, GOSF addition promoted the opposite. The authors related these results to the shape and surface activity of the GO and GOSF. The introduction of GO in the cement paste impairs the lubrication of the system. Electrostatic interactions between the negative charges of the GO sheets and the cement particles lead to the formation of flocculated structures that retain large amounts of water inside, increasing the friction between the particles. Consequently, increasing GO concentration higher the yield stress and plastic viscosity, and hence decreased the fluidity of the suspension. On the other hand, the silica fume encapsulated GO has a spherical shape that adsorb water molecules around its surface, this facilitates the roll of one particle in relation to another and reduces the contact with the cement particles, reducing the friction resistance. Besides, the negatively charged GO on silica fume provides repulsion among particles, allowing better dispersion of cement particles and releasing the entrapped water, as a result the increase of GOSF concentration raised fluidity and reduced the rheological parameters. The encapsulation of silica fume with GO completely changed the rheological effect of the nanosheets suspension in the cement paste, mainly because the shape adopted by the nanosheet. An interesting issue to be highlighted is that even with the increase of rheological parameters for GO suspensions in cement, 
the interactions that govern such behavior are different from those observed for aqueous GO suspensions.

Another mechanism of interaction is analyzed by Zhong et al. [57], who reported the effect of GO addition on the rheological behavior of viscoelastic aqueous dispersion of geopolymer (aluminosilicate and alkaline-source particles), aiming its use for 3D print. GO strongly interacts with the geopolymer, and dramatically affected the rheology of the dispersion, increasing the storage and loss moduli by one or two orders of magnitude. In addition, the yield stress has also increased. Increasing further the concentration of GO, the moduli continued to increase but yield stress dropped by around 50\%. For even higher concentrations, the moduli also begins to decrease. This behavior was related to the lubrication effects of GO.

As it was demonstrated by the stated studies, the mechanisms of interaction between graphene derivatives and the non-Newtonian matrices are strongly related to the suspension rheology. However, there are many mechanisms and structures that configure the formation of complex dispersants such as emulsions, dispersions, polymeric systems, foams, among others; and the possibilities for configuring graphene derivatives are vast as well, highlighting here the functionalized ones, which may present different types and degrees of functionalization, lateral dimensions and number of sheets. Then, it is clear that there are many variables to be studied.

Investigating and qualifying the rheological behavior of graphene derivatives suspensions in non-Newtonian dispersants is essential in order to obtain an overview of the internal microstructure and to allow understanding and predicting the influence of the configuration/morphology of these nanosheets on the mechanical characteristics and processability of complex systems, with the aim of developing manufacturing protocols to be used in different processing techniques. In this way, these types of studies become strategic so that these nanomaterials can be used in industrial processes and finally by our society.

Therefore, it is considered here the conduction of basic studies, aiming not to generate results that have immediate applications on a practical level, but that contribute to the set of fundamental knowledge that relate rheological behavior and material microstructure.

\section{2}

\section{Objective}

In this context, this study aims to contribute to the analysis of the effects of graphene derivatives suspensions in the rheology of yield stress fluids. In 
this sense, the main goal of the present work is to investigate the effects of GO and AFGO nanosheets suspended on a model yield stress fluid. More specifically, we focus our attention on the effects of the graphene derivatives functionalization type and degree and, their nanosheets concentration on the suspension rheology. To this end, we investigated the rheological behavior of GO and AFGO suspensions in aqueous dispersion of Carbopol®, trade name of a polyacrylic acid. For the first time, the effect of the functionalization degree of graphene derivatives on the rheological properties of a yield stress fluid was analyzed.

The Carbopol aqueous dispersion produces a yield stress fluid, which is widely used in several industries (a current example of its application is in the production of alcohol in gel), and as a model fluid among rheologists [79], due to its characteristics such as non-toxicity, transparency, and ease of handling. The knowledge already established regarding the mechanisms that govern the complex character of the aqueous dispersion of Carbopol® and the simplicity of the fluid composition makes it an ideal base fluid for investigating the impact of graphene derivatives sheets on the rheological properties on this kind of yield stress fluid. 


\section{2}

\section{Background and Literature Review}

The rheological behavior of a fluid is associated with its microstructure. The graphene morphology, the functionalization of nanosheets, the crosslinking of Carbopol, and a number of other factors can be determinant for the rheological properties of the final suspension. This chapter provides a review on the materials analyzed in this work. Being relatively new materials, graphene and its functionalization are the subject of a more comprehensive discussion. Information on their structure and properties is explored as well. Also, we present some discussion regarding the structure and properties of aqueous dispersions of Carbopol, used as the continuous phase of the final suspensions.

\section{1}

\section{Graphene: background, structure and properties}

The conception of graphene started to be formed decades ago. Among precursor studies, in 1859, Benjamin Brodie described the lamellar character of graphite, promoted its oxidation and observed the suspension of small crystals, which today we know to be graphene oxide [80,81]. In the 1940s, graphene was theoretically investigated by P. R. Wallace who, through calculations, predicted graphene electronic structure, with conductivity within graphite plane being 100 times greater than between planes [82-84]. In 1962, Boehm et al. produced very thin lamellae of carbon after chemical reduction of graphite oxide in an alkaline medium and, through transmission electron microscopy, they came to the conclusion that the thinnest lamellae consisted of a simple layer of carbon $[83,85]$. Later, in 1985, Boehm and coworkers recommended the use of the term graphene - an arrangement of the word "graphite" with the suffix ene, which refers to polycyclic aromatic hydrocarbons - to designate a simple layer of carbon $[86,87]$.

It was only in 2004 that pristine graphene (without the presence of heteroatoms on its surface) was isolated and characterized for the first time by Andre Geim and Kostantin Novoselov [9], an achievement that earned them the Nobel Prize in Physics in 2010 [88]. The researchers were able to extract a layer of graphene with the thickness of an atom from graphite by mechanical exfoliation, using the "Scotch tape", as shown in Figure 2.1. 
The researchers used an adhesive tape to remove thin flakes of a graphite chunk, then the carbon-covered tape was sticked against itself and peeled away repeatedly until left a single-atom thick layer of graphite (graphene) [89, 90]. The success of graphene isolation comes from the fact that graphite has a layered structure, consisting of graphene sheets stacked and held together by forces of Van der Waals [91]. Layered structures provide the opportunity to be cleaved into individual, independent atomic layers [22]. The adhesive strength of the tape exceeds the Van der Waals force that joins the graphene sheets and, thus, it is possible to separate the sheets until a single layer is isolated. With the physico-chemical characterization and consequent confirmation of the properties that graphene could present, the interest in understanding this new 2D nanomaterial, and in developing new forms of synthesis and applications has grown exponentially.

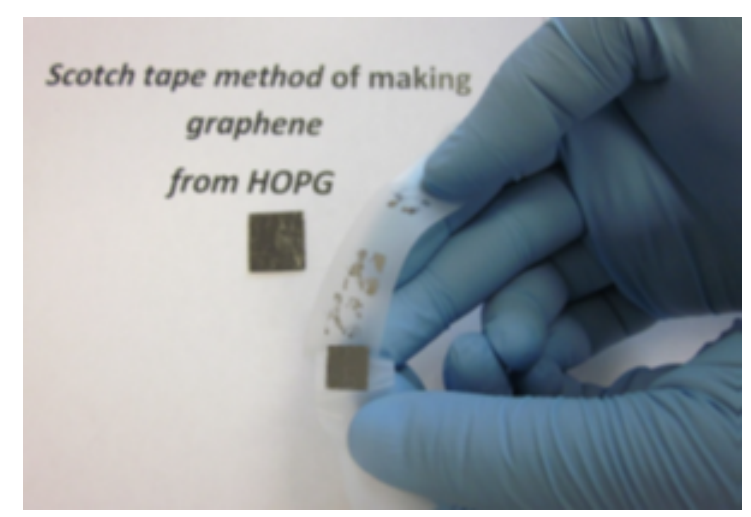

Figure 2.1: Mechanical exfoliation used by Geim and Novoselov to isolate graphene [89].

In a more complete definition, graphene consists of a two-dimensional (2D) material composed of a single layer of carbon atoms linked together by double bonds in a densely packed hexagonal arrangement [91]. It constitutes the basic unit for the formation of graphitic materials of other dimensions:, when wrapped it forms the fullerene (0D), when rolled it forms the nanotube (1D), and when stacked it forms the graphite (3D), as illustrated in Figure 2.2. However, when compared to homologous materials 0D, 1D and 3D, graphene has unique characteristics, such as electron confinement in two dimensions, which promote advantageous electronic properties, representing a promising material for the study of the fundamentals of condensed matter and electronic applications $[21,22]$. Another attractive feature is the electronic structure, which is very sensitive to external stimuli, such as chemical modification, external electric and magnetic fields, mechanical deformation and absorption of other molecules or materials [92]. The atomic thickness offers this material great mechanical flexibility, optical transparency, making it attractive in 
the manufacture of transparent and super flexible electronic/optoelectronic devices. The high width, combined with the very thin thickness of the sheet results in a high specific surface area, ideal for active surface applications [92].

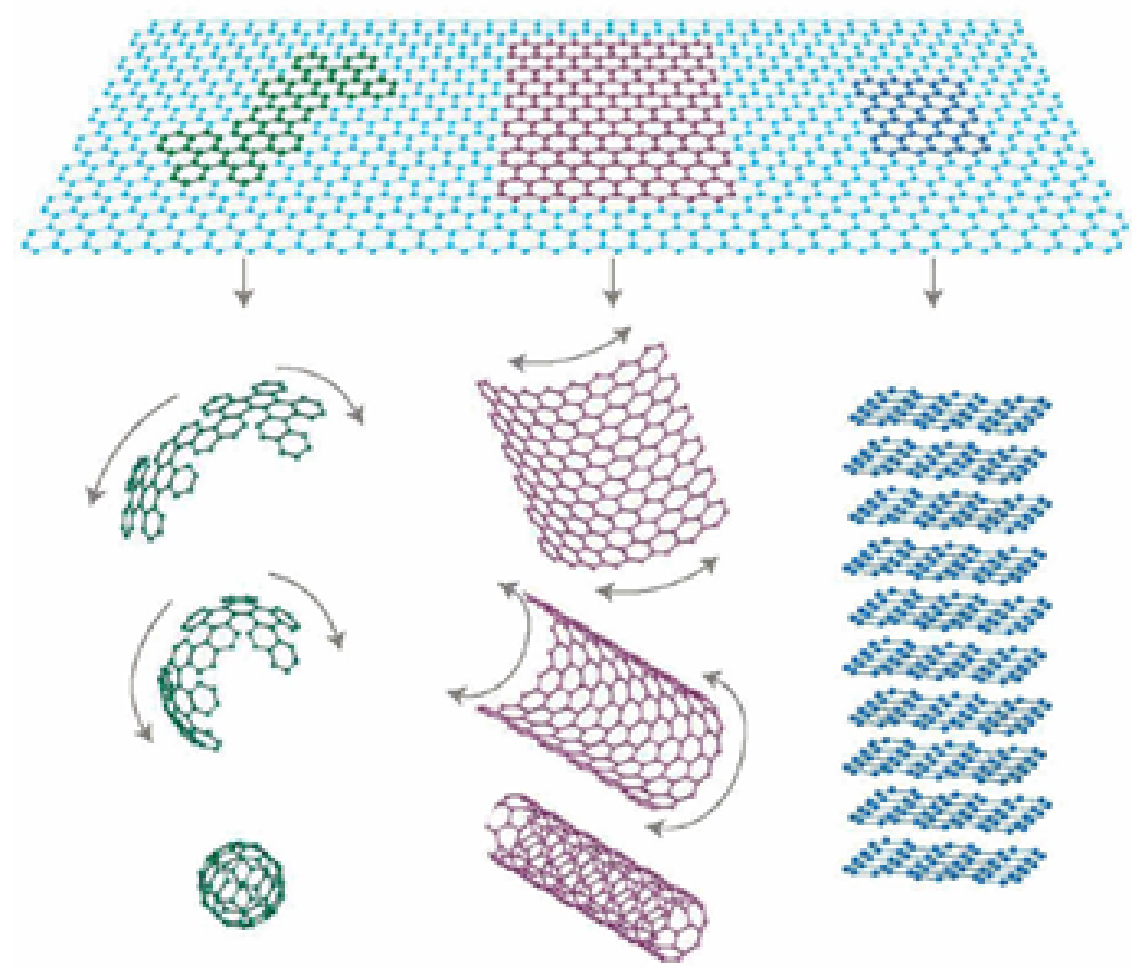

Figure 2.2: Graphene is the light blue 2D sheet forming the others graphitic dimentionalities; fullerene is the 0D green sphere; the carbon nanotube is the 1D pink cilinder; and graphite is the 3D blue stacked graphene layers [91].

The structure of graphene is formed by a network of hexagonal rings containing six carbon atoms at each vertex, connected at a distance of 0.142 $\mathrm{nm}$, like a series of fused benzene rings (without the hydrogen atoms). In this way, the atoms are in the hybridized $s p^{2}$ state, where each carbon atom bonds to three neighboring atoms through sigma $(\sigma)$ bonds (bonds formed by superposition of s, $p_{x}$ and $p_{y}$ orbitals within the plane), and forms a bond of the type pi $(\pi)$ (which occurs through the $p_{z}$ orbital outside the plane), an illustration is shown in Figure 2.3 [93].

The three orbitals that form the $\sigma$ bonds, are directed at 120 degrees from each other and are responsible for the hexagonal structure of graphene. Therefore, the $\sigma$ bonds build the plane of graphene layer, they are highly stable bonds, and they are similar in character to the pure $\sigma$ bonds, of the $s p^{3}$ type, that form the three-dimensional molecular structure of the diamond. The diamond high hardness illustrates the strength of the $\sigma$ bond between carbon atoms. In the case of graphene, the addition and dynamic nature of the $\pi$ bonds make the $\sigma$ bonds even stronger, with a bond length of $0.142 \mathrm{~nm}$, which 

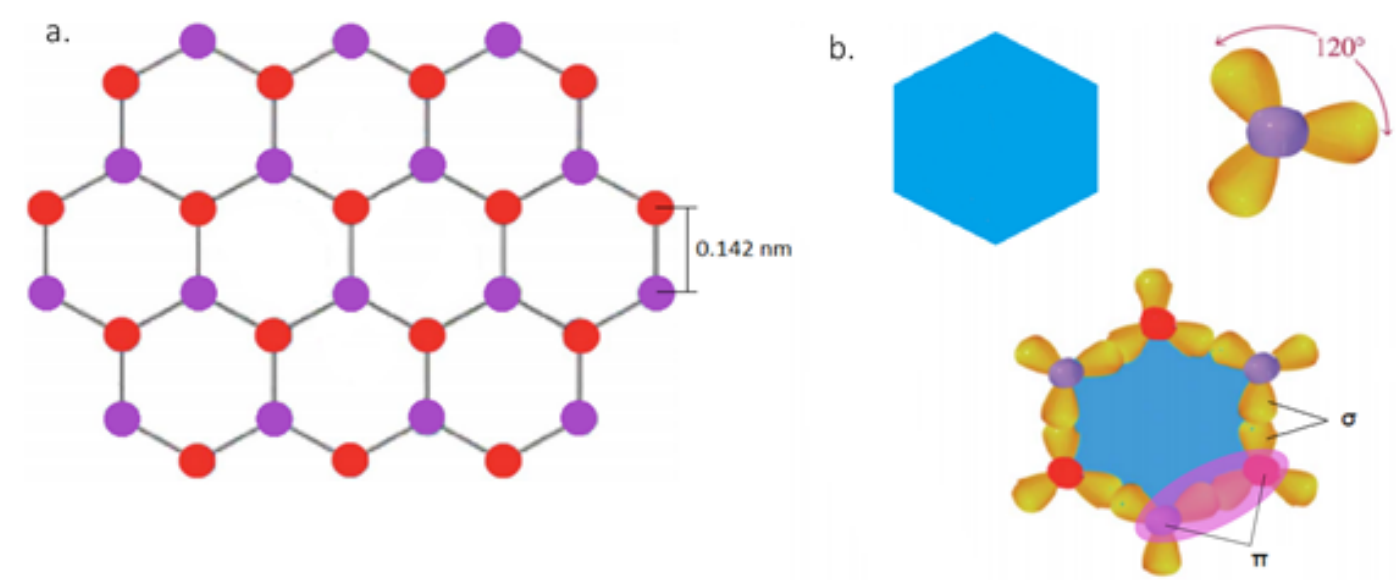

Figure 2.3: a. graphene consists of "fused" hexagonal rings containing carbon atoms on its vertices, each carbon atom bons with three other adjacent carbons atoms, and b. the carbon orbital directions are responsible for the graphene hexagonal structure through the sigma bonds, besides to form pi bons out of the plane. Adapted from [93].

is shorter than that found in the $\sigma$ bonds of the diamond. As a consequence, the $\sigma$ bonding system acting on a single layer of graphene is very strong, being the strongest one known to date [93, 94].

The $\pi$ bonds also play a fundamental role in the physical-chemical behavior of graphene. The electron present in the $p_{z}$ orbital of the carbon atom will be found in a region just above or below the plane formed by the $\sigma$ bond network. Since $\pi$ bonds can be formed with any of the three neighboring carbon atoms, there are circular regions above and below each aromatic ring where $\pi$ electrons can be located. These electrons are not fixed and can be displaced within the limits of this circular region, which is known as resonance stability. The network of rings connected allows the delocalization of electrons to be carried out on the entire layer of graphene, as illustrated in Figure 2.4.

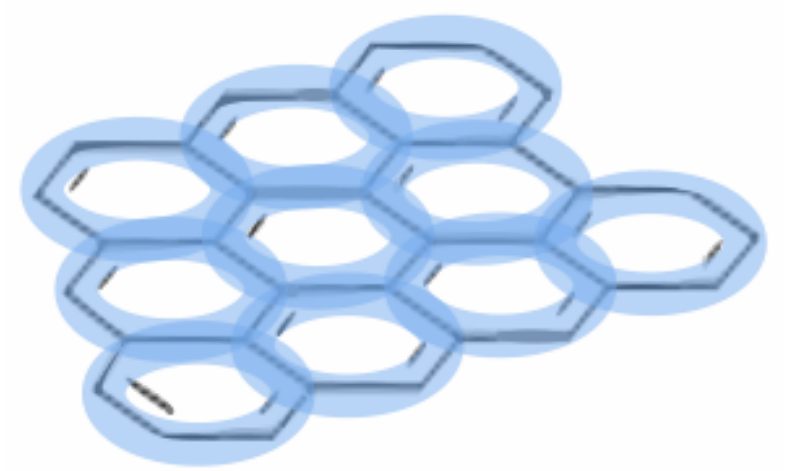

Figure 2.4: Circular regions with delocation of electrons.

This "cloud" of electrons outside the plane of graphene is closely related 
to its electrical conductivity. Since these free electrons in graphene behave as in semi-metals, commonly called massless Dirac Fermions, graphene shows a half-integer Quantum Hall Effect (QHE). In this way, the Quantum Hall Effect in graphene is unique and shows an exceptional relation between charge, thickness, and speed of the electrons [95]. Further discussions on the subject are abundant in the literature and can be found in the works of Neto and collaborators [96], Peres [97] and Tiwari et al. [95], for example. These features make graphene the most conductive material known at room temperature, reaching a conductivity of $10^{6} \mathrm{~S} / \mathrm{m}$ and a sheet resistance of $28 \Omega / \mathrm{sq}[98,99]$. This is attributed to its ultrahigh mobility of $2 \times 10^{5} \mathrm{~cm}^{2} / \mathrm{Vs}[15]$ which is almost 140 times the mobility in silicon [99].

The sigma bond network is responsible for the mechanical properties and thermal stability of graphene. The tensile strength and elastic modulus of the graphene monolayer are $125 \mathrm{GPa}$ and $1.1 \mathrm{TPa}$ [16], respectively, while its strength limit reaches $42 \mathrm{~N} / \mathrm{m}$. It is approximately 200 times stronger than structural steel [95]. Graphene is not only strong, but it is also a light material with a planar density of $0.77 \mathrm{mg} / \mathrm{m}^{2}$ [99]. The use of this $2 \mathrm{D}$ nanomaterial can be considered to improve properties when applied to composite materials [100].

The bidimensional monolayer constitution of graphene results in a material with a very wide contact surface, having a specific surface area of $2630 \mathrm{~m}^{2} / \mathrm{g}[10,101]$. Due to the $\sigma$ bonds between the carbons in the plane and because there is no perpendicular bonds or interactions between the sheet and other planes or molecules, graphene has great flexibility. Additionally, the optical properties of graphene are only dependent on the fine-structure constant, as it is a thin material, graphene layer is highly transparent, with $2.3 \%$ of white light absorbed by each single layer with a reflectance of less than $0.1 \%[11]$.

The unique crystal lattice of graphene, which contains structural holes, allows phonons (elastic waves of anomalous propagation) to be unobstructed, which leads to significant values of thermal conductivity in graphene $[13$, $95,102,103]$. The thermal conductivity of graphene at room temperature is about $5 \times 10^{3} \mathrm{~W} / \mathrm{mK}$ [13], which is around 10 times greater than the thermal conductivity of copper $(401 \mathrm{~W} / \mathrm{mK})$ [99], making graphene the best thermal conductor ever known.

However, it must be emphasized that the values found for the properties mentioned above refer to a simple graphene layer without defects. The performance of graphene properties depends on both the number of layers present and the overall quality of the crystal lattice. Defects like topological imperfections (e.g., pentagons, heptagons, or their combination), corrugations, 
vacancies, adatoms, edges/cracks, adsorbed impurities and $s p^{3}$ bonds, typically serve as scattering centers that inhibit charge transport [104, 105], which mainly affects the electrical properties of the nanosheet. Figure 2.5 shows some examples of such defects.
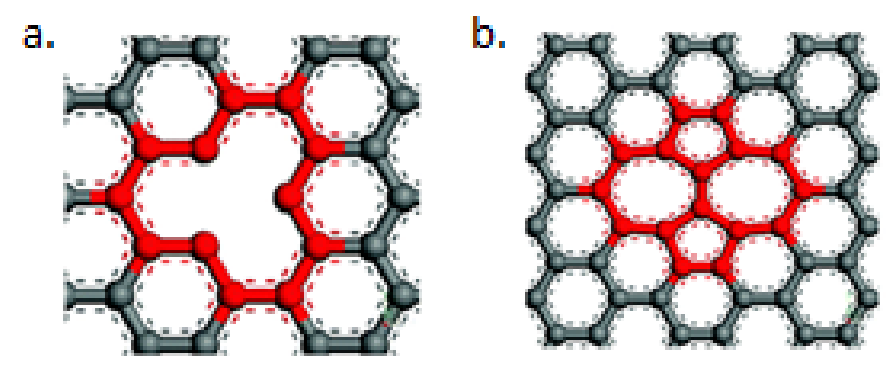

Figure 2.5: Examples of graphene defects. a. Vacancy b. Topological imperfections (pentagons and heptagons) [106].

On the other hand, the electronic structure rapidly modifies with the number of layers, approaching graphite properties. Also, increasing the number of layers will decrease the optical transparency and the contact surface, and increases the specific mass. Van der Waals interactions between layers modify the electronic behavior on the sheet surface, affecting the quantum Hall effect, for example. This allows single-, double- and few- layer graphene to be distinguished as three different types of 2D crystals ("graphenes") [91]. The number of layers, presence of defects and consequently the physical and chemical properties of graphene depend on the method adopted for its synthesis.

Since the work of Geim and Novoselov [9], many studies have been dedicated to exploring graphene synthesis, aiming to control the final characteristics of the nanosheet and large-scale production. Among the synthesis methods developed to date, mechanical exfoliation from natural graphite, chemical vapor deposition (CVD), and reduction of chemical exfoliated graphene oxide have been more prominent for the preparation of graphene [107]. Mechanical exfoliation provides high-quality graphene with lateral dimensions on the order of tens to hundreds of micrometers, which is sufficient for fundamental studies of transport physics and other properties but is not scalable to large production [10,91]. In CVD method the number of layers and defects can be controlled, pure single- or few-layer large-sized graphene can be produced, then this approach can be used to produce large, flexible, transparent and conductive graphene films [103], which have the potential to replace commercially available transparent electrodes [108]. However, the high cost and low production yield significant drawbacks that hinder the use of CVD 
for industrial applications [109]. On the other hand, the oxidation-reduction approach using graphite is one of the simplest and inexpensive methods to produce graphene and their derivatives $[103,107]$. This is one of the most developed methods in the literature, but the defects and number of layers cannot be controlled in this process [19]. Additionally, the reduction process of chemically exfoliated graphene oxide usually is incomplete, which results in successive debasement of graphene electrical properties depending on its degree of reduction [110]. Given this conjecture, it is evident that the production process is a relevant problem that hinders the widespread implementation of graphene in the market.

In addition, a feature of graphene that can become an obstacle, limiting its application, especially in suspensions and composites, is its hydrophobic and chemically inert nature. Consequently, graphene nanosheets have a poor dispersion and weak interface bonding force in most solvents and polymer matrices. This occurs due to graphene low surface activity and insolubility in the dispersant and to the formation of irreversible graphene agglomerates through cohesive forces, as Van der Waals and $\pi-\pi$ stacking, between close nanosheets $[111,112]$.

Chemical functionalization of the nanosheet offers a great solution to these problems associated with graphene. Electron-donating or -withdrawing groups can be bonded to the graphene network by synthetic chemistry methods, which could contribute to a good dispersibility in common organic solvents and to the improvement of interface activity [28]. Furthermore, surface modification is one of the main methods used to reduce the cohesive force between the graphene sheets and also to manipulate its physical and chemical properties [25]. It provides numerous additional functions to graphene sheets, hence playing a crucial role in their potential commercial applications [30].

\subsection{1}

\section{Graphene functionalization}

Despite of the amazing properties and great application potential, issues as inert reactivity, high cost of fabrication and the deficiency of manufacturing in large scale weaken the competitive strength of graphene for commercial uses. These are some of the reasons why researches aiming at applications of functionalized graphene have increased significantly $[113,114]$. Numerous chemical functionalization approaches have aimed to increase graphene processability and thus broaden its scope of applications. Graphene functionalization allows to tailor its physical properties such as resistivity, electronic structure, optical transmittance, luminescence, surface energy, and 
magnetic properties. Importantly, the changes in band-gap structure are also of huge importance in electrochemical, electronic and optoelectronic applications [115].

Several methods to conduct graphene functionalization have been developed. Among them, the covalent functionalization offers great potential to develop new functional materials, structures, and devices for interesting and promising applications [30]. The covalent functionalization of graphene is characterized by the attachment of functional groups to the edge and basal plane network by intense intermolecular forces, with high binding energy. This is typical of covalent bonds, which occurs by the reaction of $\pi$ orbitals transforming $s p^{2}$ bonds into $s p^{3}$, resulting in the formation of defects and modification of electronic properties [116-118].

There are a large number of techniques employed to covalently functionalize graphene and a huge number of fuctional groups can be attached to the nanosheets. Considering the major diversity of organic groups, it can be highlighted the functionalizations through diazonium coupling, oxidation, amidation, silanization, esterization, substitution, cycloadition, etc [119]. More information on chemical routes for functionalizing graphene can be obtained from the work of Hu and Sun [119] and Ioniţă and coworkers [120].

The most common type of functionalization is the introduction of oxygen containing groups on the graphene nanosheet surface and it happens through graphite oxidation $[116,121]$. Chemical oxidation of graphene is scalable, since graphite oxidation and exfoliation are cheap and high-performance processes, affording the possibility of mass production; and versatile in terms of being precursor for further chemical functionalization [122, 123]. These advantages mean that graphite oxidation method for producing graphene and chemically modified graphene could be used for a wide range of applications.

\subsubsection{1}

\section{Graphene oxide}

The history of the development of graphene oxide is intertwined with the discovery of pristine graphene and dates back several decades. The study published by Brodie in 1859 [80], showed that the reaction of graphite flakes with fuming nitric acid $\left(\mathrm{HNO}_{3}\right)$ and potassium chloride $\left(\mathrm{KClO}_{3}\right)$ produced a material weightier than the original graphite, composed of carbon, hydrogen and oxygen. In addition, Brodie identified that the material had good dispersibility in pure or basic water but not in an acidic medium. Brodie named such material as graphite acid, today it is known that graphene oxide was produced. Approximately four decades later, Staudenmaier [124] improved 
Brodie's reaction by incorporating sulfuric acid $\left(\mathrm{H}_{2} \mathrm{SO}_{4}\right)$ into the mixture and adding potassium chloride gradually over the course of the reaction. Staudenmaier's modification resulted in the production of a material with a higher content of oxygen. In 1958, Hummers and Offeman [125] devised an alternative oxidation method by preparing a reaction with graphite flakes, concentrated sulfuric acid, potassium permanganate $\left(\mathrm{KMnO}_{4}\right)$ and sodium nitrate $\left(\mathrm{NaNO}_{3}\right)$, resulting in the production graphite oxide with a level of oxidation similar to that of its predecessor in less time [31, 122]. Hummers' method is the most widespread one and over the years new versions and optimizations have been carried out through changes in variables such as reaction time, process temperature, nature and dosage of reagents [126]. Such versions are known as "modified Hummers' method", but the basic foundations of the Hummers and Offeman method are preserved [116]. Obtaining graphene oxide occurs by exfoliating graphite oxide.

In summary, the exposure of graphite to a highly acidic medium with the presence of oxidizing agents promotes attachment of oxidized functional groups on graphite layers plans and edges, replacing $\pi$ bonds with $\sigma$ bonds. The insertion of the functional groups between the graphite layers increases the interlayer distance, thereby reducing the interlayer Van der Waals force, which facilitates the subsequent separation of the sheets. Then, graphite oxide can be dispersed in a liquid medium and be exfoliated to form graphene oxide with single or few layers, usually by sonication or heating $[127,128]$. A scheme of these processes is showed in Figure 2.6.

Graphene oxide consists of an anisotropic single atomic layer with thickness around $1 \mathrm{~nm}$ (due to the functional groups) and lateral size extending up to hundreds of micrometers $[33,129,130]$. Therefore, GO sheets own very high aspect ratios and large surface area, since a single layer is essentially surface (in both sides) [131]. Obviously, the properties of graphene oxide depend on its structure. Many structural models of graphene oxide have been developed and the distribution of the elements is still a matter of debate, however the Lerf-Klinowski (LK) structure is the most accepted model and establishes that GO is a highly functionalized graphene with randomly distributed oxidized domains containing epoxy and hydroxyl groups on the basal planes and carboxyl and hydroxyl groups at the edges, as shown in Figure 2.6d. [132].

As a consequence of this structure, graphene oxide is an amphiphilic material with a hydrophobic basal plane and hydrophilic perimeter [33, 133]. Thus, GO has good dispersibility in many solvents, especially in water. In addition to the polarity of the oxygenated groups, when the GO nanosheets are 


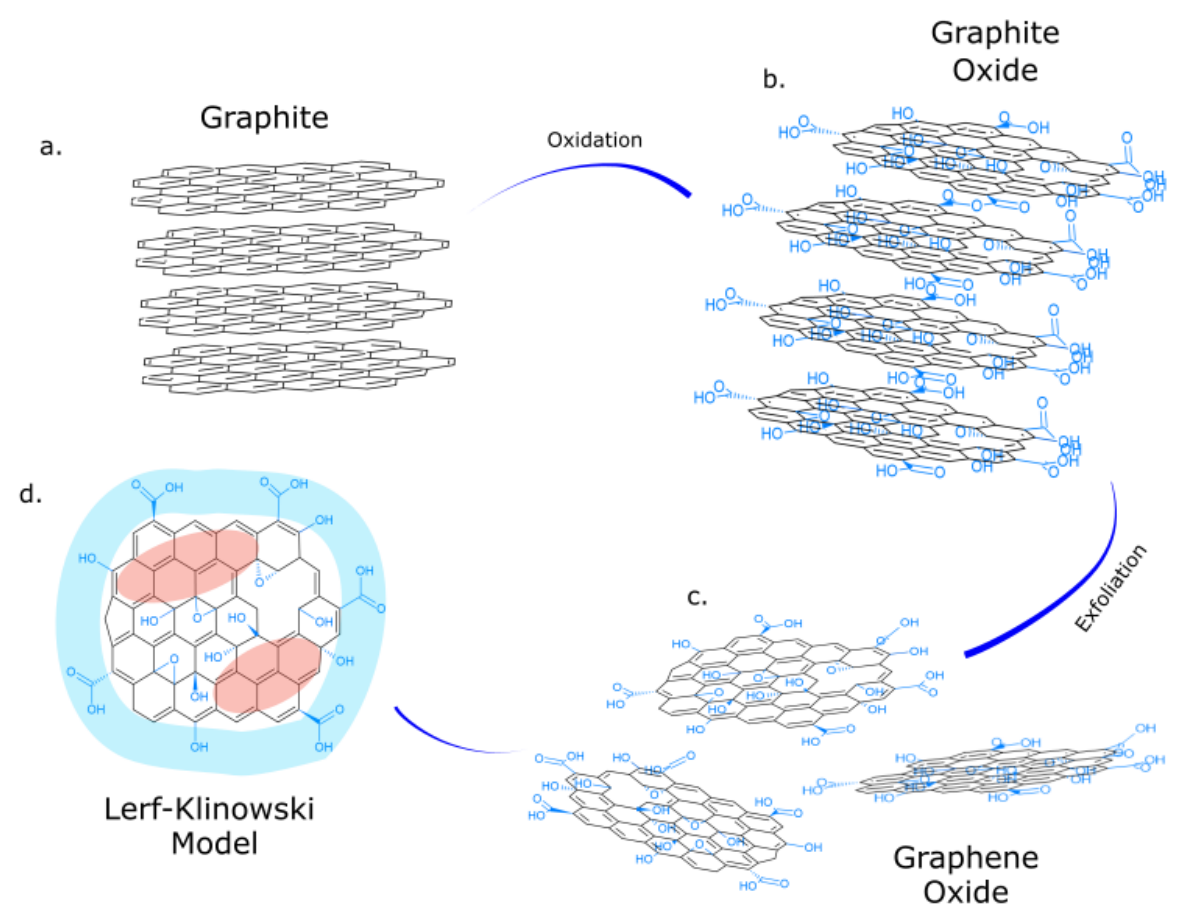

Figure 2.6: a. The pristine graphite passes through an oxidation process when exposed to an acidic medium; b. Then it is formed graphite oxide where the interplane distances are increased due the presence of oxygenated groups on graphene sheets, which weaken Van der Waals forces; c. Finally graphene oxide is obtained by graphite oxide exfoliation, usually by sonication; d. Structure model of graphene oxide nanosheets with carboxylic acids in the edges, presence of hydroxyl and epoxy groups on the sheet surface and areas of hybridized $s p^{2}$ bonds.

dispersed they become negatively charged due to the ionization of carboxylic acids and phenolic hydroxyls groups, which have pKa of 4.3 and 9 respectively [134]. It is the electrostatic repulsion between the negatively charged groups of the GO sheets that promote dispersion stability. The colloidal stability of an electrostatically stabilized dispersion is strongly dependent on $\mathrm{pH}$, the electrolyte concentration, and the content of dispersed particles [112]. In an appropriate $\mathrm{pH}$ condition, GO sheets can behave like a 2D polyelectrolyte [135].

In fact, there is a perception that GO can be considered an unconventional soft material. In addition to amphiphilic it fits the description of 2D polymer, membrane, and generates colloids and liquid crystals [33,133]. This comprehension resulted in a better understanding of the properties of the GO dispersion. Being a stable liquid crystal solution, it can be used to prepare thin films using common methods such as drop casting, spraying or spin coating [130]. In addition, the interfacial activity of GO enables its application as a surfactant, being able to adhere to interfaces and lower the 
interfacial energy [33].

Complementarily, many of the fascinating properties of graphene oxide come from its hybrid electronic structure which contains regions dominated by conductive $\pi$ bonds of hybridized $s p^{2}$ carbons as well as $s p^{3}$ hybridization domains with $\sigma$ bonds [136]. The GO properties can be tailored by altering the $s p^{2} / s p^{3}$ ratio of the carbons and the relative ratio of the epoxy and hydroxyl groups $[34,137,138]$.

On account of the large portion of $s p^{3}$ hybridized carbon atoms bonded with the oxygen functional groups, GO is typically an electrical insulating with sheet resistance of $1010 \Omega$ /sq or higher [34,139]. However, its electrical conductivity can be significantly restored through chemical, thermal, photothermal or electrochemical reduction. These methods of oxygen removal from GO reestablish part of $\pi-\pi$ conjugation of the $s p^{2}$ carbon network, increasing the area of free movement of electrons and thus, transforming the nanosheet into a semiconductor or even into a graphene-like semimetal $[34,133]$.

Apart from the synthesis of graphene, GO has several qualities that make it attractive for applications in various fields. GO exhibit unique optical properties. A graphene oxide monolayer is transparent with high optical transmittance due to its thin atomic thickness. When the thickness of GO decreases from 41 to $6 \mathrm{~nm}$, the optical transmittance increases from 20 to $90 \%$ [32]. Another important optical property of GO is its intrinsic fluorescence near infra-red, visible and ultraviolet regions which is the most notable difference from graphene, which is not photoluminescent. This property should prove useful for biosensing, fluorescence tags and optoelectronics applications $[32,130]$.

Mechanical properties of GO depend greatly on its degree of functionalization and molecular structure. The increase of oxygen content weakening $s p^{2}$ C-C bonds, hence decreasing GO mechanical strength. Experimental and theoretical studies have been performed [140-142] and indicated that structural order, defects and ratio of epoxy/hydroxyl on the nanosheet can also affect mechanical properties, besides the GO number of layers. Theoretically, the Young's modulus of a GO amorphous monolayer could variate from 290 to $430 \mathrm{GPa}$, depending on oxygen degree [140]. Experimentally, from atomic microscopy measurements, GO showed an average value of Young's modulus of $250 \mathrm{GPa}$ with a standard deviation of $150 \mathrm{GPa}$ [143]. GO papers with micrometers thick showed average Young's modulus of $32 \mathrm{GPa}$ and intrinsic strength range from 15 to $133 \mathrm{MPa}$ [144]. Both of which are higher than those reported for flexible graphite foil and bulk paper [32]. Therefore, GO can exhibit great mechanical properties, which 
makes graphene oxide a very promising for nanochemical systems, transparent conductive films, as well as many other applications [145].

The GO thermal conductivity is also greatly influenced by its oxidation level. The oxygen-containing functional groups adversely influence the thermal properties due to enhanced phonon-scattering arising from the increased number of phonon-scattering centers. The reduction of oxidation level enhances phonon transport and reduce its scattering. For a GO single layer at room temperature, the intrinsic thermal conductivity is around $72 \mathrm{~W} / \mathrm{mK}$ at an oxidation level of 0.35 and around $670 \mathrm{~W} / \mathrm{mK}$ at an oxidation level of 0.05 [146]. This indicates that GO can be adjusted to present great conductivity. By way of comparison, thermal conductivity of copper and aluminum is approximately 384 and $180 \mathrm{~W} / \mathrm{mK}$, respectively [147,148].

Graphene oxide also shows potent antimicrobial properties. The GO antimicrobial activity can be assigned to physical and chemical interactions occurring when sheets come in direct contact with the microorganisms [149]. The configuration of negatively charged single layer turns GO capable of inactivate a virus by its structural destruction [41]. Antibacterial activities have been attributed to membrane stress, induced by GO sharp edges, and oxidative stress, induced by negative charges. Besides destroying bacteria, the GO sheet can inhibit their growth $[39,150]$. Further, the GO inhibits the growth of some fungi species, this is probably due to its sharp edges [151]. These features make GO a promise material for development of antimicrobial surfaces [36, 149]. Besides, there are works considering the use of GO in medicines and related, aiming to conciliate both GO antimicrobial and drug delivery skills $[150,152]$.

In addition to these outstanding physical properties of GO itself, the oxygenated groups can largely expand the physical and chemical properties of GO by further chemical modification or functionalization, which offer an effective way to tailor the GO properties to expected extents $[34,130,145]$. The sorptive capability of graphene for anionic micropollutants can be improved through amending surfaces with positive charges by functionalization of GO with amine groups, for example [153].

All these qualities associated with the characteristics of a soft material make the GO and its functionalizations good candidates for additives in fluids with complex behavior such as gels, emulsions, suspensions, foams, colloids. Such materials are widely used in the most diverse industrial sectors, ranging from the high-tech industry to everyday products.

The great potential for the use of functionalized graphene in non-Newtonian dispersants, associated with the lack of discussions found in the literature, served as a motivation for the development of this work, 
which aims to contribute to the analysis of the influence of graphene derivatives characteristics in the rheology of its suspensions in complex fluids. For this purpose, in order to analyze the effect of the oxidation of the nanosheet, it was decided to use graphene oxide nanosheets with two levels of oxidation, since the amount of oxidized groups is a characteristic of great influence for the GO properties. Furthermore, this difference may contribute to the interpretation of the rheological results. Additionally, for the enrichment of the discussions, suspensions of amino-functionalized graphene oxide were analyzed, also with two levels of functionalization, with the aim to evaluate the effect of the different nanosheet surface charges under the rheological performance of the suspensions.

\subsubsection{2}

\section{Amine-functionalized graphene oxide}

The amino-functionalized graphene oxide is a GO sheet containing amino groups, used with the objective to increase the interaction of the nanosheets with the dispersant and promote a uniform and stable dispersion [24]. It is widely applied as additive in the development of composites, membranes and polymeric solutions [75, 154-157]. It also has antimicrobial properties, presenting better performance than GO in some cases, and showing great potential for AFGO for biomedical uses, even in very low nanosheets concentrations $[38,158]$.

The proposal for the insertion of amino groups on the surface of the GO is to increase the local density of positive charges on the nanosheet [38]. Like oxygenated groups, amino groups have the ability to form hydrogen bonds, in other words, they are hydrophilic. In addition, primary amines $\left(-\mathrm{NH}_{2}\right)$ dispersed in a solution with an appropriate $\mathrm{pH}$, ionize protonating, that is, form the $-\mathrm{NH}_{3}{ }^{+}$cation. The amine group exhibits high reactivity that allows to react easily with many other chemicals [36].

In this work, we used functionalization of the GO with triethylenetetramine (TETA) through microwave reaction [159]. In this process, TETA tends to interact with the carboxylic acids present at the edges of the GO, forming amides and leaving primary amines pending on the nanosheets, as shown in the scheme in Figure 2.7. The basicity of amines of different classes does not follow a simple pattern because the number of groups bonded to nitrogen affects the electron density at the nitrogen atom [160]. Alkylamines can therefore have multiple pKb values depending on the types of functional groups present in the molecular chain. TETA has ethylenes and primary and secondary amines. The values of such nitrogened groups 
generally range between 3 and 4 [161], indicating that when dispersed in a neutral medium, TETA has the possibility of containing positive charges.

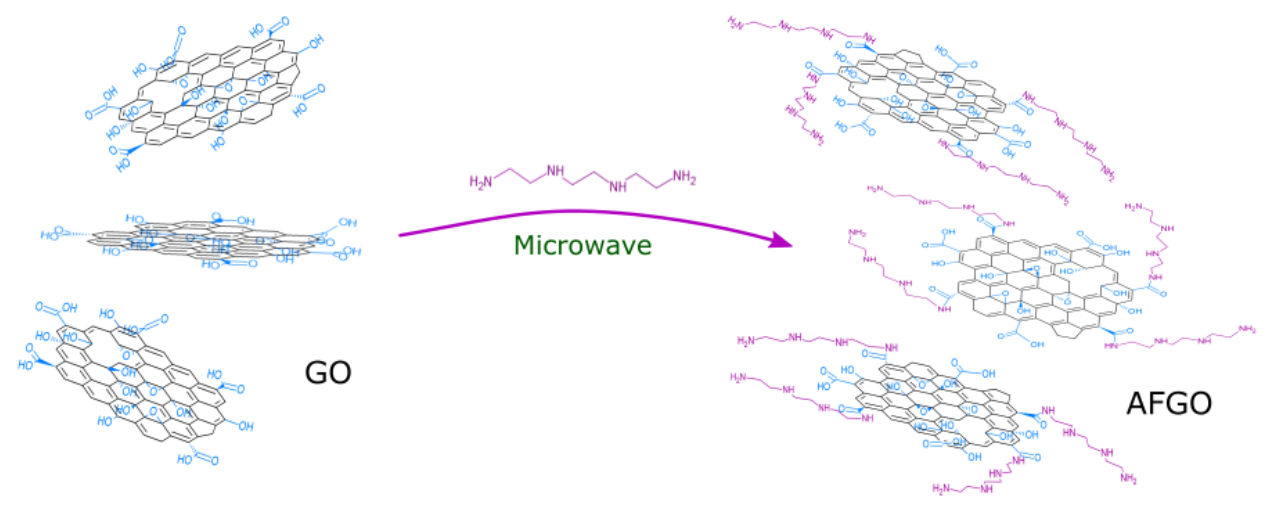

Figure 2.7: GO amine-functionalization with triethylenetetramine.

Due to the characteristics presented, these functionalized graphene nanosheets prove to be truly relevant for the development of fluids with superior properties. In this context, there is a great potential for the application of these graphene derivatives in non-Newtonian fluids, as they are widely used in the most diverse areas. However, in addition to the properties expected through the suspension of functionalized graphene, this nanosheets can affect another determining feature for the fluid application: its rheological behavior.

\section{2}

\section{Non-Newtonian fluids}

As the name suggests, non-Newtonian or complex fluids are those that do not fit the postulate of Newton, i.e. they don't present a linear relationship between shear stress and shear rate.The constitutive equation of the generalized Newtonian fluid is given by: $\overline{\mathbf{T}}=\eta(\dot{\gamma}) \overline{\mathbf{D}}$, where $\overline{\mathbf{T}}$ is the extra stress tensor, $\eta(\dot{\gamma})$ is the viscosity function (for Newtonian fluids it is a proportionality constant) and $\overline{\mathbf{D}}$ is the rate-of-strain tensor. Aditionally, defined as: $\tau=\sqrt{(1 / 2) \overline{\mathbf{T}}^{2}}$ and $\dot{\gamma}=\sqrt{(1 / 2) \operatorname{tr} \overline{\mathbf{D}}^{2}}, \tau$ and $\dot{\gamma}$ are respectively the second invariants of extra stress and rate-of-strain tensors. For a flow subject to simple shear the equation can be simplified as: $\tau=\eta \dot{\gamma}[162]$, where $\tau$ is the shear stress and $\dot{\gamma}$ the shear rate. Using this relation, it is possible to trace the curve $\tau \times \dot{\gamma}$, which relates the shear stress and the shear rate.

The complex fluids can present different behavior, from a purely viscous one, where the non-linear relationship between the stress tensor and rate-of-strain tensor means that the viscosity of the non-Newtonian fluid depends on the flow kinematics, to a viscoelastic behavior, which are time-dependent fluids that present mechanical properties between 
classic liquids and purely elastic solids [163]. Moreover, another kind of time-dependency is thixotropy, when the viscosity response depends on the time of shearing.

Structured fluids have non-Newtonian behavior. Fluids composed of multiple phases such as emulsions, suspensions of solid particles dispersed in a liquid, gas bubbles in a foam, are examples of structured fluids [164]. By mixing two or more immiscible components, new or improved properties can be achieved, and this is often a more economical route for developing new materials [165].

The stability and performance of such fluids can be adjusted by factors as the viscosity of the dispersant phase, particle shape, size and concentration, besides any interaction of the dispersed phase and the continuous phase. Generally, their rheological behavior is governed by the interactions occurring among their components. In other words, they are fluids in which the evolution of the internal microstructure affects its macroscopic dynamics [165].

The rheological properties of non-Newtonian fluids are very complex, with many types of structures and mechanisms composing them. Different kinds of non-Newtonian fluids have different rheological behaviors, such as shear thinning, shear thickening, viscoelasticity, thixotropy, among others. Additionally, several model equations have been developed to describe the different rheological behavior of non-Newtonian fluids. More in-depth discussions about the various rheological behaviors and mathematical models can be found widely in the literature [166-169]. Figure 2.8 shows qualitative flow curves on linear coordinates for some categories of complex fluids rheological behaviour; the linear relation typical of Newtonian fluid is also present.

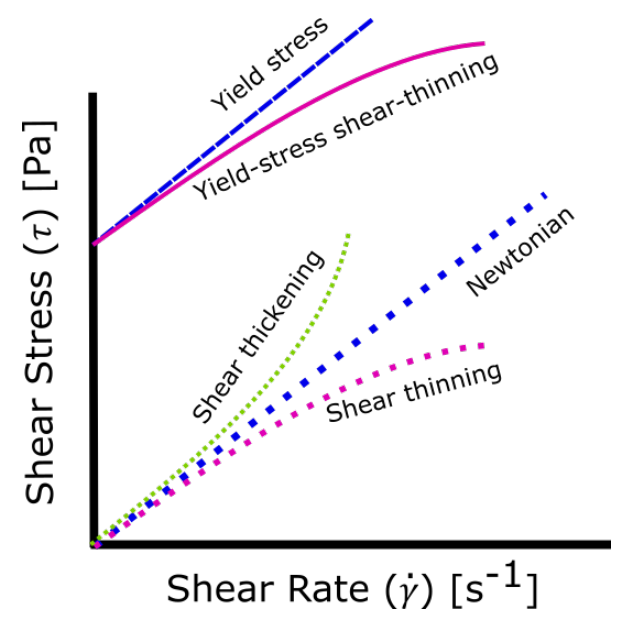

Figure 2.8: Qualitative flow curves on linear coordinates for some categories of fluids rheological behaviour. 
Rheology is the branch of physics which is concerned with the flow and deformation of materials, being subject of considerable practical interest $[170,171]$. Knowing the rheological behavior of a material is important to define manufacturing techniques and monitor processing conditions, predict performance in the final application and consumer acceptance. In addition, rheological studies help to drive the technology for better quality and consistency [172].

As an example, Naficy et al. [49], when investigating the influence of nanosheets concentration on the rheological behavior of GO aqueous suspensions, associated the suspensions rheological responses in frequency sweep tests to manufacturing processes, as shown in Figure.

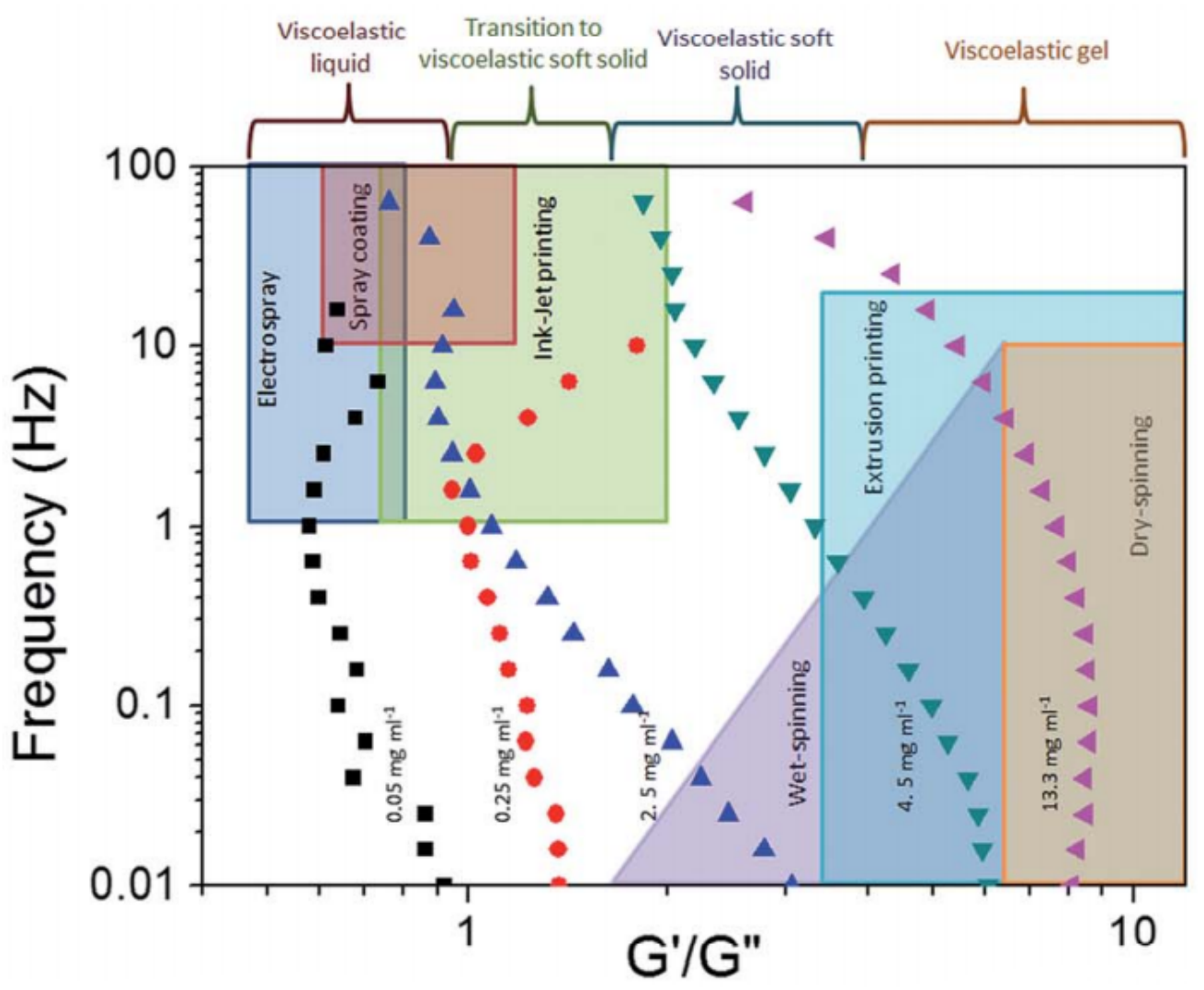

Figure 2.9: Relationship between GO aqueous suspensions rheological properties and manufacturing techniques [49]. Fluids rheological behaviors determine the manufacturing processes to which they can be submitted.

Fluids exhibiting both pseudoplastic and viscoplastic properties are one of most utilized soft complex materials in our world today $[173,174]$.

\subsection{1}

\section{Yield-stress shear-thinning fluids}

This type of fluid has two non-Newtonian characteristics, yield stress and pseudoplasticity. Yield stress fluids are characterized by the existence of 
a threshold stress (the yield stress) which must be exceeded for the fluid to flow. When subjected to stresses lower than the yield stress the fluid will behave like a highly viscous viscoelastic fluid, with a strong microstructure. The breakage of the structure when the fluid is subjected to a stress below the yield stress can be reversed. After the total or partial removal (below the yield stress) of the applied shear stress to the fluid, its internal structure has the ability to reorganize itself and the fluid can regain its yield stress value. For being also a shear thinning (or pseudoplastic) fluid, once the magnitude of the external stress overcome the yield stress, the fluid starts to flow, and its viscosity decreases with the increase of shear rate [164].

Fluids that combine these characteristics are used in the most diverse products, from toothpaste to rocket fuel, and the knowledge of their rheological properties are very important for their applications. For example, in 3D printing applications the shear-thinning feature is ideal for the fluid flow through the extrusion die while the yield-stress is responsible for holding the ink in the extruded shape [175]. In the case of drilling fluids, during the drilling activity, the shear-thinning behavior facilitates the pumping of the fluid through the annular regions, however shutdowns are constantly necessary, and the drilling fluid must be able to keep cuttings in suspension, which is possible due to the presence of the yield stress [176]. In biomedical applications, an evolving model of moldable hydrogels is based on yield-stress fluids that are capable of drug delivery $[173,177]$.

The most common rheological models used to describe these fluids behavior is the Herschel-Bulkley model $[178,179]$, where the viscosity function is expressed as follows:

$$
\begin{array}{ll}
\eta=\left(k \dot{\gamma}^{n-1}+\tau_{y} / \dot{\gamma}\right), & \tau \geq \tau_{y} \\
\eta=\infty \quad(\dot{\gamma}=0), & \tau<\tau_{y}
\end{array}
$$

Being $\tau$ and $\dot{\gamma}$ the second invariants of extra stress and rate-of-strain tensors, respectively. Three inherent parameters of the fluid govern the Herschel-Bulkley model, namely, the consistency index $(k)$, the flow index $(n)$ and the yield stress $\left(\tau_{y}\right)$. Below the yield stress, the Herschel-Bulkley model predicts that the shear rate is identically zero. This behavior is commonly observed in dispersions above a certain dispersed particles concentration. The model accounts for $\tau_{y}$ combined with power law behavior, which reduces to the Bingham fluid model when $n=1$, where flow above the yield stress would be purely Newtonian and the constant $k$ would represent the viscosity. When 
$n<1$, the fluid is shear thinning.

A well-known problem is the difficulty in measuring the material yield stress. Depending on the techniques employed, the selection of the geometries, the experimental protocols established, different yield stress values can be obtained for the same material, even in controlled rheology experiments [180-182]. Discussions on this subject are widely found in the literature, such as in the works of Barnes and Walters [183], Nguyen and Boger [184], Barnes [180], Moller, Mewis and Bonn [181], Moller and coworkers [182], Dinkgreve and collaborators [185], among others. Despite this measurement complication and consequent discussion about yield stress being considered a real material property, there is a consensus that this parameter is very useful in engineering projects and process operations $[182,184]$. Currently, in the characterization of the material yield stress, two types of yield stresses are often considered, one static and the other dynamic. The static yield stress is classified as the stress above which a material in solid state becomes liquid (begins to flow), on the other hand, the dynamic yield stress is determined as the stress below which a material in liquid state starts to behave as a solid (stops flowing) [182]. In this work, the dynamic yield stress will be considered, being analyzed through the flow curve and defined by fitting the curve with a mathematical model.

The presence of yield stress is a consequence of the material predominant three-dimensional internal network structure and microscale heterogeneity, which provide sufficient rigidity to withstand an external stress lower than, offering flow resistance although allowing elastic deformation [186,187]. Factors within the microstructure, such as colloidal interactions between dispersed components, the junctions between structural elements, the properties of the structural elements, the interfacial behavior between phases, the rheology and structure of individual component phases are determinants [188].

Therefore, since GO and AFGO are nanosheets that can become charged, the introduction of these 2D materials in these complex dispersants can modify the interactions occurring into the fluid microstructure, affecting its rheological behavior, which may compromise the fluid application.

Many formulations can present a yield-stress shear-thinning behavior. Some are very popular, such as Bentonite dispersion, water-in-oil and oil-in-water emulsions [173]. In this work, we chose to contribute to the discussions on the influence of the suspension of graphene functionalizations in complex fluids, from the analysis of suspensions of GO and AFGO in Carbopol aqueous dispersions. 


\subsubsection{1}

\section{Carbopol® aqueous dispersion}

Carbopol® is the trade name for a carbomer currently marketed by the company "The Lubrizol Corporation". Carbopols are high molecular weight polyacrylic acids crosslinked with allyl sucrose or allyl pentaerythritol [189-191]. These materials are available in several grades, different by their chemical crosslinking type and level, molecular weight, and can be formed by homopolymers, copolymers or interpolymers [Lubrizol]. They were introduced to the market in the 1950 s by B.F. Goodrich Co., and due to the synthetic nature of their production - which has enabled a quality control - combined with their thickening properties even at low concentrations, they emerged as an alternative to natural gum, being used as a thickener agent [190].

Carbopol is used in a variety of commercial and industrial applications. Due to its yield stress behavior the dispersion can entrap drugs and other components within its structure. In pharmaceutical sector, it provides controlled drug release in tablets and bioadhesion in buccal, ophthalmic, nasal, intestinal applications [192-194]. It is also used in the cosmetics industry, composing lotions, creams and gels [195]. In addition, it is found in other areas, such as to prevent settling of abrasives in cleaning products and to reduce splashes in bleaches [196].

In its simplest form, Carbopol is a dry polymer powder containing acrylic acid along its entire polymeric chain, and its chemical structure unit is presented in Figure 2.10. When dispersed in water these carboxylic acids of the polymeric chain dissociate, therefore Carbopol is a polyelectrolyte. Even at relatively low Carbopol concentrations, the large amount of carboxylic groups present in the polymer chain reduces the $\mathrm{pH}$ of the aqueous dispersion when deprotonating [79]. To increase the ionization level of Carbopol macromolecules, the dispersion must be neutralized. After neutralization, the carboxylic acids fully dissociate, the Carbopol chains open due to the repulsion between negatively charges and become strongly associated with water. This fact combined with the presence of crosslinks, leads to the swelling of the macromolecules, increasing dramatically its volume, and hence increasing viscosity $[189,190,197]$.

For concentrations of Carbopol above a critical value, the swollen macromolecules will overlap and tend to interact with each other, due to the negative charged chains, this interaction will occur through electrostatic repulsion. Each swollen macromolecule can be considered a microgel unit. Unlike a linear chain polymer, these microgels cannot interpenetrate extensively, thus they become closely-packed at the overlap concentration 


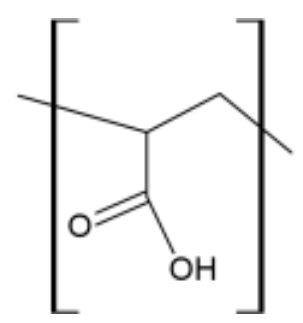

Figure 2.10: Carbopol molecular structure unit.

$[190,198,199]$. In this configuration they are sterically confined by their neighbors, producing the so-called jamming effect whereby the particles become so tightly packed that their motion becomes restricted. Above the critical concentration, Carbopol dispersion produces a 3D network that displays solid-like behavior at low stresses: they possess an equilibrium threshold stress, and complete recovery of elastic strain is observed at low stresses [198]. Therefore, these structure of Carbopol aqueous dispersion at higher concentrations forms a yield-stress shear-thinning fluid, that fits the Herschel-Bulkley model. With the increase of Carbopol concentration the available space for particle motion decreases even more, increasing the viscosity and yield stress values as well. Complementarily, this dispersion results in a transparent, non-toxic and easy-to-handle gel. A scheme of Carbopol gel formation is showed in Figure 2.11.

a.

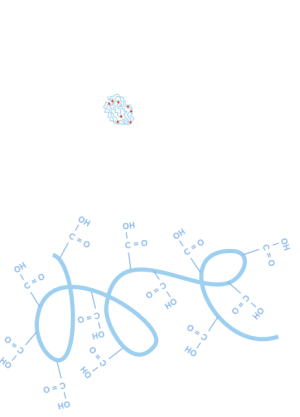

b.
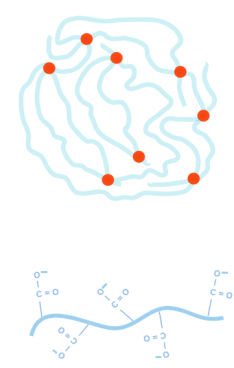

c.

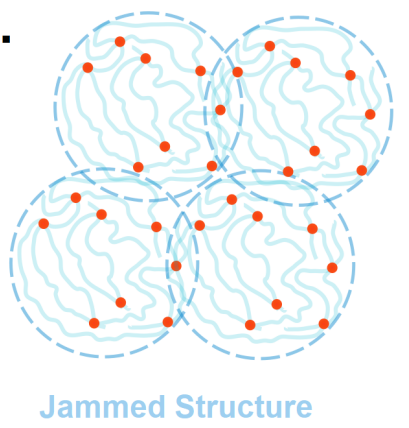

Figure 2.11: Carbopol gel formation. a. Dry Carbopol macromolecule, the chains are coiled, and the red dots are crosslinking points; b. Neutralized Carbopol macromolecule, the chains are uncoiled and strongly interacting with water, hence the macromolecule volume is very higher; and c. Jammed structure of Carbopol aqueous dispersion at higher concentrations.

Microgel particles have the compressibility of foams and emulsions, they display jamming analogous to hard spheres, yet they still retain much of the behavior and chemistry of their composite polymer chains. A more comprehensive discussion of the behavior of Carbopol dispersions can be found in the work of Gutowski [200,201]. 
The $\mathrm{pH}$ value is an important variable for the rheological behavior of the Carbopol dispersion, since at lower values the poor ionization of carboxylic acids on the polymer backbone do not promote the macromolecule swelling and at high values the increase of cations in the surrounding solution leads to the macromolecule deswelling [201]. In this work the $\mathrm{pH}$ of the dispersions will be maintained at around 7 . Under these conditions, the functionalized graphene nanosheets will also be ionized. 


\section{Materials and Methods}

\section{1}

\section{Graphene functionalizations}

\subsection{1}

\section{Synthesis of graphene oxide}

The GO was obtained from the exfoliation of graphite oxide $(\mathrm{GrO})$. The synthesis of graphite oxide was performed at PUC-Rio, with Mackgraphe support, using the modified Hummers method [202,203], described as follows. In a round-bottom flask, placed in an ice bath, $1.0 \mathrm{~g}$ of graphite (graphite powder $95 \%, \leq 45 \mu \mathrm{m}$ - SigmaAldrich) was added to $60 \mathrm{~mL}$ of $\mathrm{H}_{2} \mathrm{SO}_{4}$ (Sigma-Aldrich - 99\%), this mixture was stirred for 15 minutes. Then, $3.5 \mathrm{~g}$ of $\mathrm{KMnO}_{4}$ (Sigma-Aldrich) was slowly added over 15 minutes to the system. After that, the flask was removed from the ice bath to continue the oxidation process. Graphite oxide samples were prepared with two different oxidation times, 2 and 96 hours, in order to obtain nanosheets with different oxidation degree. Stopping the oxidation process, the system was again placed in an ice bath, $200 \mathrm{~mL}$ of deionized water was added followed by addition of aqueous $\mathrm{H}_{2} \mathrm{O}_{2}$ solution (Synth - 30\%) up to the mixture stopping bubbling, meaning that the oxidation reaction has ended. After that, the flask was removed from the bath and the mixture left to decant for 24 hours. The generated product was then vacuum filtered and washed with a series of solvents: $500 \mathrm{~mL}$ of deionized water, $250 \mathrm{~mL}$ of $10 \%$ wt aqueous $\mathrm{HCl}$ solution (Synth - 36.5-38\%), $500 \mathrm{~mL}$ of ethanol (Sigma-Aldrich) and finally $250 \mathrm{~mL}$ of deionized water. The obtained solid was dried at $100^{\circ} \mathrm{C}$ for 12 hours, Figure 3.1 shows some pictures of the process. The exfoliation of graphite oxide was performed as a step in the nanofluid preparation. 

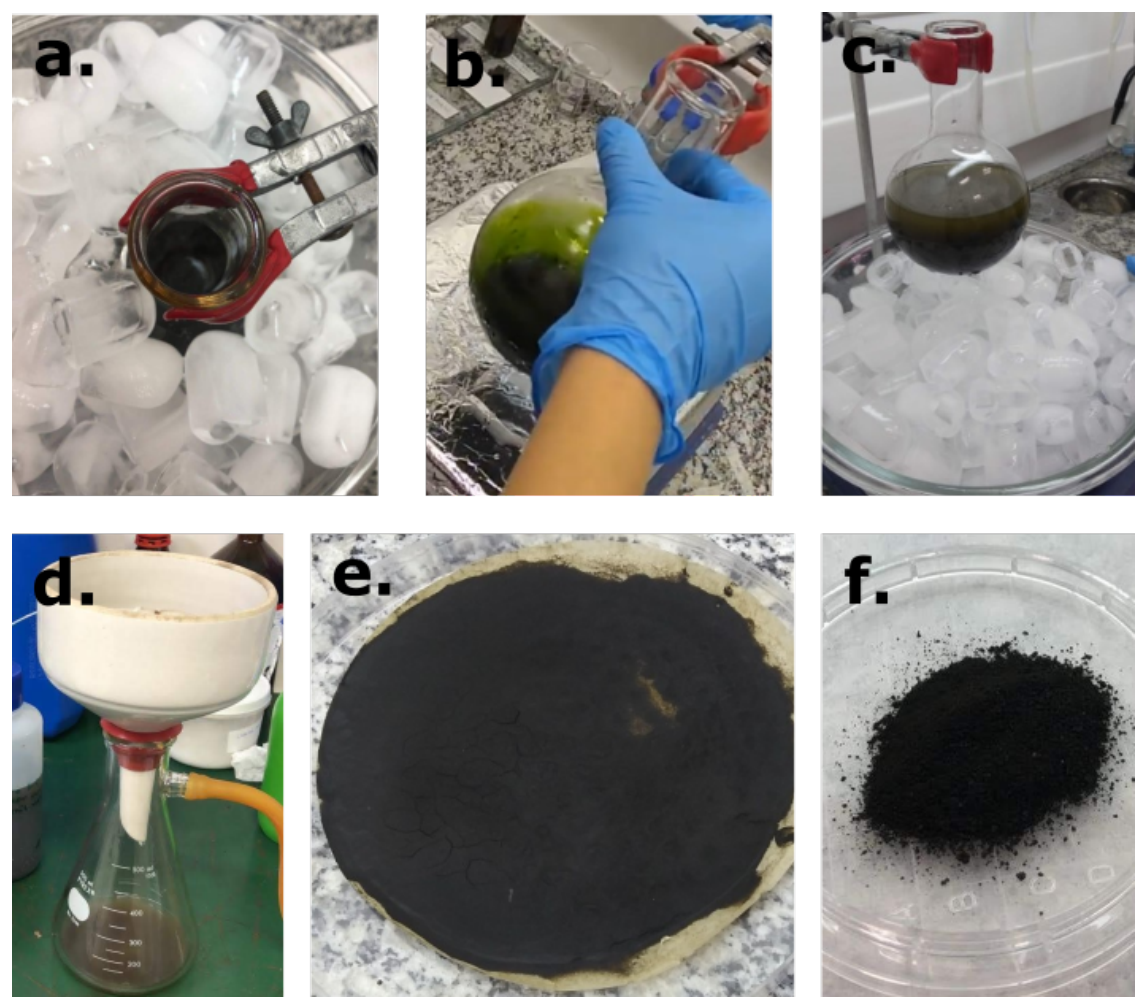

Figure 3.1: a. start of the process with mixture of graphite, $\mathrm{H}_{2} \mathrm{SO}_{4}$ and $\mathrm{KMnO}_{4}$; b. elapsing of oxidation process; c. interruption of the oxidation process with $\mathrm{H}_{2} \mathrm{O}_{2}$; d. Filtration and washing of the resulting material with deionized $\mathrm{H}_{2} \mathrm{O}, \mathrm{HCl}$ and ethanol; and. drying; f. graphite oxide.

\subsection{2}

\section{GO amine-functionalization}

The amine-functionalized GO (AFGO) was produced by the Center for the Development of Nuclear Technology (CDTN) in partnership with Mackgraphe. The AFGO synthesis route followed the work of Ribeiro et al. 2015 [159], based on microwave assisted reaction. The procedure was applied separately for the GO nanosheets with different levels of oxidation and occurred as described:

$150 \mathrm{~mL}$ of triethylenetetramine (TETA) was added in a round bottom flask together with $500 \mathrm{mg}$ of GO. Then the flask with the mixture was placed in a microwave reactor configured to work at a temperature of $120^{\circ} \mathrm{C}$, with increasing power from 0 to $200 \mathrm{~W}$, under magnetic stirring for 30 minutes. After the reaction was finished and the system was cooled, $300 \mathrm{~mL}$ of anhydrous ethanol were added to the mixture, which was subjected to an ultrasonic bath for 1 hour and then filtered and washed carefully with more anhydrous ethanol to remove excess TETA that did not react. The filtered material was dried in a vacuum oven at $100^{\circ} \mathrm{C}$ for 12 hours.

The produced nanosheets were named as AFGO $2 \mathrm{~h}$, for AFGO made 
from the less oxidized GO; and AFGO $96 \mathrm{~h}$, for AFGO produced from the most oxidized GO.

\section{2}

Preparation of the suspensions

\subsection{1}

\section{Graphene oxide suspensions}

The polyacrylic acid used in the composition of the base fluid was Carbopol®, grade Ultrez 10 (Lubrizol Corporation). The base fluid preparation followed the procedure given by the supplier [204] and the study carried out by Varges et al. [205]. Samples with concentrations of $0.15 \mathrm{wt} \%$ and $0.3 \mathrm{wt} \%$ were prepared.

To prepare the base fluid, Carbopol ${ }^{\circledR}(\mathrm{pKa} 4.0 \pm 0.5)$ was hydrated in deionized water for 10 minutes, and then the mixture was dispersed by stirring in a mixer with an anchor-type shovel at $300 \mathrm{rpm}$ for 1 hour. In the next step, the Carbopol dispersion was neutralized by equimolar amount of sodium hydroxide $(\mathrm{NaOH})$ addition. Finally, the suspension remained under mechanical agitation with an anchor-type shovel at $300 \mathrm{rpm}$ for three days to achieve homogeneity.

The Carbopol supplier indicates that a highest viscosity plateau and good stability behavior for an aqueous dispersion of Carbopol Ultrez 10 are found with pH between 6-9 [204]. Then, for the pure Carbopol dispersion and for all GO-Carbopol suspensions the $\mathrm{pH}$ was kept inside this range. The $\mathrm{pH}$ values were measured using the pHmeter Quimis (precision of \pm 0.02 ), and are given in Tables 1 and 2. Despite the GO nanosheets produced have many different chemical groups linked in its structure, such as carboxylic acid (pKa 4.3 - 6.6), phenol (pKa 10), among others [134,206], these functional groups do not contribute significantly to the $\mathrm{pH}$ of the suspension due to their very low concentration in solution.

Three preparation methods were evaluated to prepare the suspension of GO in Carbopol. In preparation method \#1, the graphite oxide ( $\mathrm{GrO}$ ) was directly exfoliated into the base fluid ( $\mathrm{pH} 7.0$ ) by 2 hours of ultrasonic bath at a maximum temperature of $40^{\circ} \mathrm{C}$. This direct liquid exfoliation promoted the separation of $\mathrm{GrO}$ layers, resulting in graphene oxide nanosheets (GO), a scheme of this preparation method is showed in Figure 3.2.

In method \#2, a slightly amount of $\mathrm{NaOH}$ was added into the base fluid to promote a slight increase of $\mathrm{pH}$, until $\mathrm{pH}$ 7.5. Then, the $\mathrm{GrO}$ was added, and the same procedure of method \#1 was done. 
In preparation method $\# 3$, the GrO was first exfoliated in deionized water to obtain the GO aqueous suspension. Then Carbopol powder was added, and the preparation procedure for the base fluid preparation was followed.
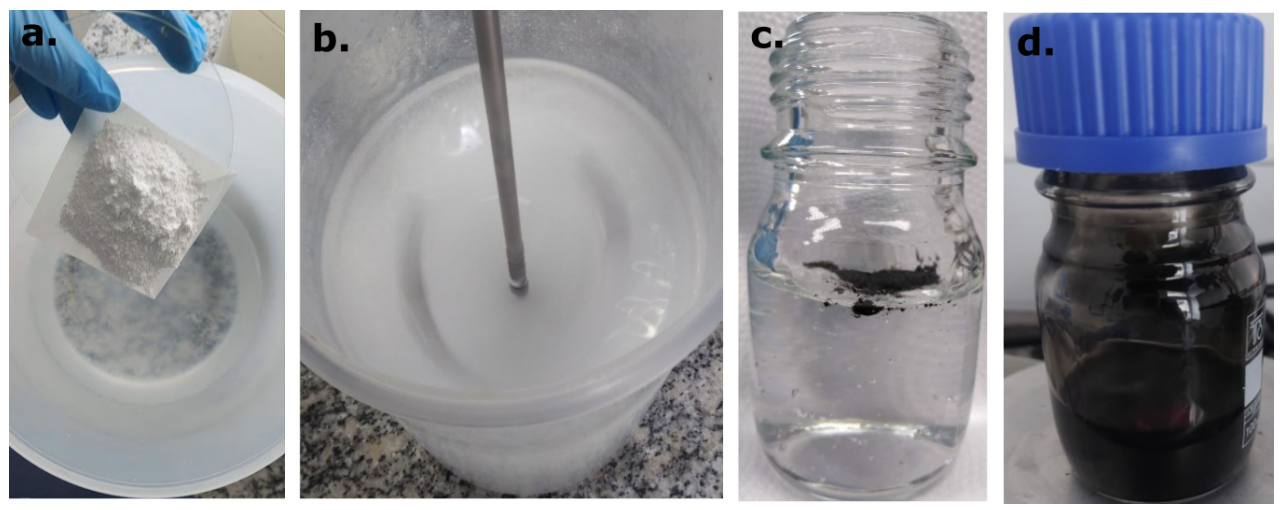

Figure 3.2: Suspension of graphene oxide by method \#1. a. Carbopol hydratation; b. Mixture strirring for 3 days; c. Exfoliation of GO directly in Carbopol gel; d. GO suspension.

\subsection{2}

\section{Amine-functionalized graphene oxide suspensions}

The preparation method adopted to carry out AFGO suspensions was different from that used for GO suspensions for reasons that will be discussed in the next chapter. All samples were produced for a dispersion of $0.3 \%$ wt of Carbopol.

The suspensions of the AFGO nanosheets were carried out in 3 stages. The first step consisted of exfoliating the mass relative to the desired concentration of AFGO in a solution composed of deionized water (40\%wt of the total to be used for the suspension) and $\mathrm{NaOH}$ (50\% wt of the equimolar amount needed to neutralize the entire carbopol dispersion) for 4 hours in an ultrasonic bath. The second stage consisted of a modified preparation of the base fluid. In a beaker, the total of Carbopol was hydrated in deionized water (50\% wt of the total water ) for 10 minutes and then the mixture was subjected to stirring in a mechanical mixer with a shovel at $300 \mathrm{rpm}$ for 1 hour. Then the mixture was "partially neutralized" with the addition of aqueous $\mathrm{NaOH}$ solution (composed of $10 \%$ wt of the remaining deionized water plus the remaining $50 \%$ wt of $\mathrm{NaOH}$ ). The gel produced remained under stirring for 15 minutes. The third stage consisted of adding the suspension prepared in the first stage to the Carbopol gel formed in the second stage, promoting the dilution of the carbopol gel and the total neutralization of the system, the resulting suspension stayed under stirring at $300 \mathrm{rpm}$ for three days. Figure 3.3 presents pictures of the preparation steps. 
The $\mathrm{pH}$ values of the suspensions were measured using a pHmeter Quimis and remained within the ideal value indicated by the Carbopol Ultrez 10 supplier [204].
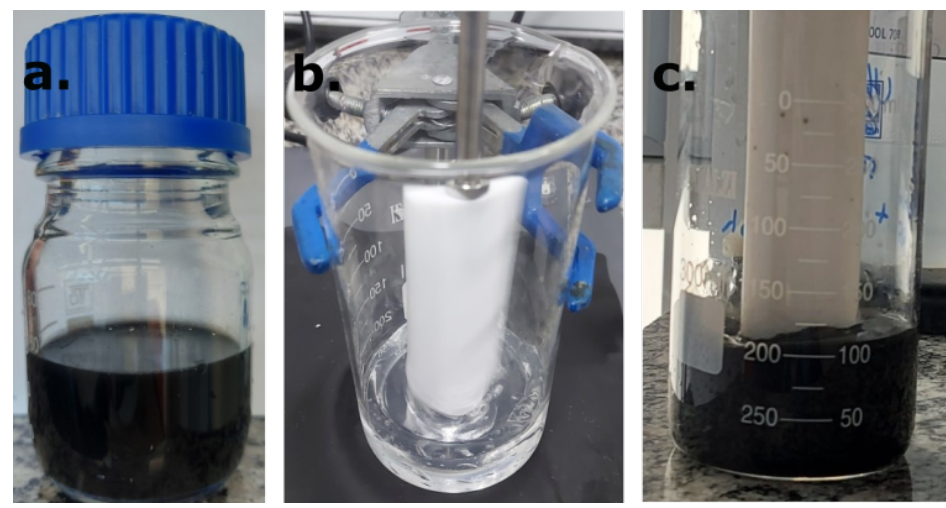

Figure 3.3: a. Exfoliation of AFGO in $\mathrm{NaOH}$ aqueos solution; b. Carbopol gel "partially neutralized"; c. AFGO suspension.

\section{3}

\section{Characterization of the nanosheets}

The physical-chemical characterization techniques described below were used to evaluate only the graphene oxide nanosheets.

\subsection{1}

XRD

The X-ray diffraction technique (XRD) was used to evaluate the influence of oxygenated groups on the interplanar distance of the GO layers. A Rigaku diffractometer, model Miniflex II, was used, equipped with copper monochromator (radiation $\lambda_{C u K \alpha}=1,54 \AA, 5^{\circ} \leq 2 \theta \geq 60^{\circ}$ e $\Delta 2 \theta=0,02$ ), operating with a voltage of $30 \mathrm{kV}$ and a current of $15 \mathrm{~mA}$.

For structural characterization of the GOs oxidized for 2 and 96 hours, firstly the respective graphite oxides were exfoliated in deionized water (concentration of $1 \mathrm{mg} / \mathrm{mL}$ ) in an ultrasonic bath for two hours. After drying the resulting material, the techniques described below were applied:

\subsection{2}

\section{Raman}

From the Raman spectroscopy it was possible to analyze the quality of the GO particles and obtain information on their oxidized groups levels, analyzing the intensity of the D and/or G bands. A Witec confocal microscope, Alpha 300R, 50X objective lens and the $532 \mathrm{~nm}$ laser were used. The samples were 
prepared by diluting $1 \mathrm{mg}$ of GO in $1 \mathrm{~mL}$ of deionized $\mathrm{H}_{2} \mathrm{O}$, dripping a drop of the solution onto a silicon oxide substrate.

\subsection{3}

\section{FTIR}

Fourier transform infrared spectroscopy (FTIR) reveals the chemical bonds present in the materials. In addition to the GOs oxidized for 2 and 96 hours, the spectrum of pure Carbopol was analyzed. The equipment used to obtain the results was the Bruker spectrometer, model Velex 70, D-Latgs detector, MIR source, $10 \mathrm{kHz}$. The absorption spectra were obtained from suspensions of graphene oxides prepared with a concentration of $1 \mathrm{mg} / \mathrm{mL}$ in deionized $\mathrm{H}_{2} \mathrm{O}$ and $\mathrm{pH}>5$. The suspension was dripped onto a silicon oxide wafer $\left(\mathrm{SiO}_{2}\right)$ and the samples were analyzed after dried. Each sample was measured in triplicate.

\subsection{4}

TEM

Transmission Electron Microscopy (TEM) was used to analyze the nanosheets morphological characteristics. TEM micrographs were obtained in a Quanta 200 equipment, model FEG-FEI 2006. The measurement occurred under vacuum with the $200 \mathrm{kV}$ electron beam (tungsten filament), with acceleration voltage between 5 and $30 \mathrm{kV}$. The GO suspensions in water were dropped onto a grid of carbon and copper (Holey Carbon Copper Grids) for TEM studies. Prior to the measurements, the oxidized samples were exfoliated in water using an ultrasonic bath with low power and frequency of $37 \mathrm{~Hz}$, for 2 hours at a maximum temperature of $40^{\circ} \mathrm{C}$, later they were dripped in copper grid and evaporated in air at room temperature for 24 hours.

\subsection{5}

AFM

Atomic Force Microscopy (AFM) was performed to determine the number of GO's layers. The image obtained at AFM relates the thickness of the sample to a color scale. The nanosheets present in the sample are identified and associated with their respective thickness, and from there a thickness distribution profile is established. It was used a 10 Bruker microscope, model Icon Dimension, with a resolution of 512 lines with 512 points in the areas of each image, captured with Scan Asyst mode. The samples were made from the dilution of $1 \mathrm{mg}$ of GO in $1 \mathrm{~mL}$ of deionized $\mathrm{H}_{2} \mathrm{O}$, and from this suspension, 
a further dilution of 1:200 with a total volume of $1 \mathrm{~mL}$ was prepared. The analyses were performed after complete drying of the samples.

The following techniques were used to characterize both the GO and AFGO nanosheets.

\subsection{6}

\section{TGA and DTG}

The thermogravimetric analysis quantitatively indicates the oxidation degree of GOs oxidized for 2 and 96 hours and amination level of the AFGO $2 \mathrm{~h}$ and AFGO $96 \mathrm{~h}$. The equipment used for the analysis was the SDT-Q600 from TA Instrument. The temperature range analyzed was from $25^{\circ} \mathrm{C}$ to $1000^{\circ} \mathrm{C}$, with a variation rate of $10^{\circ} \mathrm{C} / \mathrm{min}$ and in an atmosphere of synthetic air.

\subsection{7}

XPS

X-ray Photoelectron Spectroscopy (XPS) was used to analyze the surface of the AFGO nanosheets and identify their constituents. The system used to obtain the spectra was the VG Scientific Escalab 220-IXL. The measurements were performed under vacuum (base pressure in the chamber of $2.0 \times 10^{-10}$ mbar) and with an $\mathrm{Mg}$ anode, generating X-rays in the $K_{\alpha}$ line $(\mathrm{E}=1487 \mathrm{eV})$. The spectra were obtained in the region between 0-1000 eV (extended spectra) with a $1 \mathrm{eV}$ step and high resolution spectra with a $0.1 \mathrm{eV}$ step in the $\mathrm{C} 1 s$, $\mathrm{N} 1 s$ and $\mathrm{O} 1 s$ photoemission regions. The electron energy analyzer operated in large area mode, with passage energy of $50 \mathrm{eV}$ for extended spectra and $20 \mathrm{eV}$ for analysis of the individual lines. For measurements, AFGO 96h was previously exfoliated in isopropyl alcohol for 1 hour in an ultrasonic bath, then the sample was dripped onto silicon substrate and the analysis was conducted after drying the sample.

\section{4}

\section{Characterization of the suspensions}

\subsection{1 \\ Rheological measurements}

Rheological tests were performed on an AR-G2 (TA Instruments) tension controlled rotational rheometer, presented in Figure 3.4. The geometry used was a cross-hatched parallel plates with diameter of $60 \mathrm{~mm}$ and a gap of $1 \mathrm{~mm}$, to avoid wall slip. All tests were conducted at room temperature $\left(25^{\circ} \mathrm{C}\right)$ and pressure. To ensure homogeneity, the suspensions were placed in an ultrasonic 
bath for 16 minutes prior to each test. All tests were repeated in triplicate, and a good repeatability was obtained. The suspensions rheology was analyzed for steady-state and oscillatory flow tests. Flow curves were obtained with shear rates ranging from 1000 to $0.01 \mathrm{~s}^{-1}$. Before each test, the sample was kept at rest for $10 \mathrm{~min}$ so that thermal equilibrium is obtained, and the fluid microstructure is allowed to rebuild after loading. Moreover, each point was recorded to guarantee that steady state was obtained, considering that the time to reach steady state is of order of the inverse of the applied shear rate [205]. At each $10 \mathrm{~s}$ an average torque is recorded, and after three consecutive 10 s periods, the average torques are compared. Steady state is assumed when the differences are below $0.1 \%$, or until a maximum time of 1200 s. Since the base fluid is non-Newtonian, a stress correction was performed directly through TA Instruments analysis software using the Weissenberg-Rabinowitch equation. The responses of the storage ( $\left.G^{\prime}\right)$ and loss $\left(G^{\prime \prime}\right)$ moduli with the stress amplitude variation were also obtained. The stress amplitude ranged from 0.1 to $100 \mathrm{~Pa}$, with a frequency of $1 \mathrm{~Hz}$. Hysteresis tests were also performed to evaluate time effects. In this test, two flow curves were recorded consecutively, following the procedure described above. The first flow curve was obtained with the shear rate increasing from 0.01 to $1000 \mathrm{~s}^{-1}$, and the second with the shear rate decreasing from 1000 to $0.01 \mathrm{~s}^{-1}$. Steady state tests for the suspensions prepared with GO $2 \mathrm{~h}$, AFGO $2 \mathrm{~h}$ and AFGO $96 \mathrm{~h}$ were repeated after one month as a complementary way of analyzing the stability of the produced nanofluids.For these tests the suspensions have not been previously sonicated.

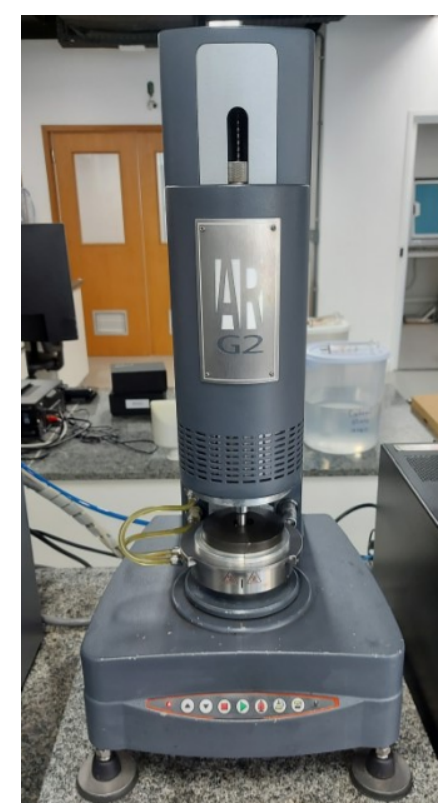

Figure 3.4: AR-G2 tension controlled rotational rheometer. 


\subsection{2 \\ Zeta potential}

Measurements of zeta potential were carried out in order to evaluate the stability of the suspensions. Furthermore, more information about the charges of the nanosheets and the macromolecule contribute to the discussions about the microstructure and rheological response of the suspensions. The equipment used was a Zetasizer, model Nano ZS90, by Malvern Panalytical, with 632.8 nm laser and polycarbonate DTS1070 zeta cell with gold-plated electrodes. In zeta potential measurements, an electrical field is applied across the sample and apparatus register electrophoretic mobility of the particles by dinamic light scattering (DLS). In this work application of Huckel approximation, represented by the equation: $\mu=2 \varepsilon_{r} \varepsilon_{0} \zeta / 3 \eta$ (where: $\mu$ is the electrophoretic mobility; $\zeta$ is the zeta potencial; $\varepsilon_{r}$ and $\eta$ are, respectively, the relative permittivity, and the viscosity of the solution; and $\varepsilon_{0}$ is the permittivity of vaccum) [207] allowed the convertion of experimental data in zeta potential information. Zeta potential by definition does not depend on concentration of solid particles dispersed in the solvent [208].Samples of the Carbopol base dispersion and the suspensions with $5 \mathrm{mg} / \mathrm{mL}$ of GO 2h, AFGO 2h and AFGO $96 \mathrm{~h}$ were diluted in deionized water in the proportion of 1:400 to perform the measurements. All samples had pH 7. In addition, samples of $1 \mathrm{mg} / \mathrm{ml}$ of aqueous suspensions of GO 2h, AFGO $2 \mathrm{~h}$ and AFGO 96h were also diluted in deionized water (1:400) and measured, these suspensions also had pH 7. 


\section{4}

\section{Results and Discussions}

\section{1}

\section{Physico-chemical aspects of functionalized graphene nanosheets}

Knowing the chemical and physical characteristics of the nanosheets is important to understand the rheological responses of the suspensions. Thus, it is worth mentioning that each batch of synthesized GO is unique, being affected by the synthesis method employed, by the quality of the materials involved in the reactions, even by the individual who conducts the synthesis procedures. Therefore, although some criteria must be met - such as the presence of bonds between carbon and oxygen, for example - the results of the chemical and structural characterizations presented below are specific to this work. As an example, to vary the degree of oxidation of GO nanosheets, only the oxidation time was varied during the GrO synthesis, with the amount of reagents involved in the process not being varied (which would probably produce nanosheets with different degrees of oxidation in relation to the which will be presented).

The X-ray diffraction (XRD) technique was used to characterize the GOs oxidized for 2 and 96 hours (GO 2 h and GO 96 h, respectively). Figure 4.1 shows the resultant crystalline patterns of these nanostructures.

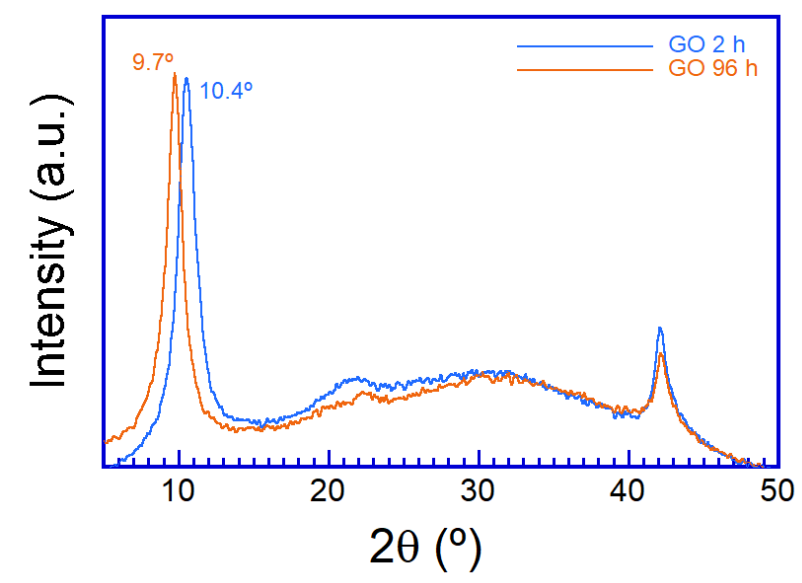

Figure 4.1: XRD patterns of GO $2 \mathrm{~h}$ and GO $96 \mathrm{~h}$

The XRD graphite pattern has characteristic peaks in $2 \theta=26,5^{\circ}$ and $2 \theta=54,5^{\circ}$ to the planes (002) and (004), respectively [49]. The plane (002) 
referring to the interplanar distance (d-spacing) of the graphite. From Figure 1 (a) it is possible to observe that the peaks related to the plane (002) of the GOs shifted to smaller angles, $2 \theta=10.4^{\circ}$ for GO $2 \mathrm{~h}$ and $2 \theta=9.7^{\circ}$ for GO 96 h. Applying Bragg's Law to the plane (002) the d-spacing obtained for graphite is $0.336 \mathrm{~nm}$ [209], for GO $2 \mathrm{~h}$ is $0.850 \mathrm{~nm}$, and for GO $96 \mathrm{~h}$ is $0.909 \mathrm{~nm}$. The increase in the distance between GOs planes in relation to graphite is due to the oxygenated functional groups between graphite planes, indicating that the synthesis process used was effective. By analogy, the fact that the d-spacing for GO $96 \mathrm{~h}$ is higher is an indication that this material has a greater amount of oxygenated functional groups introduced between its plans.

The characteristic Raman spectrum of graphite presents a high intensity band ( $\mathrm{G}$ band) at $1575 \mathrm{~cm}^{-1}$, a low intensity band (D band) around 1355 $\mathrm{cm}^{-1}$, besides a $2 \mathrm{D}$ band at $2700 \mathrm{~cm}^{-1}[210,211]$. Here the analyzes of the $\mathrm{G}$ and $\mathrm{D}$ bands are emphasized. The $\mathrm{G}$ band is related to the stretching of $s p^{2}$ bonds between carbon pairs [212]. The D band appears due to the presence of structural defects in the graphical nanosheets, such as, edge effects, $s p^{3}$ hybridized carbons, among others [210]. Figure 4.2 shows the Raman spectra of GO oxidized for 2 and 96 hours (GO $2 \mathrm{~h}$ and GO $96 \mathrm{~h}$, respectively). The $\mathrm{G}$ bands present in the spectra are intense and broad and, unlike graphite $[159,209]$, D bands are also intense and broad, indicating that graphene oxides have a greater number of defects, resulting from the introduction of oxygenated groups in surfaces and edges of its sheets. When calculating the intensity ratio of the $\mathrm{I}_{D} / \mathrm{I}_{G}$ peaks, it is possible to characterize the defects level of the GOs. GO $2 \mathrm{~h}$ presented $\mathrm{I}_{D} / \mathrm{I}_{G}$ ratio $=0.96$, while GO $96 \mathrm{~h}$ presented $\mathrm{I}_{D} / \mathrm{I}_{G}=1.05$, which means that GO $96 \mathrm{~h}$ was more affected by structural defects.

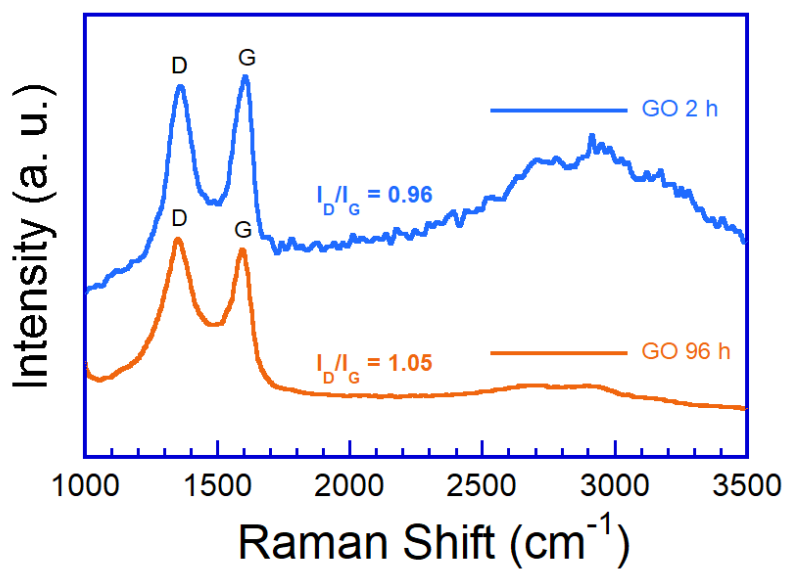

Figure 4.2: Raman spectra of GO nanosheets oxidized for 2 and $96 \mathrm{~h}$.

Fourier Transform infrared spectroscopy allowed to analyze which functional groups and bonds integrate the GO samples. Figure $4.3 \mathrm{a}$ and $\mathrm{b}$ 
show the FTIR spectra for GO $2 \mathrm{~h}$ and GO $96 \mathrm{~h}$, respectively.Both spectra show vibrations associated with oxygenated functional groups, further evidence that the synthesis of GO was successful.
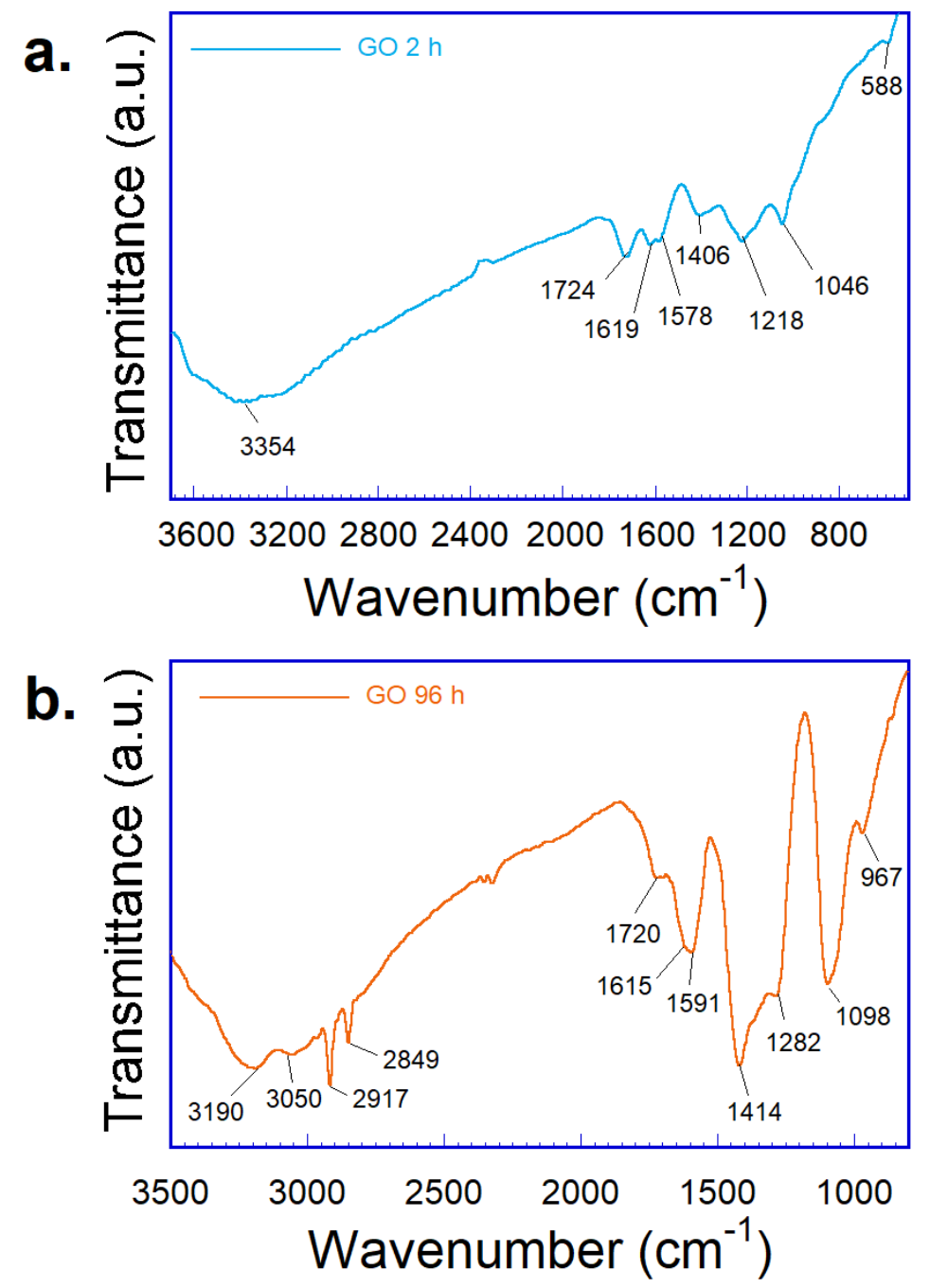

Figure 4.3: FTIR spectrum of GO oxidized for: a. 2 hours and b. $96 \mathrm{~h}$.

The small band that appears for the frequency of $588 \mathrm{~cm}^{-1}$ in the GO $2 \mathrm{~h}$ spectrum indicates the presence of $\mathrm{C}=\mathrm{O}$ out-of-plane deformation vibrations. The $967 \mathrm{~cm}^{-1}$ peak in the GO $96 \mathrm{~h}$ spectrum is associated with the presence of out-of-plane deformation of the carboxylic acid group [213]. The peaks at 1046 and $1098 \mathrm{~cm}^{-1}$ for the GO $2 \mathrm{~h}$ and GO $96 \mathrm{~h}$ spectra, respectively, establish the existence of $\mathrm{C}-\mathrm{O}$ stretching, which can be related to alcohols. The peaks at 1218 and $1282 \mathrm{~cm}^{-1}$ also determine the presence of stretching C-O bonds, and can be related to carboxylic acids, esters and ethers (epoxy) [213, 214]. The peaks that manifest at frequencies $1406 \mathrm{~cm}^{-1}$ for GO $2 \mathrm{~h}$ and $1414 \mathrm{~cm}^{-1}$ for GO $96 \mathrm{~h}$ indicate the presence of $\mathrm{O}-\mathrm{H}$ deformation vibrations, while the peaks for the frequencies of 1619 and $1615 \mathrm{~cm}^{-1}$ are associated with the $\mathrm{C}=\mathrm{C}$ 
stretch, and at 1578 and $1591 \mathrm{~cm}^{-1}$ they are related to the fact that the $\mathrm{C}=\mathrm{C}$ bonds are arranged in aromatic rings. The bands at 1724 and $1720 \mathrm{~cm}^{-1}$ in Figures $4.3 \mathrm{a}$ and $\mathrm{b}$, respectively, determine the stretching of $\mathrm{C}=\mathrm{O}$ bonds, which may be related to the presence of carboxylic acids and ketones. The broad bands between the frequencies of 3600 and $2500 \mathrm{~cm}^{-1}$ in both spectra are associated with $\mathrm{OH}$ in the samples. The peaks at $3354 \mathrm{~cm}^{-1}$ for the GO $2 \mathrm{~h}$ spectrum and 3190 and $3050 \mathrm{~cm}^{-1}$ for the GO $96 \mathrm{~h}$ arise due to the $-\mathrm{OH}$ stretch from carboxylic acids and hydrogen bonds derived from moisture in the samples. However, the fine peaks that appear at the frequencies of 2917 and $2849 \mathrm{~cm}^{-1}$ in the GO $96 \mathrm{~h}$ spectrum indicate symmetric and asymmetric $\mathrm{C}-\mathrm{H}$ stretching that can be related to the appearance of local defects in the GO nanosheets [215]. The appearance of frequencies associated with $\mathrm{C}-\mathrm{H}$ agrees with the results of Raman spectroscopy, which presented a higher $\mathrm{I}_{D} / \mathrm{I}_{G}$ ratio for GO $96 \mathrm{~h}$.

The evaluation of the GO oxidation degree and AFGO amination level was carried out through thermogravimetric analysis. The TGA and DTG graphs for GO $2 \mathrm{~h}$ and GO $96 \mathrm{~h}$ are shown in Figure 4.4.
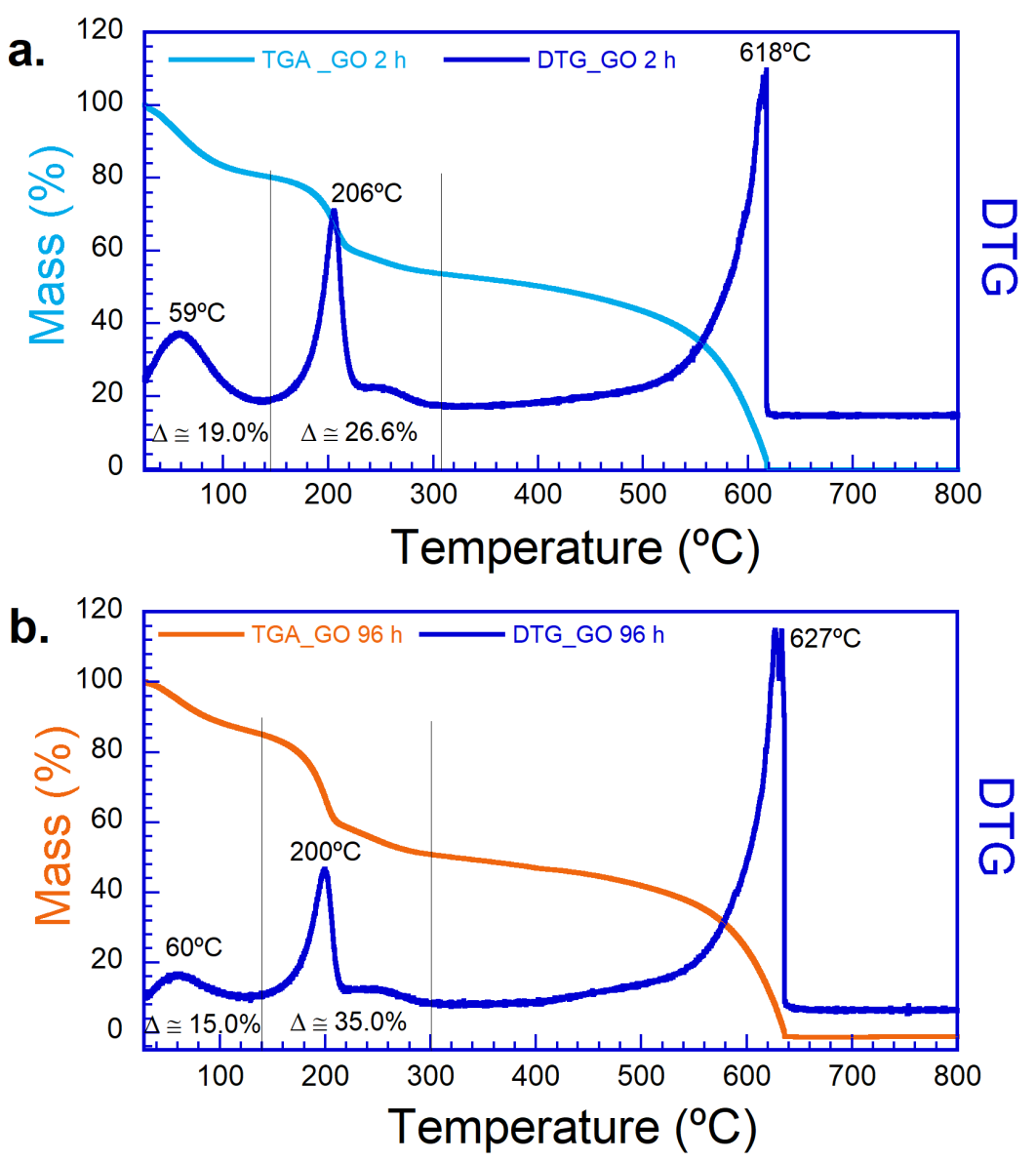

Figure 4.4: TGA and DTG of GO oxidized for: a. 2 hours and b. $96 \mathrm{~h}$. 
In the GOs thermograms it is possible to identify three stages in which loss of mass occurs in the samples. The first stage is correlated to the moisture evaporation that occur in the GOs. For GO $2 \mathrm{~h}$, the highest evaporation rate occurred at $59^{\circ} \mathrm{C}$ and the total lost mass was equal to $19 \%$, while for GO $96 \mathrm{~h}$ the maximum evaporation rate occurred at $60^{\circ} \mathrm{C}$ and the lost mass was equal to $15 \%$. The second stage of mass loss concerns of the degradation of the oxygenated groups introduced in the graphite structure, that is, it indicates the degree of oxidation of the GO. The temperatures where the maximum rates of degradation occurred were close, equal to $206^{\circ} \mathrm{C}$ for GO $2 \mathrm{~h}$ and $200^{\circ} \mathrm{C}$ for GO $96 \mathrm{~h}$. Regarding the mass of degraded functional groups, GO $2 \mathrm{~h}$ showed a loss of approximately $26.6 \%$ while GO 96 h lost around $35 \%$ of its total mass. In other words, the GO oxidized for 96 hours has $8.4 \%$ more functional groups than the GO $2 \mathrm{~h}$, showing that the exposure time of graphite exerts influence to the oxidation process. Finally, the third stage of mass loss comes from the degradation of the GOs graphitic structure.

Figure 4.5 shows the TGA and DTG curves of the AFGO nanosheets.
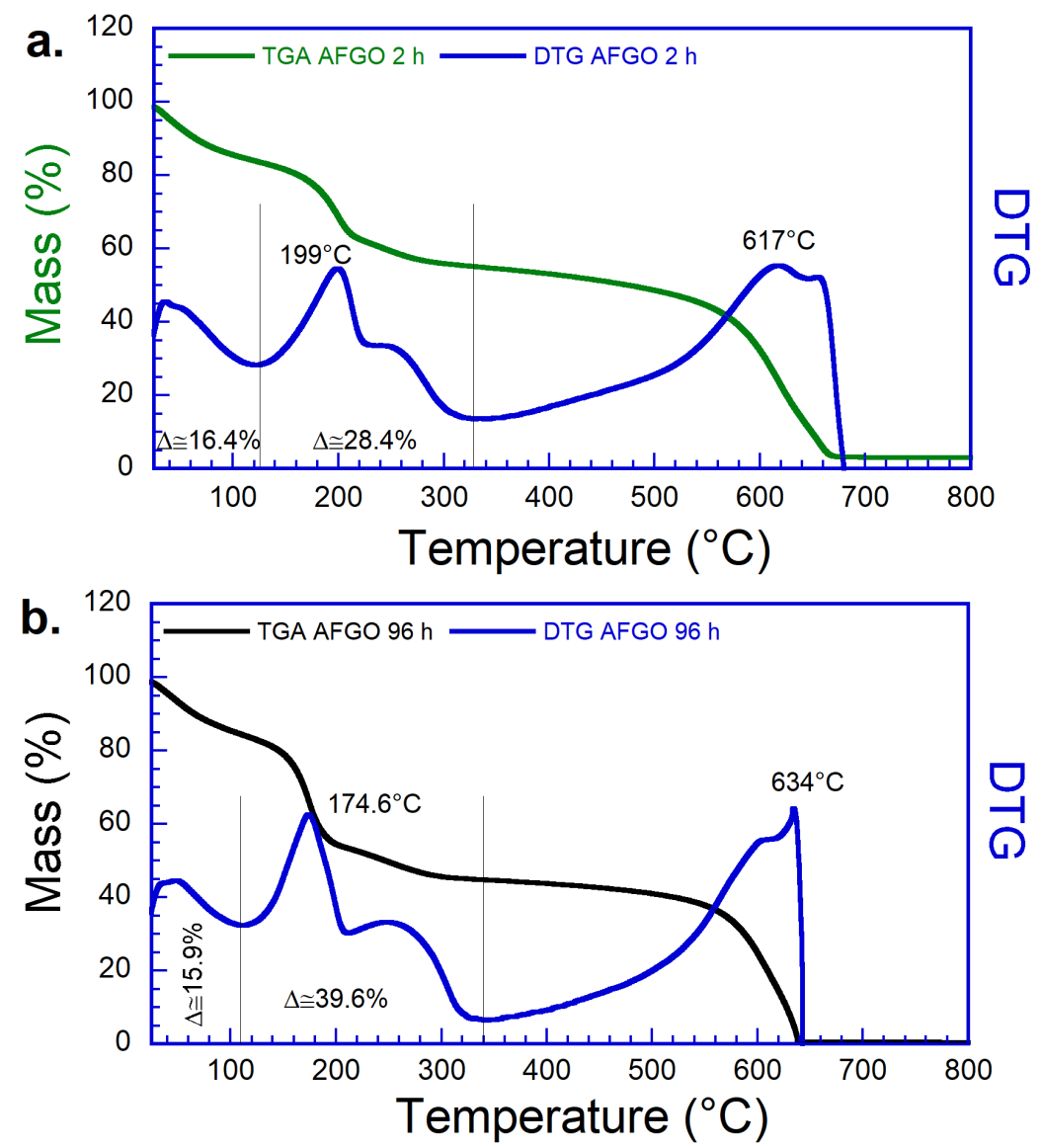

Figure 4.5: TGA and DTG of AFGO: a. $2 \mathrm{~h}$ and b. $96 \mathrm{~h}$.

As observed for the GO nanosheets, three stages of mass loss are identified in the AFGO thermograms. The first stage also corresponds to the evaporation 
of moisture from the samples, indicating $16.4 \%$ of mass loss for AFGO $2 \mathrm{~h}$ and $15.9 \%$ for AFGO $96 \mathrm{~h}$. The second stage, related to the decomposition of the functional groups, presents a loss of $28.4 \%$ in mass for AFGO $2 \mathrm{~h}$ with maximum loss rate occurring at a temperature of $199^{\circ} \mathrm{C}$, and $39.6 \% \mathrm{wt}$ of loss for AFGO $96 \mathrm{~h}$ with maximum loss rate occurring at $174.6^{\circ} \mathrm{C}$. Therefore, the AFGO $96 \mathrm{~h}$ has $11.2 \%$ wt more of functional groups in relation to the AFGO 2 h. Additionally, an important characteristic of the AFGO nanosheets is obtained by analyzing the DTG in the second stage. Adjacent to the peak of maximum mass loss rate, there is the presence of a second curve (or a new peak) associated with TETA decomposition $[159,216,217]$. Such an evident curve was not observed for the GO thermograms. For AFGO $2 \mathrm{~h}$, the decomposition of the TETA occurs between $234^{\circ} \mathrm{C}$ and $331^{\circ} \mathrm{C}$, corresponding to $5.8 \%$ of the loss of mass of the material. For the AFGO $96 \mathrm{~h}$, a drop of $8.7 \%$ wt of the nanomaterial is observed for the range of $212^{\circ} \mathrm{C}$ to $350^{\circ} \mathrm{C}$. The AFGO thermography, in addition to indicating the presence of TETA on the nanosheets, shows that GO nanosheets containing a greater amount of oxygenated groups promotes functionalization with a greater amount of amino groups. AFGO 96h has a greater number of functional groups than AFGO $2 \mathrm{~h}$, with $2.9 \%$ wt of the difference in mass between these nanomaterials corresponding only to TETA. The third stage of mass loss is originated from the degradation of the AFGOs graphitic structure.

The morphology and structure of the nanosheets were analyzed through images obtained by TEM and AFM. Figure 4.6 shows the TEM images obtained for the GOs, where it is possible to see wavy, crumpled and translucent nanosheets with lateral size up to $10 \mathrm{~nm}$, which translate as sheets with few layers of GO for both samples. The images suggest that the exfoliation process promoted the breaking of Van der Waals interactions present between the graphical nanosheets [216].
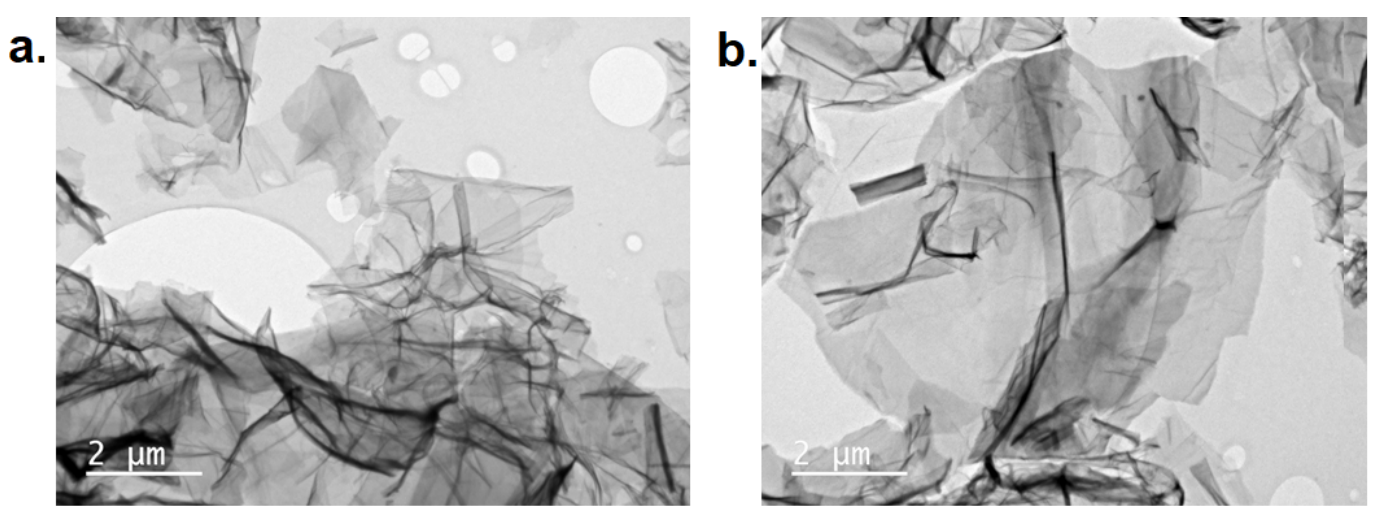

Figure 4.6: TEM images of GO oxidized for: a. 2 hours and b. 96 h.

The different interplanar distances, number of defects and number of 
functional groups present between the GOs sheets can influence the exfoliation level of the layers. AFM images allow to estimate the distribution of the nanosheets thickness. Figure 4.7 shows an AFM image of GO 2 h.

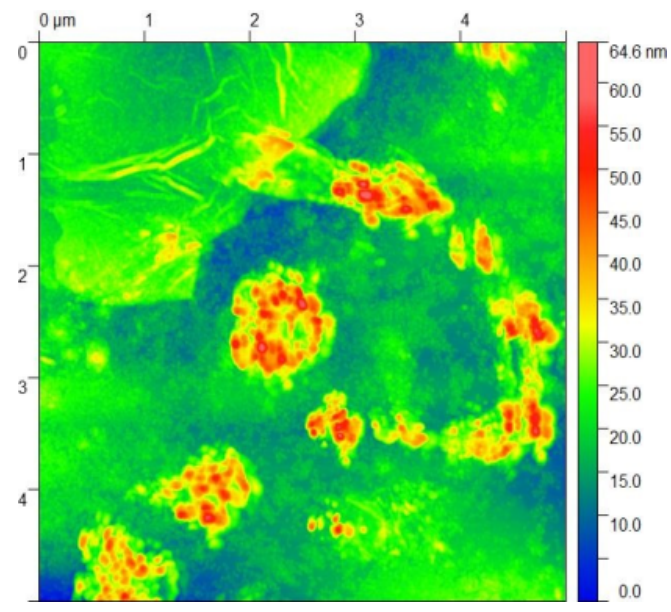

Figure 4.7: AFM image of GO oxidized for 2 hours.

Figure $4.8 \mathrm{a}$ shows that the GO $2 \mathrm{~h}$ nanosheets thickness presented an average value of $\sim 17 \mathrm{~nm}$, while Figure $4.8 \mathrm{~b}$ indicates that the GO 96 h showed an average thickness of $\sim 6 \mathrm{~nm}$. Thus, it is observed that the exfoliation process was more efficient for this GO 96h sample, as confirmed by the diffractogram of Figure 4.1. The small red portion of the topography shown in the AFM image may be related to the presence of artifacts from salt residues from the GrO synthesis process, or by the presence of carbonic debris contained in the sample [159].

Since the interplanar distance of the GOs is known from XRD results, it is possible to estimate the number of sheets of the GO samples from the thickness distribution. This result can be confirmed by the thickness distribution profiles for GO $2 \mathrm{~h}$ and GO $96 \mathrm{~h}$, respectively, shown in Figures 4.8b and 4.8c. Figure $4.8 \mathrm{~b}$ shows that about $71 \%$ of the GO $2 \mathrm{~h}$ nanosheets produced are up to $20 \mathrm{~nm}$ thick. Consequently, the largest percentage of nanosheets has up to 19 layers, and this can be considered a multilayer graphene oxide (mGO). Regarding the GO oxidized for 96 hours, Figure 4.8c exposes that approximately $52 \%$ of the nanosheets are up to $6 \mathrm{~nm}$ thick and $83 \%$ of the sample is up to $10 \mathrm{~nm}$. Thus, slightly more than half of the nanosheets have up to 4 layers (few-layer graphene oxide - FLGO), and more than $80 \%$ of the sample is composed of mGO of up to 9 layers. Therefore, the exfoliation of GrO $96 \mathrm{~h}$ produces nanosheets with a lower number of layers compared to the GrO 2 h, due to the greater number of functional groups introduced in the sheet surface. It is worth noting that, for technical reasons, the thickness distribution determined for the GO $96 \mathrm{~h}$ was processed using an image with a $20 \times 20 \mu \mathrm{m}$ scale, while 

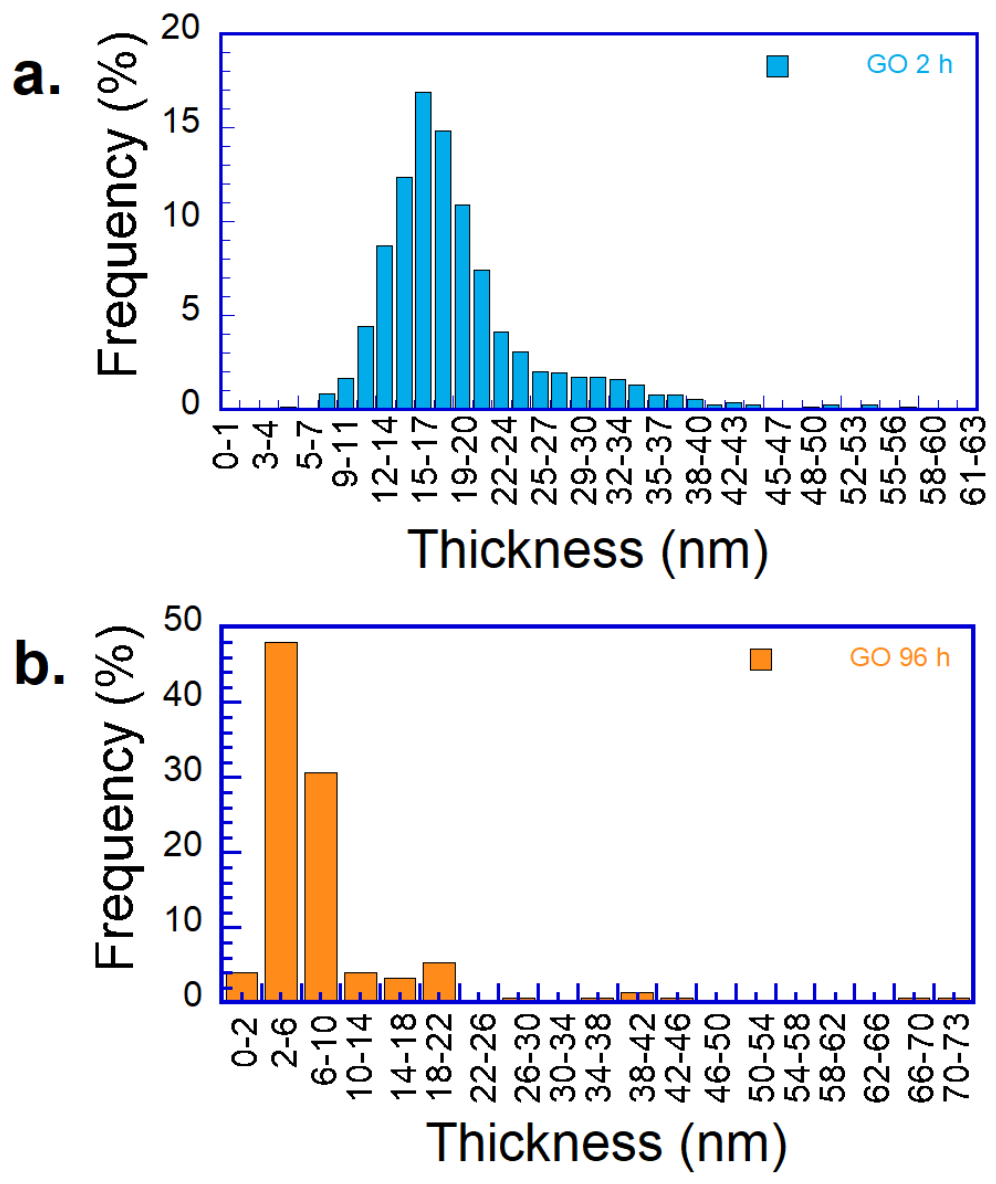

Figure 4.8: a. Thickness distribution profile of the GO $2 \mathrm{~h}$ nanosheets; b. Thickness distribution profile of the GO $96 \mathrm{~h}$ nanosheets.

the GO $2 \mathrm{~h}$ results were obtained using an image of $5 \times 5 \mu \mathrm{m}$. In other words, even on a larger scale the number of layers present in the GO $96 \mathrm{~h}$ nanosheets is lower.

XPS is a powerful spectroscopic technique for the characterization of surfaces. Therefore, XPS was used to get more information on the chemical composition of graphite, graphene oxide and amine-functionalized graphene oxide samples. Figure 4.9 shows the XPS scan survey of these samples.

All the XPS data were corrected using the binding energy of $\mathrm{C}-\mathrm{C}$ at $284.5 \mathrm{eV}$. It was identified in survey spectra the presence of photoemission peaks for $\mathrm{C} 1 s$ at $284.6 \mathrm{eV}, \mathrm{N} 1 s$ at $400.0 \mathrm{eV}$ (only for AFGO sample) and $\mathrm{O} 1 s$ at $531.0 \mathrm{eV}$. Some of $\mathrm{C}$ signal identified in the graphite sample before chemical modification is related to the surface contamination that generally occurs during the preparation process and to the exposure of the sample to air, as commonly observed in XPS measurements. Figure 4.10 shows the high-resolution photoemission peak for the carbon atom. The photoemission C1s peaks were studied between $280-295 \mathrm{eV}$.

Figures 4.10a, 4.10b and 4.10c show a peak at approximatelyv $284.6 \mathrm{eV}$ 


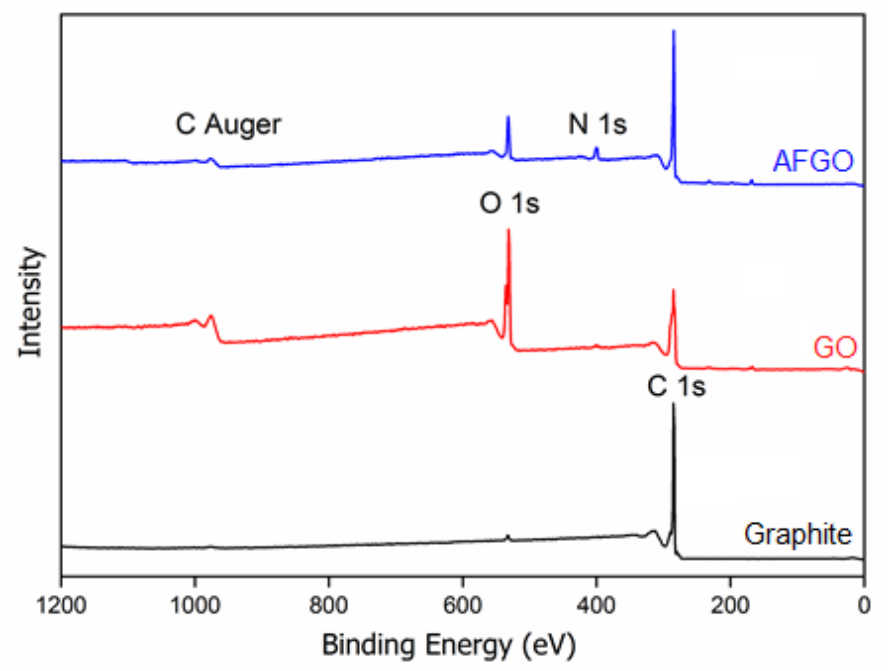

Figure 4.9: XPS spectra for graphite, GO 96h and AFGO 96h.

C $1 s$
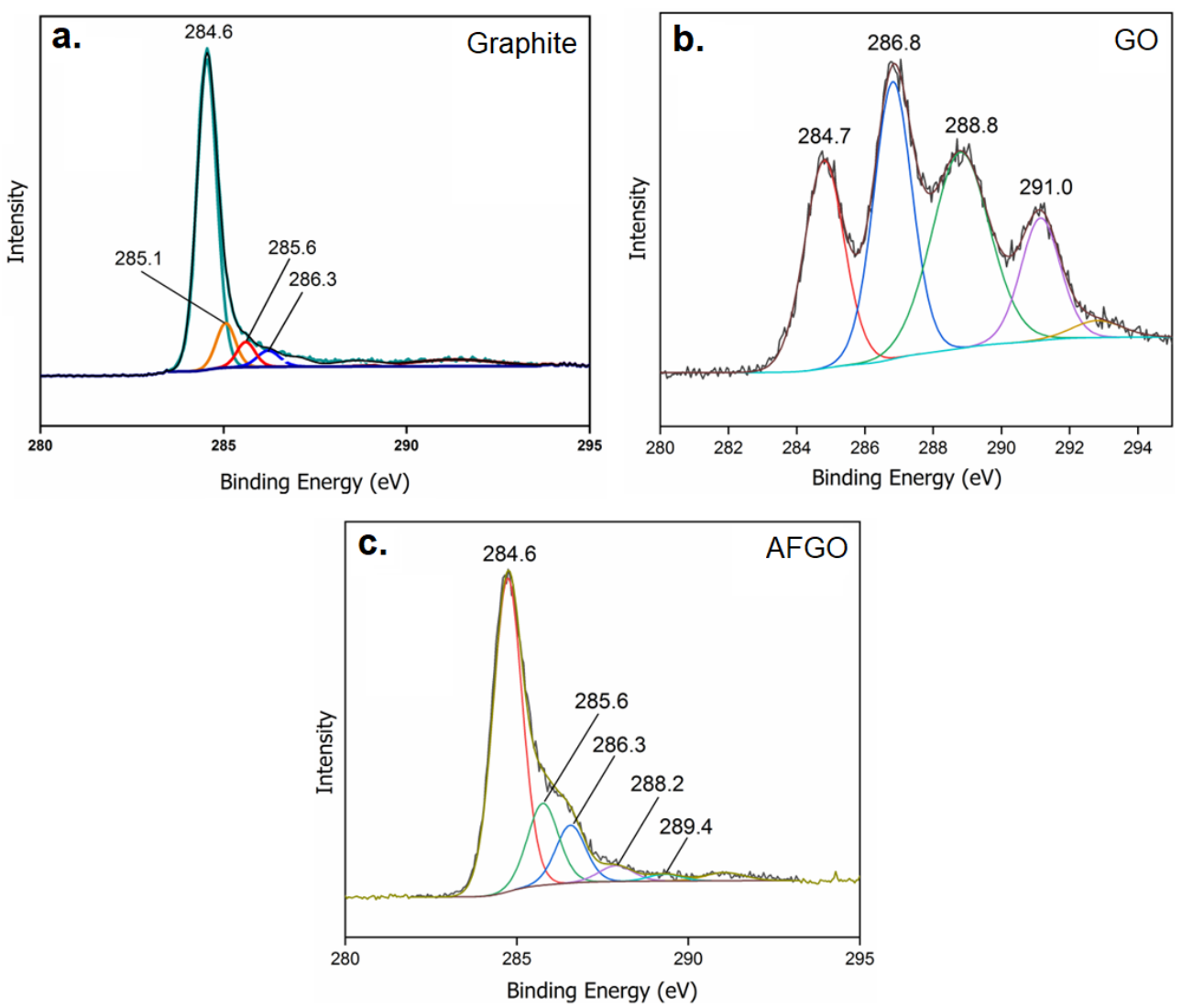

Figure 4.10: High-resolution photoemission $\mathrm{C} 1 s$ peaks for a. graphite; b. GO and c. AFGO.

regarding the $s p^{2}$ hybridized $\mathrm{C}$-C bonds in extensive $\pi$-conjugated systems $[218,219]$. A secondary peak are verified at 285.1 and 285.7 (Figures 4.10a and $4.10 \mathrm{c}) \mathrm{eV}$, which is characteristic of $s p^{3}$ hybridized C-C bonds present at defective locations [220]. Photoemission peaks were also observed at 285.6, 
286.3, 286.8, 286.6 and $287.1 \mathrm{eV}$ (Figures 4.10a, 4.10b and 4.10c). The first is attributed to carbon atoms bonded to oxygen atoms (-C-O-R), and the others are characteristic of $s p^{3}$ carbons attached to hydroxyl groups (-OH) or carbon atoms pertaining to carbonyl groups $(-\mathrm{C}=\mathrm{O})[159,220]$. The evidence of carboxylic groups presence is obtained by the observation of a peak at 288.8 $\mathrm{eV}$ (Figure 4.10b), which is typical for this functional group [221]. Figure 4.10c shows the presence of carbon at $-\mathrm{N}-\mathrm{C}=\mathrm{O}$ bond with absorption at $288.2 \mathrm{eV}$ and the photoemission peak at 289.4 indicates the presence of carboxylated groups. This observation of carbon in the amide group shows the efficiency of the covalent functionalization of graphene with TETA. In approximately 291.0 $\mathrm{eV}$ (Figure 4.10a and 4.10b), a satellite peak is observed, which is caused by the $\pi-\pi^{*}$ electronic transition [159,221,222].

The adjustments of the photoemission peaks for O1s are in Figure 4.11. Peak at 532.1 is atribuited to the $\mathrm{C}=\mathrm{O}$ bonds, at 533.9 can be assigned to the $\mathrm{C}-\mathrm{OH}$ bond of water, adsorbed on the surface of the material (Figure 4.11a). After the oxidation process, peaks related with binding energies of 532.7, 534.6 and $536.5 \mathrm{eV}$ represent the $\mathrm{C}=\mathrm{O}, \mathrm{C}-\mathrm{O}-\mathrm{C}$ and $\mathrm{C}-\mathrm{OH}$, respectively [223]. After the TETA functionalization, peaks related to the -C-O bond are observed at 531.5, and the $-\mathrm{C}=\mathrm{O}$ bond appear at $533.0 \mathrm{eV}$ (Figure 4.11c) [219].

The N1s peak is observed only for the AFGO sample. The presence of the characteristic carbonyl amide functional group is identifiable in the detailed N1s spectrum (Figure 4.12). After adjustment, three significant contributions in terms of binding energy were observed between 395.0- $405.0 \mathrm{eV}$. The first at $398.6 \mathrm{eV}$, attributed to nitrogen atoms of primary amines, the second at 400.0 $\mathrm{eV}$ assigned to the amide group and the third and last at $401.7 \mathrm{eV}$ attributed to secondary amines present in the molecule of TETA [159,224]. The XPS results indicate the sucessfull introduction of TETA molecule covalently linked to GO surface.

\section{2}

\section{Rheological and structural aspects of the suspensions}

\subsection{1}

\section{Graphene oxide suspensions characteristics}

The flow curves for the suspensions of $1 \mathrm{mg} / \mathrm{ml}$ of $\mathrm{GO} 2 \mathrm{~h}$ in $0.15 \mathrm{wt} \%$ of Carbopol aqueous dispersion obtained for the three preparation methods described in subsection 3.2.1 are presented in Figure 4.13a. The experimental data in all the plots show the mean value of the three data measured for each sample. 


\section{$01 s$}
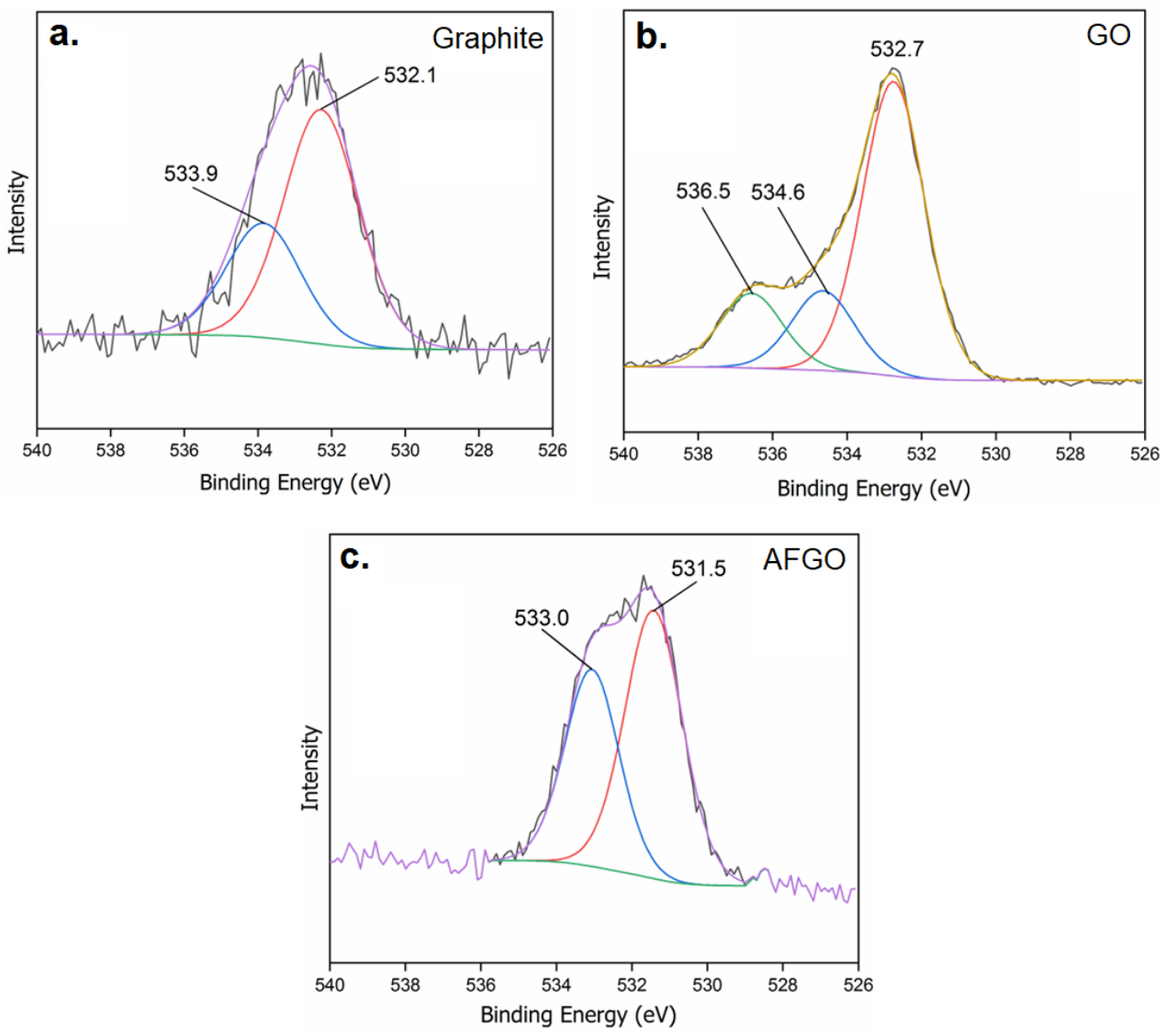

Figure 4.11: High-resolution photoemission O1s peaks for a. graphite; b. GO and c. AFGO.

\section{$\mathbf{N}$ 1s}

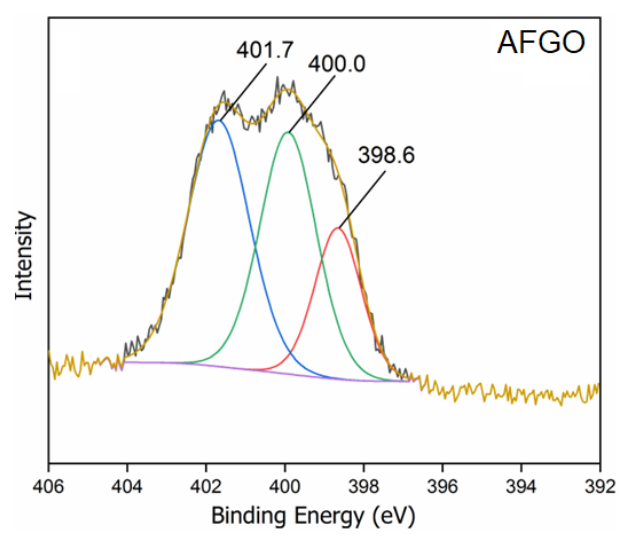

Figure 4.12: High-resolution photoemission N1s peaks for AFGO.

The pure Carbopol's aqueous dispersion is a model yield stress fluid that usually fits the Herschel-Bulkley model, described by the equations 2-1 and $2-2[178,201,205,225]$. This behavior is commonly observed in dispersions above a certain polymer concentration. These fluids maintain an irregular internal order forming three-dimensional structures with sufficient rigidity to 


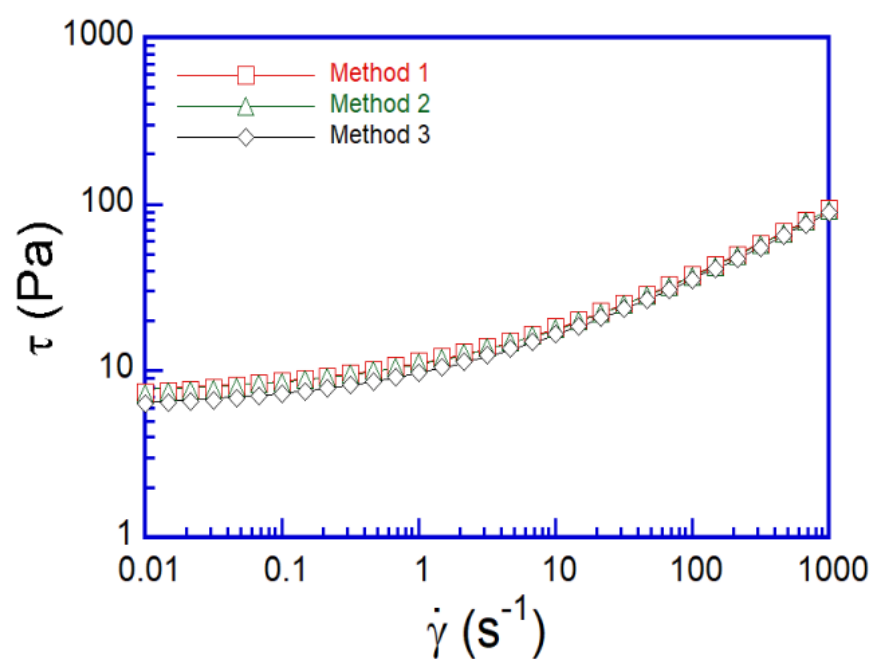

Figure 4.13: Rheology of the Carbopol $0.15 \%$ wt suspensions with $1 \mathrm{mg} / \mathrm{mL}$ of GO oxidizedfor $2 \mathrm{~h}$. Comparison of the three different preparation methods. Flow curves obtained experimentally (symbols) and Herschel-Bulkley curve fitting (continuous lines).

withstand an external stress lower than $\tau_{y}$, offering flow resistance although allowing elastic deformation [186]. At the yield stress, the structure breaks leading to a steep decrease in the viscosity, followed by a shear thinning behavior as the applied stress increases. Figure 4.13 shows that the three GO suspensions, prepared with different methods, present similar behavior, and can be modeled by the Herschel-Bulkley equation, similar to the pure Carbopol aqueous dispersion. The rheological parameters that describe the behavior of the three suspensions as well as their respective $\mathrm{pH}$ values are presented in Table 4.1 .

Table 4.1: Herschel-Bulkley fitting parameters and $\mathrm{pH}$ of the $0.15 \mathrm{wt} \%$ of Carbopol suspensions with $1 \mathrm{mg} / \mathrm{ml}$ of GO $2 \mathrm{~h}$. Standard errors of the curve fittings were below $3.04 \%$.

\begin{tabular}{c|ccc} 
Parameters & Method 1 & Method 2 & Method 3 \\
\hline$\tau_{y}$ & 8.2 & 7.5 & 6.0 \\
$k$ & 4.0 & 3.7 & 3.7 \\
$n$ & 0.46 & 0.46 & 0.45 \\
$\mathrm{pH}$ & 6.30 & 7.40 & 5.70
\end{tabular}

The results of stress sweep tests of the same suspensions are shown in Figure 4.14.

It can be noted that the results are similar for the three cases. Three regions can be identified, which are also characteristic of pure Carbopol 


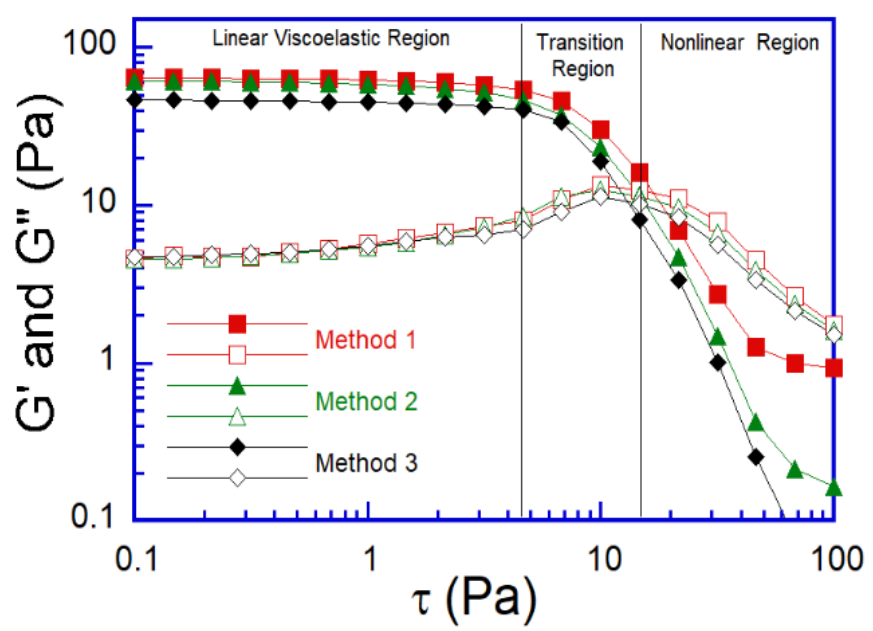

Figure 4.14: Comparison of the three different preparation methods. Stress sweep curves (filled symbols indicate G' and empty symbols represent G").

dispersions: the linear viscoelastic region (LVR) in the range of low stress, where the storage and loss moduli, G' and G" respectively, are independent of stress [198, 200, 205, 226-228]. The stresses applied in this region are not sufficient to break the bonds that make up the microstructure of the fluid [205]. Then, the molecules that form the microgels can deform elastically, but do not shift significantly from their initial positions. The fact that $G^{\prime}$ is greater than G" indicates that below yield stress such microstructure gives the fluid the predominance of elastic behavior and low internal dissipation [228]. As the stress increases, a transition region occurs. G' begins to decrease, indicating decreased elasticity and breakage of the initial fluid microstructure [226]. This region is located at an intermediate stress range, close to the crossover between G' and G'. Within this region there are failures in the fluid microstructure, or in other words, the molecules move significantly from their original positions. The increase in G" occurs due to the dissipation of mechanical energy resulting from the movement of molecules. However, the fluid microstructure is still enough rigid to maintain a considerable elastic response, so $\mathrm{G}^{\prime}$ is still high [205]. Further increasing, the stress amplitude leads to a nonlinear region that begins after the crossover point between G' and G". The storage modulus decreases rapidly to values lower than G", which in turn grows to a maximum value decreasing in sequence. This stress level causes a sharp breakdown of the fluid microstructure that results in a viscous behavior. The greater is the stress amplitude applied, the lower is the level of fluid structure, consequently the lower is the elastic response [205].

The results show that the suspension prepared by method \#3 has a slightly lower G'. Since in method \#3 the GrO goes through the exfoliation 
process first, it is possible that the polymer chains did not open in the same way as for the other suspensions leading to weaker elasticity [229]. The three preparation methods presented quite similar results from the rheological point of view, so the simpler preparation procedure, method $\# 1$, was chosen to be used in all the following suspensions presented in this work. In addition the Carbopol concentration on the base fluid was increased with the aim to maintain a significant yield stress in order to continue with the use of parallel plate geometry that requires less fluids to perform measurements.

It is important to mention that all the curves measured for each sample showed high repeatability. Figure 4.15 shows the three flow curve measurements performed for the suspension sample with $1 \mathrm{mg} / \mathrm{mL}$ of GO $2 \mathrm{~h}$ in $0.3 \%$ wt Carbopol dispersion. None of the three flow curves measured for each suspension sample of this work presented a relative error greater than 0.05 , all curves considered similar have a relative error of less than $5 \%$.

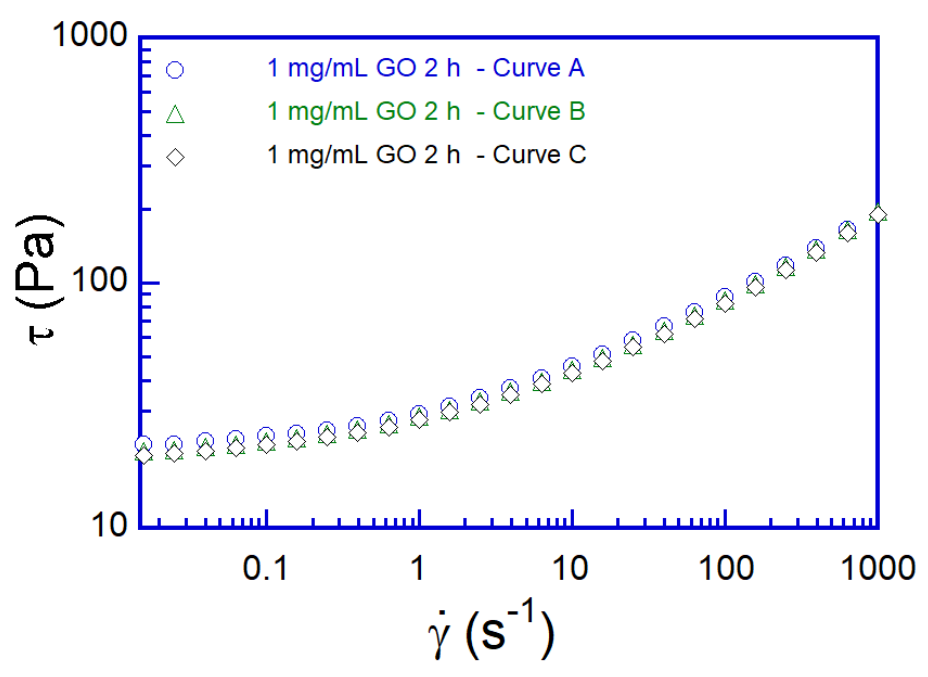

Figure 4.15: The three flow curve measurements performed for the suspension sample with $1 \mathrm{mg} / \mathrm{mL}$ of GO $2 \mathrm{~h}$ in $0.3 \%$ wt Carbopol dispersion.

The effect of GO concentration in the suspension rheology is presented in Figures 4.16 and 4.17. The suspensions were prepared with concentrations of $0.1,1$ and $5 \mathrm{mg} / \mathrm{mL}$ of GO oxidized for 96 hours in a $0.30 \%$ wt Carbopol ${ }^{\circledR}$ aqueous dispersion. The flow curves obtained experimentally, with their respective Herschel-Bulkley curve fittings, are shown in Figure 4.16. The base fluid presents a slightly higher viscosity than the 0.1 and $1 \mathrm{mg} / \mathrm{mL}$ suspensions of GO. As the concentration increases to $5 \mathrm{mg} / \mathrm{mL}$ of $\mathrm{GO}$, a more pronounced decrease of the suspension viscosity is noted, while the Herschel-Bulkley equation continues to model the fluid behavior. Therefore, the increased concentration of GO promotes the decrease of the suspension viscosity, as it will be discussed in the follow. 


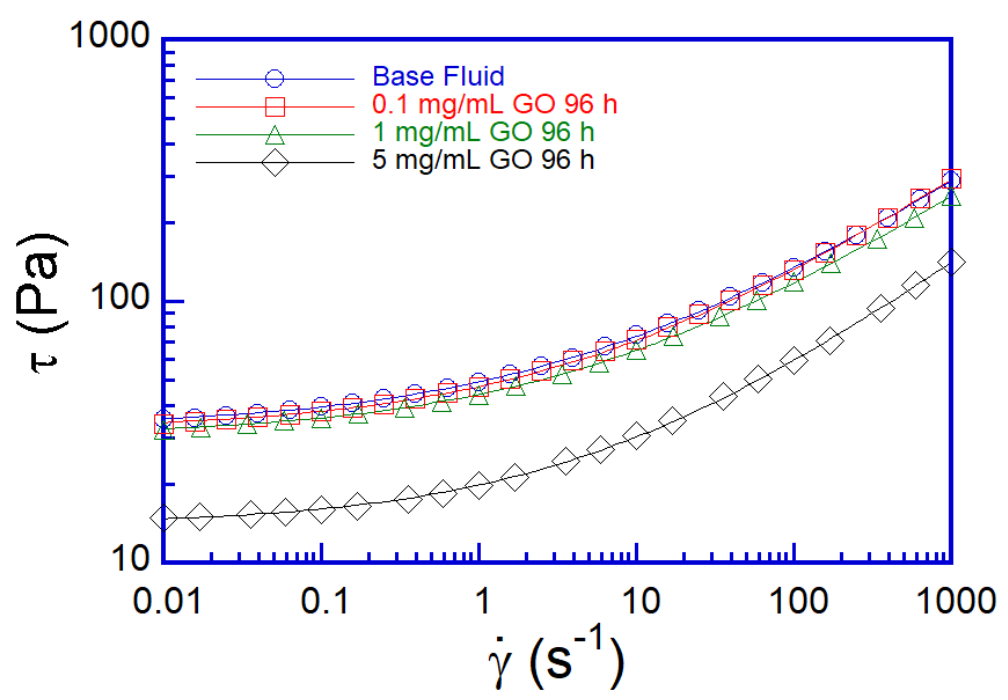

Figure 4.16: Flow curves of the suspensions with 0 (Base fluid), 0.1, 1, and $5 \mathrm{mg} / \mathrm{mL}$ of GO oxidized for $96 \mathrm{~h}$, obtained experimentally (symbols) and Herschel-Bulkley curve fitting (continuous lines).

The rheological characteristics of the aqueous dispersion of Carbopol come from polymer chains ionization. After dispersion neutralization, the polymer backbone is negatively charged, and, consequently the chain uncoils and absorbs water, developing the swelling and forming a microgel unit. It turns out that for dispersions with Carbopol concentrations above a certain critical value, these units are so close to each other that repulsive interactions restrict the motion among them, and a jammed structure (reversible network) is formed [197,198,200,225,226,230-232], being necessary to apply a stress above the critical (yield) value to break the structure and allowing the hydrogel to flow. Since graphene oxide has carboxylic acids, as it was demonstrated on the chemical characterization, it becomes negatively charged in water, and it will interact with Carbopol. However, these repulsive electrostatic interactions between GO and the hydrogel are weaker than the polymer-polymer interactions, which will form weaker bonds within the material [233]. Therefore, after GO is incorporated in the Carbopol it will be part of the formulation [234, 235], and their interactions will dominate within the system, causing a perturbation and developing at the end a weaker microgel network [233]. As a result, the addition of GO to the Carbopol aqueous dispersion suggest the formation of a weaker hydrogel, with lower viscosity and yield stress. This behavior can be enhanced by the increase of GO concentration, which can lead to agglomerates and result in micro-phase separation of components [235], and can contribute as well as to lubrication effects of GO $[84,157,209]$ developing a significant viscosity decrease, as it is observed for the higher concentration in Figure 4.16. 
Stress sweep results for the same suspensions are shown in Figure 4.17. It can be observed that all suspensions have G' higher than G" in LVR, which indicates the behavior of a gel [198]. However, with the increase of GO concentration, both G' and G" decrease, due to the weakness of the hydrogel as stated above. Moreover, the crossover points between G' and G" occur for smaller stress amplitudes with the increase of GO concentration, indicating loss of fluid elasticity, and consequently the breakdown of the physical crosslinking of these suspensions. These results are in agreement with the decrease of the yield stress observed previously.

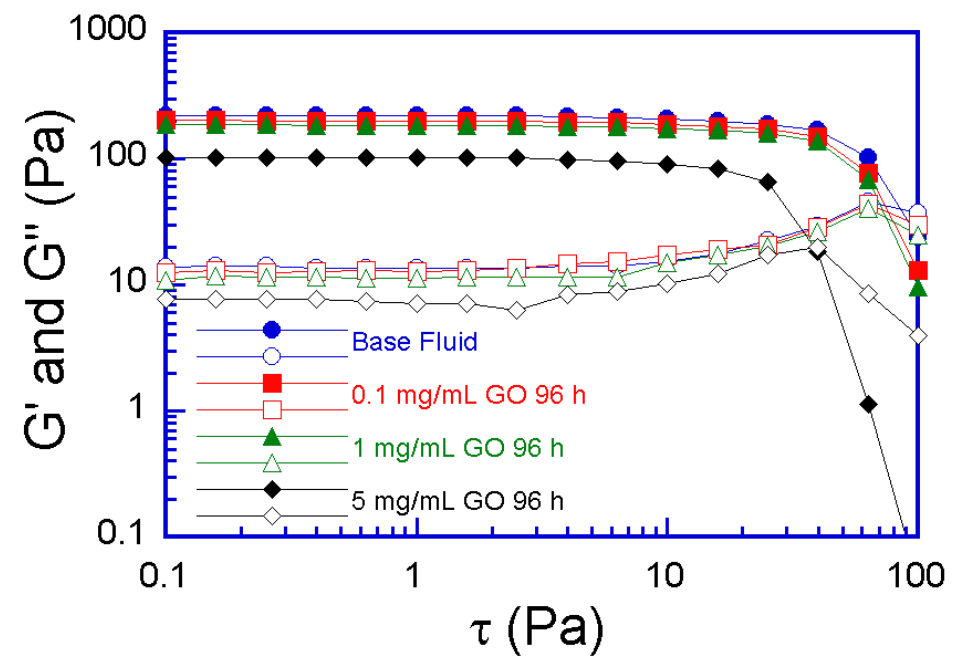

Figure 4.17: Stress sweep curves of the suspensions with 0 (Base fluid), 0.1, 1, and $5 \mathrm{mg} / \mathrm{mL}$ of GO oxidized for $96 \mathrm{~h}$. Filled symbols correspond to G' and empty symbols represent G".

The effect of GO oxidation time on fluid rheology is presented in Figures 4.18 and 4.19. Figure 4.18 shows the flow curves of the suspensions with 1 and $5 \mathrm{mg} / \mathrm{mL}$ of GO oxidized for 2 and 96 hours. Table 4.2 shows the values of the rheological parameters of the suspensions prepared for the two types of GO, as well as their $\mathrm{pH}$ values, which are within the $\mathrm{pH}$ range for the high constant viscosity plateau $[201,204]$. The results show that the suspensions prepared with GO oxidized for 2 hours present higher drop in yield stress, consistency index and viscosity than the suspensions prepared with GO oxidized for 96 hours. This behavior is addressed in the following discussion.

Although both GOs contribute to the drop of the rheology of the suspensions, less oxidized GO leads to higher decrease of yield stress, consistency index and viscosity. This behavior is another indication that the relatively smaller number of ions present in the GO interface is an important factor for the weakness of the microstructure of the Carbopol dispersion. TGA results showed that the GO oxidized for 96 hours has higher degree of oxidation 


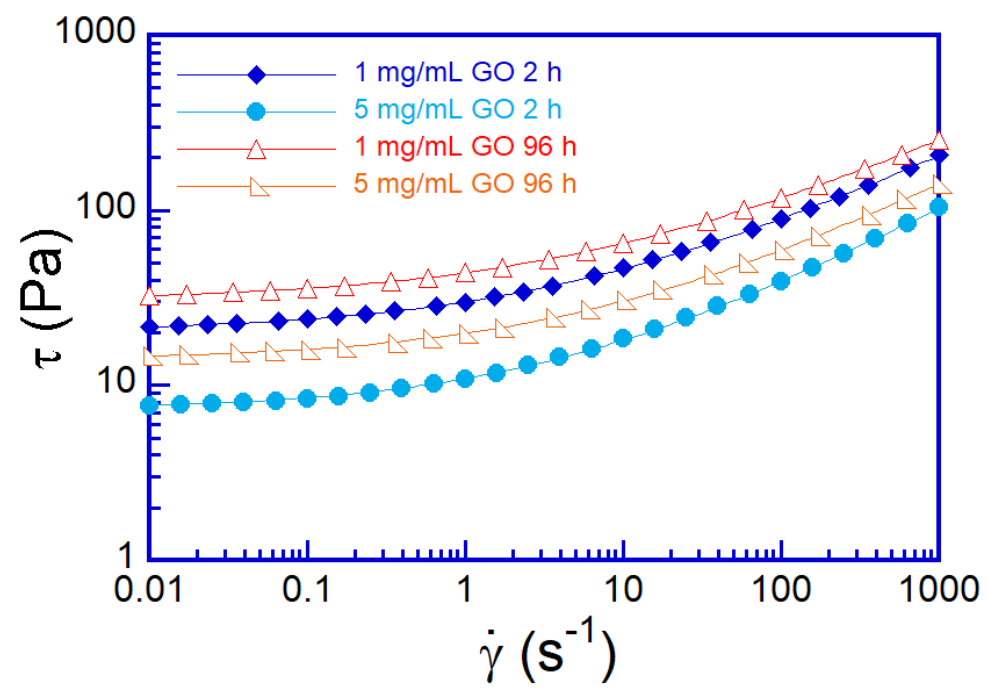

Figure 4.18: Flow curves of the suspensions with 1 and $5 \mathrm{mg} / \mathrm{mL}$ of GO oxidized for $2 \mathrm{~h}$ and $96 \mathrm{~h}$ obtained experimentally (symbols) and Herschel-Bulkley curve fitting (continuous lines).

Table 4.2: Herschel-Bulkley fitting parameters of the suspensions of GO oxidized for 2 and 96 hours. The base fluid was made with $0.3 \%$ wt of Carbopol concentration. Standard errors of the curve fittings were below $2.85 \%$.

\begin{tabular}{c|cc|cc|cc|cc} 
Concentration & \multicolumn{2}{|c|}{$\tau_{y}(\mathrm{~Pa})$} & \multicolumn{2}{|c|}{$k\left(\mathrm{Pas}^{n}\right)$} & \multicolumn{3}{|c|}{$n$} & \multicolumn{2}{c}{$\mathrm{pH}$} \\
$(\mathrm{mg} / \mathrm{mL})$ & $2 \mathrm{~h}$ & $96 \mathrm{~h}$ & $2 \mathrm{~h}$ & $96 \mathrm{~h}$ & $2 \mathrm{~h}$ & $96 \mathrm{~h}$ & $2 \mathrm{~h}$ & $96 \mathrm{~h}$ \\
\hline 0.1 & 27.2 & 32.3 & 13.3 & 15.0 & 0.42 & 0.41 & - & - \\
1 & 20.2 & 30.7 & 9.8 & 13.4 & 0.43 & 0.41 & 7.00 & 7.05 \\
5 & 6.2 & 14.5 & 3.6 & 5.9 & 0.47 & 0.45 & 6.33 & 6.50 \\
0 & 35.0 & \multicolumn{2}{|c|}{15.9} & \multicolumn{2}{|c|}{0.41} & \multicolumn{2}{|c}{7.00}
\end{tabular}

(8.4\% more functional groups) in relation to the GO oxidized for 2 hours, as well as the XRD have shown higher d-spacing for GO $96 \mathrm{~h}$, suggesting the increase of the effect of oxidation time. Such increase in oxidation degree probably is sufficient to balance the repulsive electrostatic interactions between GO 96h and Carbopol, and developed a tougher hydrogel when compared to the GO 2h. Thus, these results lead the suggestion that there is a competition between interactions that affects the rheological behavior of the Carbopol with different oxidation degree of GO. If from one side, the presence of negative charges from the carboxylic acids of the GO turns the hydrogel weaker, from other side the increase in oxygenated groups could enhance the interactions by hydrogen bonding [233]. At the end, the increase in GO oxidation time (96 h) leads a weaker hydrogel when compared to the Carbopol, however, tougher when compared with the GO oxidized with $2 \mathrm{~h}$. Similar results were recently reported by Soares et al. [51], where viscosity was observed to increase 
with GO oxidation degree, which was probably due to the higher dispersed morphology (since more oxidazed GO was easier to exfoliate), and the bridging effect between the GO and polymer chains.

The responses of the storage and loss moduli as a function of the stress amplitude are correspondent to a gel, with G' higher than G" in the LVR, as shown in Figure 4.19.

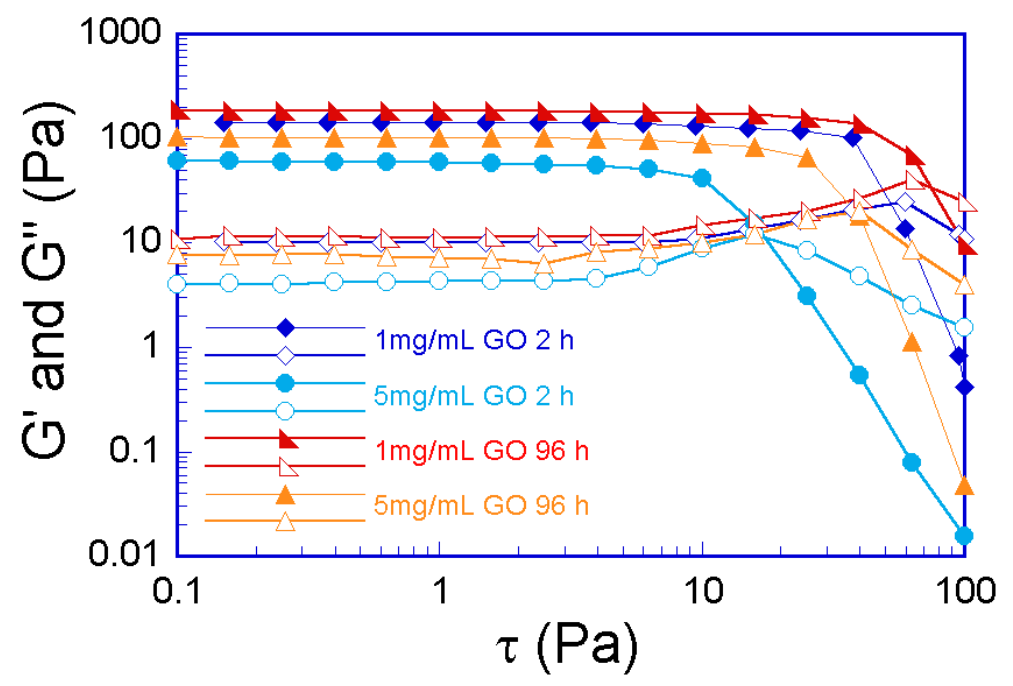

Figure 4.19: Stress sweep curves of the suspensions with 1 and $5 \mathrm{mg} / \mathrm{mL}$ of GO oxidized for $2 \mathrm{~h}$ and $96 \mathrm{~h}$ (filled symbols represent $\mathrm{G}^{\prime}$ and empty symbols indicate G").

Stress sweep tests also showed significant differences between GO 2 and $96 \mathrm{~h}$. The curves for the suspension made with GO oxidized for $2 \mathrm{~h}$ show lower level of elasticity, with G' smaller than GO oxidized for 96h. These results suggest that the competition between interactions discussed for the steady shear behavior, also influence the viscoelastic behavior of the Carbopol. The suspension with GO 96 h, which has more oxygenated groups, behaves as a tougher gel than the GO $2 \mathrm{~h}$, which the crossover point occurs at lower stress amplitudes. This is another indication, that GO oxidation degree influences the rheological behavior of the Carbopol, due to different interactions between GO and the hydrogel.

Another interesting result concerns the hysteresis of suspensions made with particles of different levels of oxidation. Figure 4.20 shows the results of hysteresis tests performed to evaluate time effects, for the base dispersion of $0.3 \%$ wt of Carbopol with the suspension of $5 \mathrm{mg} / \mathrm{mL}$ of GO oxidized for $2 \mathrm{~h}$, and with $5 \mathrm{mg} / \mathrm{mL}$ of GO oxidized for $96 \mathrm{~h}$.

Thixotropic behavior can be related to weak attraction forces, which allows the fluid microstructure to change reversibly when submitted to a moderate stress [236]. The thixotropic behavior in GO suspensions has been 


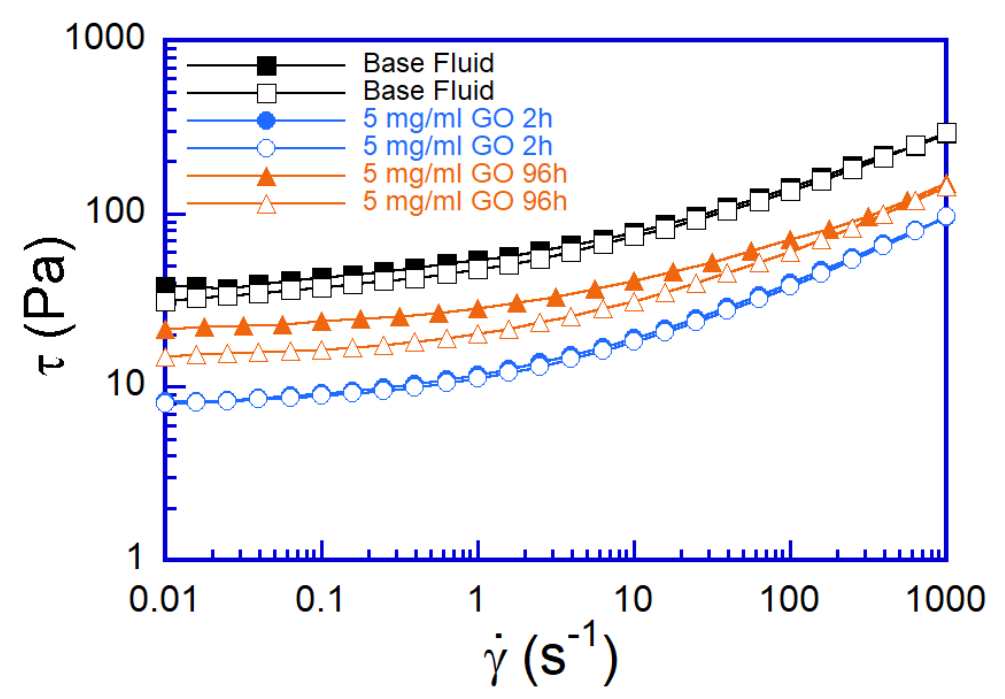

Figure 4.20: Hysteresis tests performed with $0.3 \%$ wt Carbopol concentration (base fluid) and with the suspensions of $5 \mathrm{mg} / \mathrm{mL}$ of GO oxidized for 2 and 96 hours. Filled symbols indicate shear rates ranging from 0.01 to $1000 \mathrm{~s}^{-1}$ while empty symbols indicate shear rate ranging from 1000 to $0.01 \mathrm{~s}^{-1}$.

associated with the fact that under shear, due to sheet morphology and electrostatic repulsion between sheets, the GO nanosheets take an orientation order which destroys the 3D network percolation [237]. Comparing the hysteresis curves of pure Carbopol dispersion, and the suspensions with 5 $\mathrm{mg} / \mathrm{mL}$ of GO $96 \mathrm{~h}$ and with $5 \mathrm{mg} / \mathrm{mL}$ of GO $2 \mathrm{~h}$, it is noted that only the suspension of GO $96 \mathrm{~h}$ presents a time dependent behavior. This behavior can be explained by the fact that the GO 96 h presents more functional groups, which leads to higher distances between nanosheets. This resulted structure induces a slower dynamic that characterizes the thixotropic behavior. For higher shear rates, the GO nanosheets are probably completely oriented, and the dynamics for structure changes is easier, so there is no difference between the upward and downward shear rate flow curves. For shear rates below 100 $\mathrm{s}^{-1}$, the downward curve shows that the GO $96 \mathrm{~h}$ nanosheets did not have the necessary time to reach the organizational level of the upward curve, leading to the hysteresis observed in the steady states flow curves loop. From the results obtained, it can be stated the degree of oxidation of GO has a significant impact on the final rheological properties of a yield stress fluid.

The stability of the suspensions was assessed by repeating rheological tests and evaluating zeta potential measurements. For technical reasons, these analyzes could not be performed for GO $96 \mathrm{~h}$ suspensions. The figure 4.21 shows the flow curves of the suspension with $5 \mathrm{mg} / \mathrm{mL}$ of GO oxidized for $2 \mathrm{~h}$ freshly prepared and after one month of aging.

The curves of Figure 4.21 show that the shear stress of the suspension 


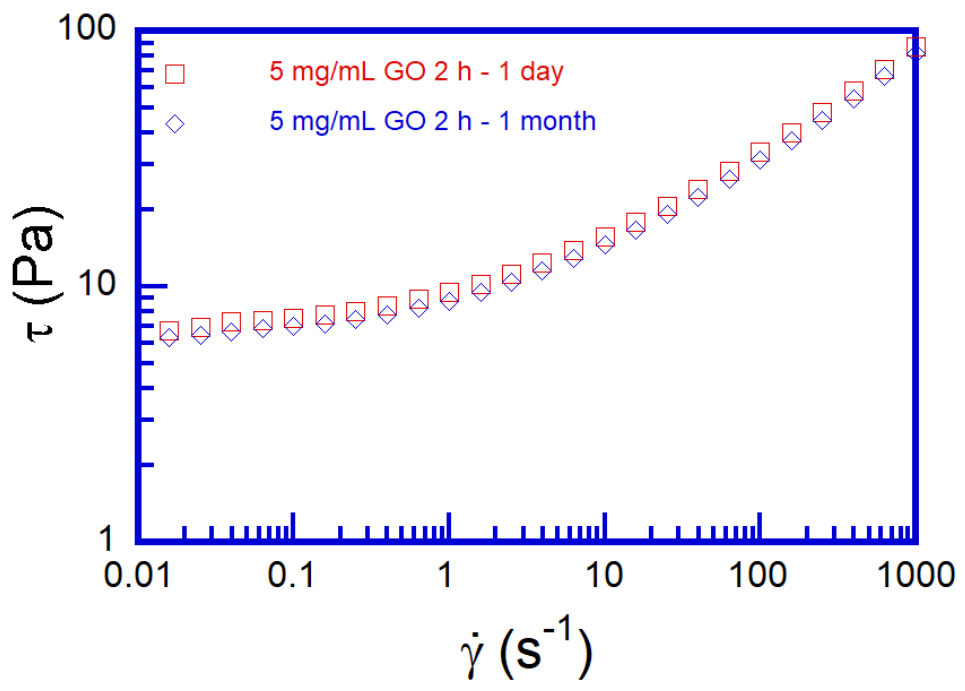

Figure 4.21: Flow curve stability of $5 \mathrm{mg} / \mathrm{mL}$ GO $2 \mathrm{~h}$ suspension after one month.

remains similar over time, indicating that the GO suspension is quite stable even with a higher concentration. This behavior is an indication that even with the GO causing the decrease of the yield stress, consistency index, viscosity and elaticity, the produced nanofluids are still formed by repulsive electrostatic interactions sufficient strong to avoid any attraction, precipitation or diffusion of particles [238].

The analysis of the zeta potential is one of the most used methods to evaluate the stability of suspensions. In a solution, particles with a net charge will have a layer of ions (of opposite charge) strongly bounded to their surface; it is the Stern layer. A second diffuse outer layer is comprised of less firmly associated ions. These two layers are collectively called the electrical double layer. As the particle moves (due to Brownian diffusion or applied force), a distinction is created between ions in the diffuse layer that move with the nanoparticle and ions that remain with the bulk dispersant. The electrostatic potential at this "slipping plane" boundary is called the zeta potential and is related to the surface charge of the particle [239]. The magnitude of the zeta potential gives an indication of the potential stability of the system and is decisive for the fluid microstructure. If all the particles in suspension have a large negative or positive zeta potential then they will tend to repel each other and there will be no tendency for the particles to come together. Particles with zeta potentials more positivehigher than $+30 \mathrm{mV}$ or more negativelower than $-30 \mathrm{mV}$ are strongly cationic and anionic, respectively, being usually considered stable [240]. On the Table 4.3 measurements of electrophoretic mobility and their respective zeta potential values are presented for three systems: aqueous dispersion of Carbopol, aqueous suspension of GO $2 \mathrm{~h}$ 
nanosheets and suspension of GO $2 \mathrm{~h}$ in Carbopol dispersion.

Table 4.3: Zeta potential values of Carbopol dispersion and GO $2 \mathrm{~h}$ suspensions

\begin{tabular}{c|cc} 
System & $\mu(\mu \mathrm{m} . \mathrm{cm} / \mathrm{Vs})$ & $\zeta(\mathrm{mV})$ \\
\hline Carbopol & -9.2 & -174.0 \\
GO 2 h & -3.1 & -40.0 \\
Carbopol + GO 2 h & -6.1 & -117.0
\end{tabular}

All systems have a zeta potential below $-30 \mathrm{mV}$, indicative of the colloidal stability of macromolecules and nanosheets. This result was already expected for Carbopol, however at $\mathrm{pH} 7$ the magnitude of the zeta potential of the GO depends strongly on the amount of carboxylic groups distributed in the nanosheets. Therefore, the GO $2 \mathrm{~h}$ nanosheets have enough carboxylic groups so that after exfoliation they do not tend to aggregate. The values of zeta potential are in agreement with the rheological stability observed for the suspension with $5 \mathrm{mg} / \mathrm{mL}$ of GO $2 \mathrm{~h}$, which even after remaining for one month at rest presented a flow curve similar to the one of the freshly prepared suspension. The high magnitude of Carbopol's zeta potential indicates an extremely negatively charged material and this is a determining factor for the electrostatic repulsion that forms the "jammed structure" of the Carbopol hydrogel. As shown in the Table 4.3, the introduction of GO $2 \mathrm{~h}$ in the Carbopol dispersion led to a decrease in the magnitude of the zeta potential, which suggests a decrease in the electrostatic repulsion between the solid particles of the system. Being proportional to the electrophoretic mobility, the value of zeta potential decreases because assince in the system there are the presence ofpresent two types of particles, one very charged and the other not so much, and the resulting speed will be intermediate to the speed value registered for each particle individually. In an analogy, it is as if the system were composed of a single type of particle with a smaller zeta potential. With less zeta potential, the electrostatic repulsion between the solid particles is not as strong as before and the microstructure of the suspension is more fragile, causing the drop in the yield stress, viscosity and elasticity of the fluid. Therefore, the results of zeta potential complement the discussions on the aspects that influence the rheological behavior of GO suspensions in the Carbopol dispersion.

\subsection{2}

\section{Amine-functionalized graphene oxide suspensions characteristics}

Initially, it is interesting to contextualize the reason for the modification of the method used to prepare the AFGO suspensions. An attempt was made to 
exfoliate AFGO directly in the Carbopol aqueous dispersion through sonication for two hours, but an effective exfoliation did not occur, as illustrated in Figure 4.22 .

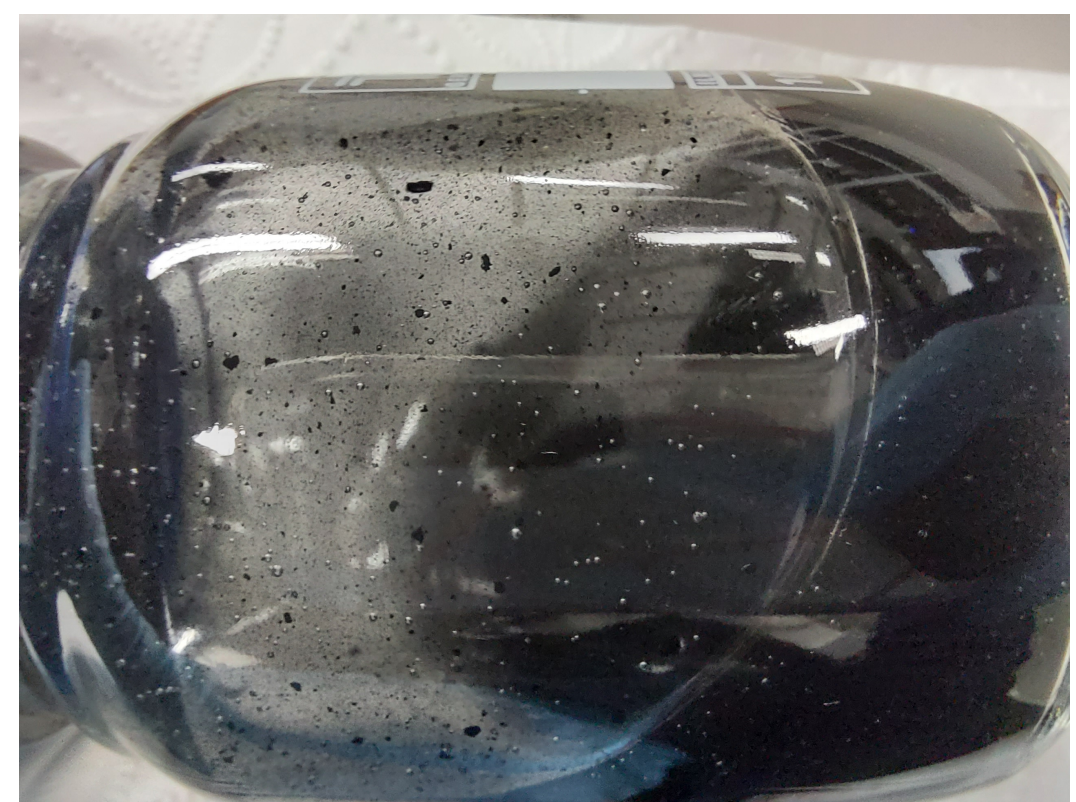

Figure 4.22: The AFGO was not effectively exfoliated when directly sonicated in the Carbopol aqueous dispersion.

Containing a lower number of carboxylic groups (altered by the formation of covalent bonds with the TETA), the layers of the AFGO have greater resistance to separation in the neutral medium. As an alternative, it was necessary to exfoliate the AFGO in an alkaline medium with a $\mathrm{pH}$ above 9 , in order to stimulate the deprotonation of the hydroxyls present on the surfaces of the nanosheets. The exfoliation of GO and its derivatives has been proven to be potentiated when the process is carried out in basic media (since the negative charges produced by the deprotonation of hydroxyls and carboxylic acids repel, facilitating the separation of the layers) [134]. In addition, due to the results obtained for preparation method \#3 evaluated for the GO suspension, it was decided to promote the deprotonation of Carbopol carboxylic acids in advance and then to introduce the AFGO nanosheets to the system. For these reasons the method described in subsection 3.2.2 was used. The Carbopol aqueous dispersion was previously produced using this new method and the obtained rheological results were similar to the behavior of the dispersion prepared using the method \#1.

After analyzing the effects of $\mathrm{GO}$ on the rheological properties of its suspensions in aqueous dispersion of Carbopol, we started to evaluate how the rheology of these suspensions could affect with the introduction of amino groups in the GO nanosheets. The flow curves of AFGO $96 \mathrm{~h}$ suspensions 
with concentrations of $0.1,1$ and $5 \mathrm{mg} / \mathrm{mL}$ are compared with the one of the Carbopol dispersion in Figure 4.23.

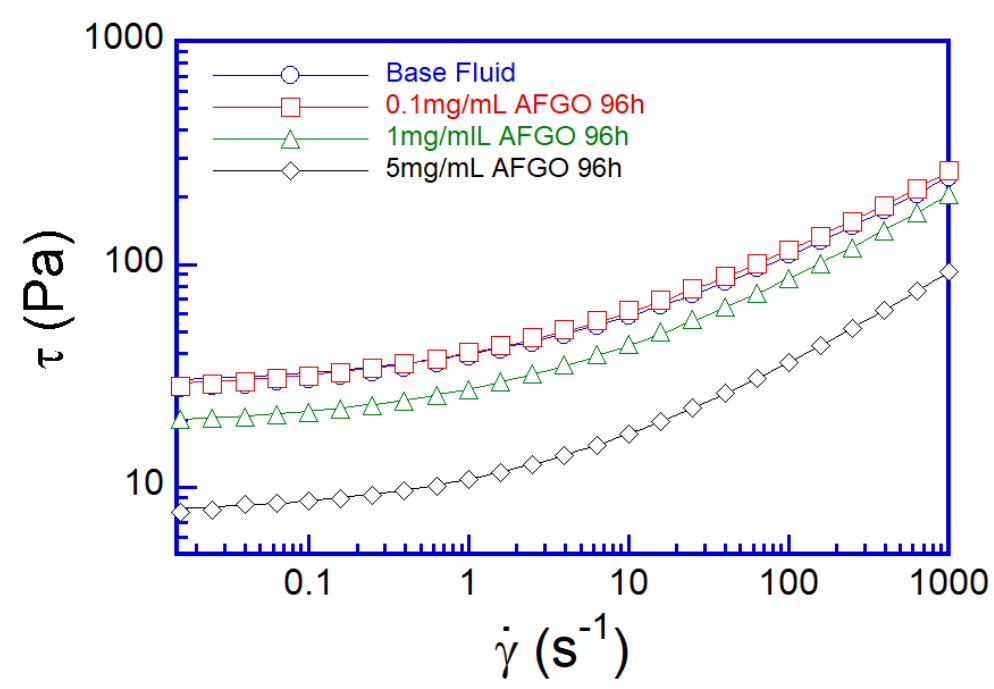

Figure 4.23: Flow curves of the suspensions with 0 (Base fluid), 0.1, 1, and $5 \mathrm{mg} / \mathrm{mL}$ of AFGO $96 \mathrm{~h}$, obtained experimentally (symbols) and Herschel-Bulkley curve fitting (continuous lines).

The flow curves show that the AFGO suspensions are also fitted for the Herschel-Bulkley model. Even though the nanomaterial is suspended in a neutral medium and with the presence of amino groups in its layers - which fostered the expectation that the nanosheets could act as bridges connecting the macromolecules - the increase in the concentration of AFGO causes the drop in the yield stress and viscosity of the suspensions. For the suspension of $0.1 \mathrm{mg} / \mathrm{mL}$ of AFGO $96 \mathrm{~h}$, there was no change in rheology in relation to the base fluid, while for the suspension with $5 \mathrm{mg} / \mathrm{mL}$ there was a significant downward displacement of the flow curve, with the $\tau_{y}$ decreasing by an order of magnitude in relation to Carbopol's aqueous dispersion. In other words, the AFGO suspension in the Carbopol dispersion weakened the fluid's microstructure. Oscillatory tests also contribute to this understanding and are shown in Figure 4.24.

The sweep stress curves show the existence of an LVR with a storage modulus considerably larger than the viscous modulus, i. e., for low oscillatory stresses, the suspensions have elasticity. The increase in the concentration of AFGO leads to decrease in the $G^{\prime}$ values with $G$ " modulus decreasing as well but slighter, and the crossover point between $G^{\prime}$ and $G^{\prime \prime}$ starts to occur for lower oscillatory stresses. In general, as occurred for the suspensions of GO, the introduction of AFGO in the Carbopol hydrogel promotes the formation of a fluid with more fragile microstructure, with less rigidity and lower viscosity. 


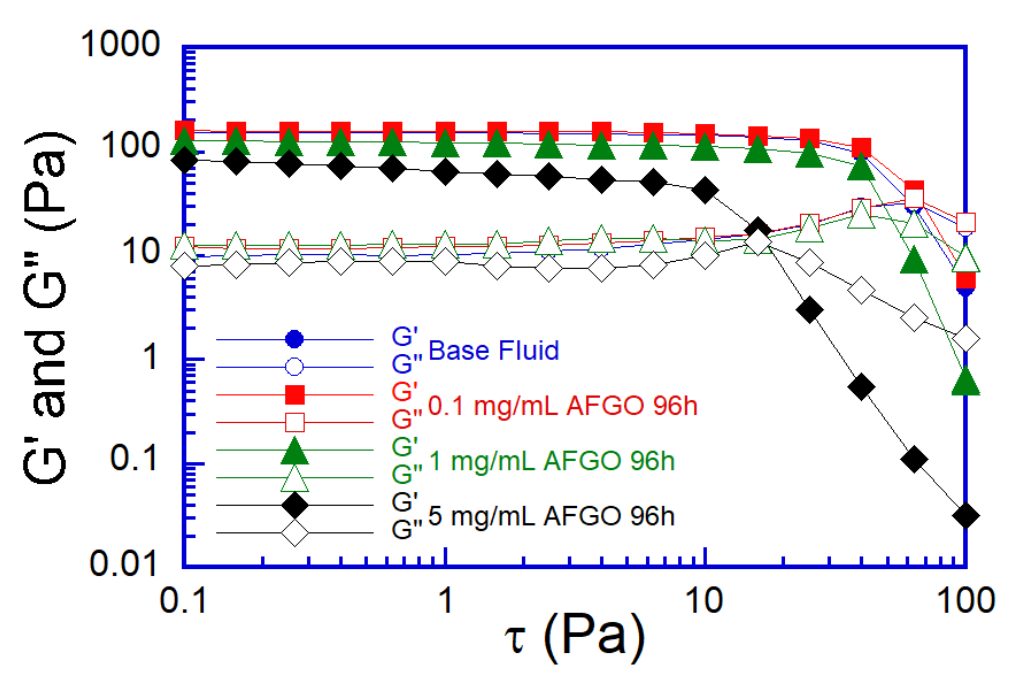

Figure 4.24: Stress sweep curves of the suspensions with 0 (Base fluid), 0.1, 1, and $5 \mathrm{mg} / \mathrm{mL}$ of AFGO $96 \mathrm{~h}$. Filled symbols correspond to G' and empty symbols represent G".

The effect of the nanosheets amination level on the rheology of the suspensions was also analyzed and a comparison between the flow curves of the suspensions with 1 and $5 \mathrm{mg} / \mathrm{mL}$ of AFGO $2 \mathrm{~h}$ and $96 \mathrm{~h}$ is shown in the Figure 4.25. Table 4.4 presents a comparison of the Herschel-Bulkley parameters for the AFGO $2 \mathrm{~h}$ and $96 \mathrm{~h}$ suspensions as well as their $\mathrm{pH}$ values, which remained within the ideal $\mathrm{pH}$ range for achievement of high viscosity plateau [204].

The suspensions of both nanosheets, AFGO 2 and 96 h, in the Carbopol aqueous dispersion promote a drop of the yield stress and viscosity - which decrease even more with the increase in the nanosheets concentration. As observed on the effects of the oxidation level on the rheological properties of the GO suspensions, the amination degree of the AFGO nanosheets also has an influence on the rheology of their suspensions. While the increasing in oxygenated groups attenuates the drop of yield stress and viscosity of the GO suspensions, the flow curves of Figure 4.25 indicate that the increase in the amination degree of AFGO nanosheets promotes a more pronounced drop in such suspension's parameters. However, this trend is more evident for suspensions with a higher concentration of AFGO.

The results show that for lower concentrations ( 0.1 and $1 \mathrm{mg} / \mathrm{mL}$ ) the rheological behavior of the AFGO $2 \mathrm{~h}$ suspensions and $96 \mathrm{~h}$ are similar, with the slightly higher $k$ values of the AFGO 2 h suspensions indicating that these fluids could be a little more structured than those of the same concentration prepared with AFGO $96 \mathrm{~h}$. On the other hand, for suspensions with $5 \mathrm{mg} / \mathrm{mL}$ the effect of the amination degree becomes more evident, with the AFGO $96 \mathrm{~h}$ suspension showing lower values of $\tau_{y}$ and $k$ compared to the one with AFGO 


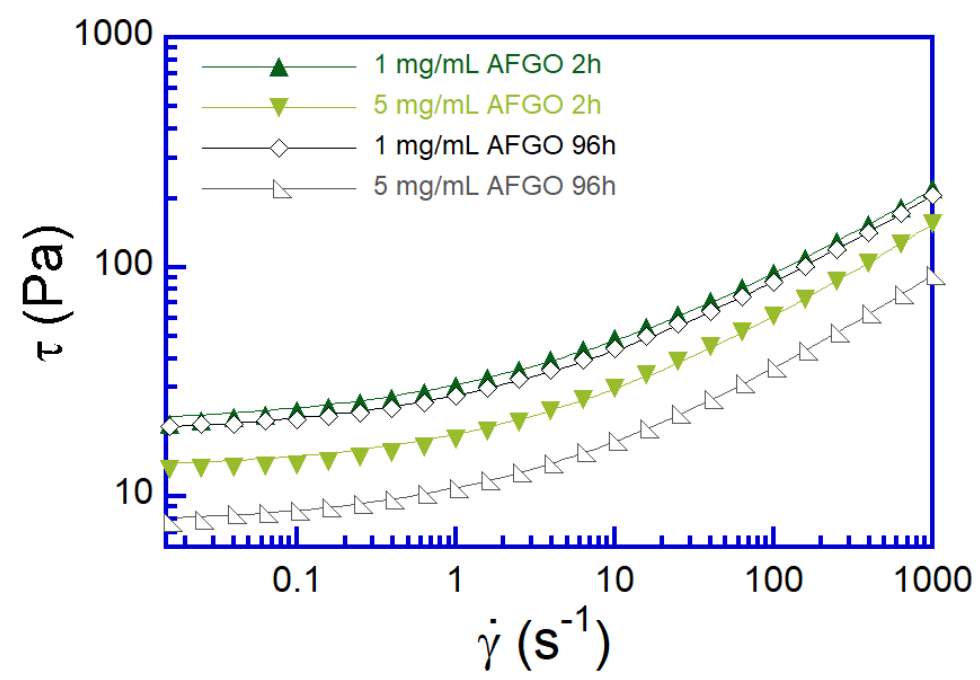

Figure 4.25: Flow curves of the suspensions with 1 and $5 \mathrm{mg} / \mathrm{mL}$ of AFGO $2 \mathrm{~h}$ and $96 \mathrm{~h}$ obtained experimentally (symbols) and Herschel-Bulkley curve fitting (continuous lines).

Table 4.4: Herschel-Bulkley fitting parameters of the suspensions of AFGO 2 and 96 hours. The base fluid was made with $0.3 \%$ wt of Carbopol concentration. Standard errors of the curve fittings were below $3.07 \%$.

\begin{tabular}{c|cc|cc|cc|cc} 
Concentration & \multicolumn{2}{|c|}{$\tau_{y}(\mathrm{~Pa})$} & \multicolumn{2}{|c|}{$k\left(\mathrm{Pas}^{n}\right)$} & \multicolumn{2}{|c|}{$n$} & \multicolumn{2}{c}{$\mathrm{pH}$} \\
$(\mathrm{mg} / \mathrm{mL})$ & $2 \mathrm{~h}$ & $96 \mathrm{~h}$ & $2 \mathrm{~h}$ & $96 \mathrm{~h}$ & $2 \mathrm{~h}$ & $96 \mathrm{~h}$ & $2 \mathrm{~h}$ & $96 \mathrm{~h}$ \\
\hline 0.1 & 26.0 & 26.4 & 13.6 & 12.5 & 0.41 & 0.42 & 7.77 & 7.44 \\
1 & 20.0 & 18.7 & 10.3 & 8.9 & 0.43 & 0.44 & 7.44 & 7.35 \\
5 & 12.0 & 7.5 & 6.1 & 3.4 & 0.45 & 0.47 & 7.43 & 6.54 \\
0 & 32.1 & \multicolumn{2}{|c|}{15.9} & \multicolumn{2}{|c|}{0.41} & \multicolumn{2}{|c}{7.00}
\end{tabular}

$2 \mathrm{~h}$. The TGA and DTG tests showed that the AFGO $96 \mathrm{~h}$ nanoseets have $2.9 \%$ wt more amine groups than the AFGO $2 \mathrm{~h}$. Considering the fact that only a part of the aminated elements will protonate in a neutral medium, this variation may not be so robust as to cause a more latent difference between the rheological properties of the AFGO $2 \mathrm{~h}$ and $96 \mathrm{~h}$ suspensions. In spite of this, the results obtained suggest that the presence of the amine groups on the nanosheets contributes to the weakening of the suspension's microstructure. The results of the oscillatory tests reinforce this behavior and are shown in Figure 4.26.

The stress sweep curves also show that the influence of the amination degree is noticeable for suspensions with the concentration of $5 \mathrm{mg} / \mathrm{mL}$. All samples showed elastic behavior at low oscillatory stresses, with G' being greater than G" in the LVR. The storage module and crossover point between $\mathrm{G}^{\prime}$ and $\mathrm{G}^{\prime \prime}$ for the $1 \mathrm{mg} / \mathrm{mL}$ AFGO $2 \mathrm{~h}$ and $96 \mathrm{~h}$ suspensions are very 


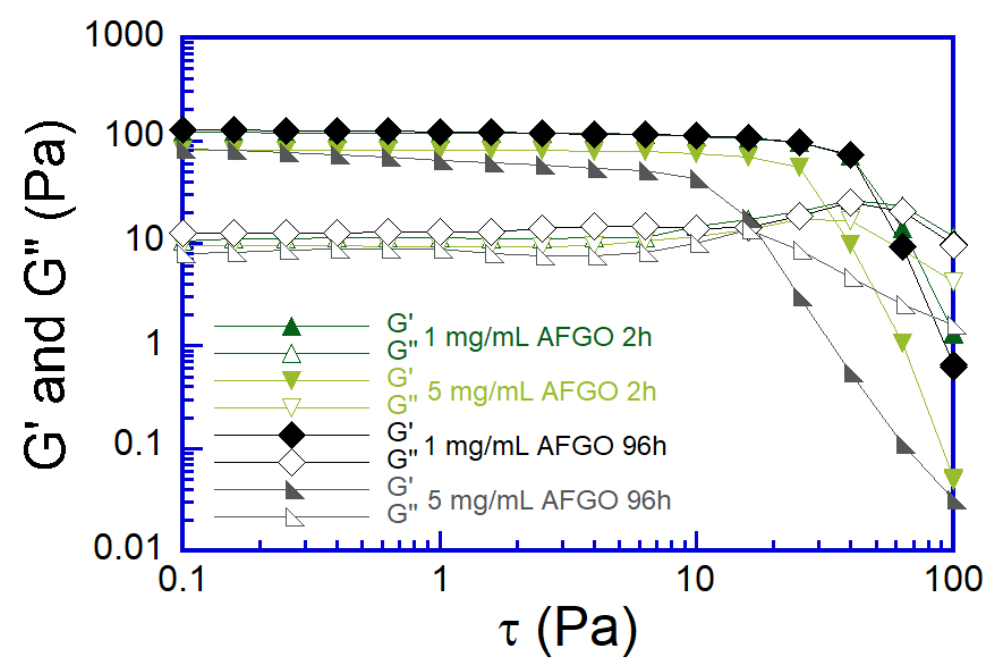

Figure 4.26: Stress sweep curves of the suspensions with 1 and $5 \mathrm{mg} / \mathrm{mL}$ of AFGO $2 \mathrm{~h}$ and $96 \mathrm{~h}$ (filled symbols represent G' and empty symbols indicate G").

similar. Comparing the curves of the fluids with $5 \mathrm{mg} / \mathrm{mL}$, it is clear that the suspension of AFGO $96 \mathrm{~h}$ promotes a greater drop in G', showing a difference around a order smaller in relation to the gel containing AFGO 2 h, besides the crossover point between $G^{\prime}$ and $G^{\prime \prime}$ starts to occur for lower stresses. Therefore, the amination level of the AFGO nanosheets really has an effect on the rheology of its suspensions in the Carbopol dispersion, and it is observed that the greater the amination degree, the more pronounced the drop of the yield stress, viscosity and elasticity. For some reason, the AFGO amino groups are facilitating the movement between the solid particles of the system, culminating in a fluid with less viscosity and elasticity. A deeper discussion about the reason that promotes this behavior cannot be elaborated without a more precise knowledge about the surface charges present on the AFGO nanosheets. This information is obtained by analyzing the zeta potential, which will be accomplished further on.

Hysteresis analyzes of the AFGO suspensions were also conducted, but none of the samples showed a significant difference between the upward and downward flow curves. The figure 4.27 shows the hysteresis results for suspensions with $5 \mathrm{mg} / \mathrm{mL}$ of AFGO.

The presence of hysteresis between the upward and downward flow curves is associated with the presence of thixotropy. Thus, AFGO suspensions do not have a thixotropic character, and their rheological parameters do not vary over time. This is an indication that even for suspensions with a higher concentration, the AFGO's surface with a higher loads present in AFGO with a greater number of functional groups are not sufficient to affect the 


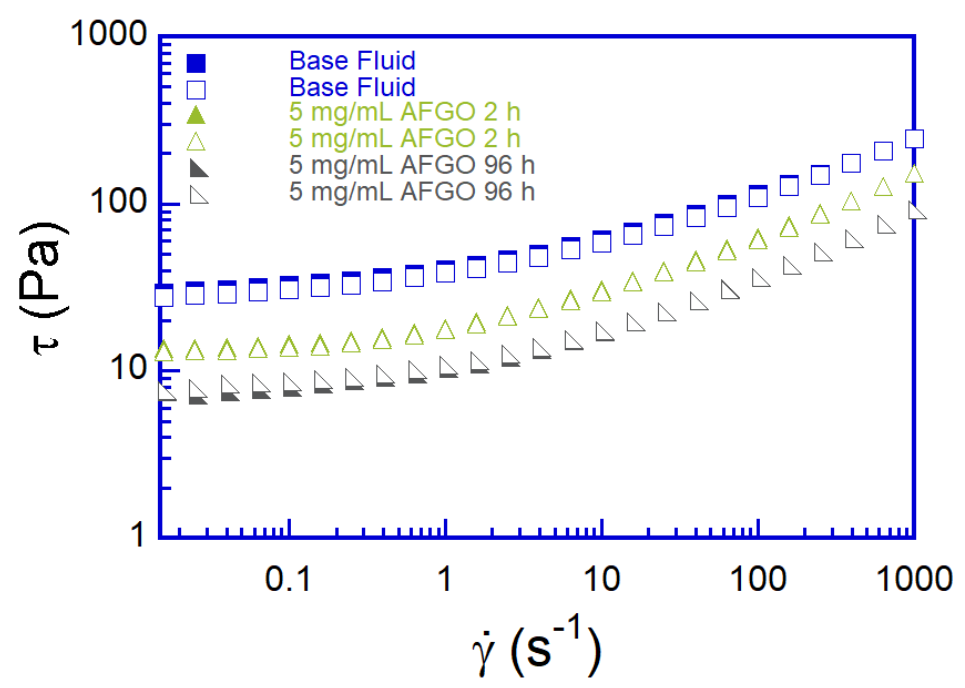

Figure 4.27: Hysteresis tests performed with $0.3 \%$ wt Carbopol concentration (base fluid) and with the suspensions of $5 \mathrm{mg} / \mathrm{mL}$ of AFGO $2 \mathrm{~h}$ and $96 \mathrm{~h}$. Filled symbols indicate shear rates ranging from 0.01 to $1000 \mathrm{~s}^{-1}$ while empty symbols indicate shear rate ranging from 1000 to $0.01 \mathrm{~s}^{-1}$.

orientation dynamics of the nanosheets nanowills under shear, which even at low rates occurs quickly. In order to investigate the stability of the suspensions, flow curves measurements were repeated after one month from the nanofluids preparation. Figure 4.28 shows the flow curves of the suspensions with 1 and 5 $\mathrm{mg} / \mathrm{mL}$ of AFGO $2 \mathrm{~h}$ and $96 \mathrm{~h}$ freshly prepared and after one month of aging.

The flow curves of the aged suspensions are similar to those of the freshly prepared ones, even after with the increase of the nanosheets concentration and the amination degree of AFGO. This result indicates that the suspensions are quite stable and that no type of adverse reaction occurs, even though the AFGO nanosheets contain points of opposite charge to those of the Carbopol macromolecules. The Carbopol dispersion alone is highly stable, with the macromolecules showing a high magnitude of zeta potential, as already presented. The introduction of AFGO in the system does not cause instabilities, which may be an indication of the nanosheets colloidal stability.

The results show that the suspension of AFGO on the Carbopol dispersion leads to the weakening of the fluid microstructure with decreasing in yield stress, viscosity and elasticity. The results of zeta potential are vital for understanding the reason for this behavior. The Table 4.5 presents the mobility and zeta potential values of 5 systems: aqueous dispersion of Carbopol, aqueous suspension of AFGO $2 \mathrm{~h}$, aqueous suspension of AFGO $96 \mathrm{~h}$, suspension of AFGO 2 h on Carbopol dispersion and suspension of AFGO 96 h on Carbopol dispersion.

The first consideration to be made is that all systems have a zeta 


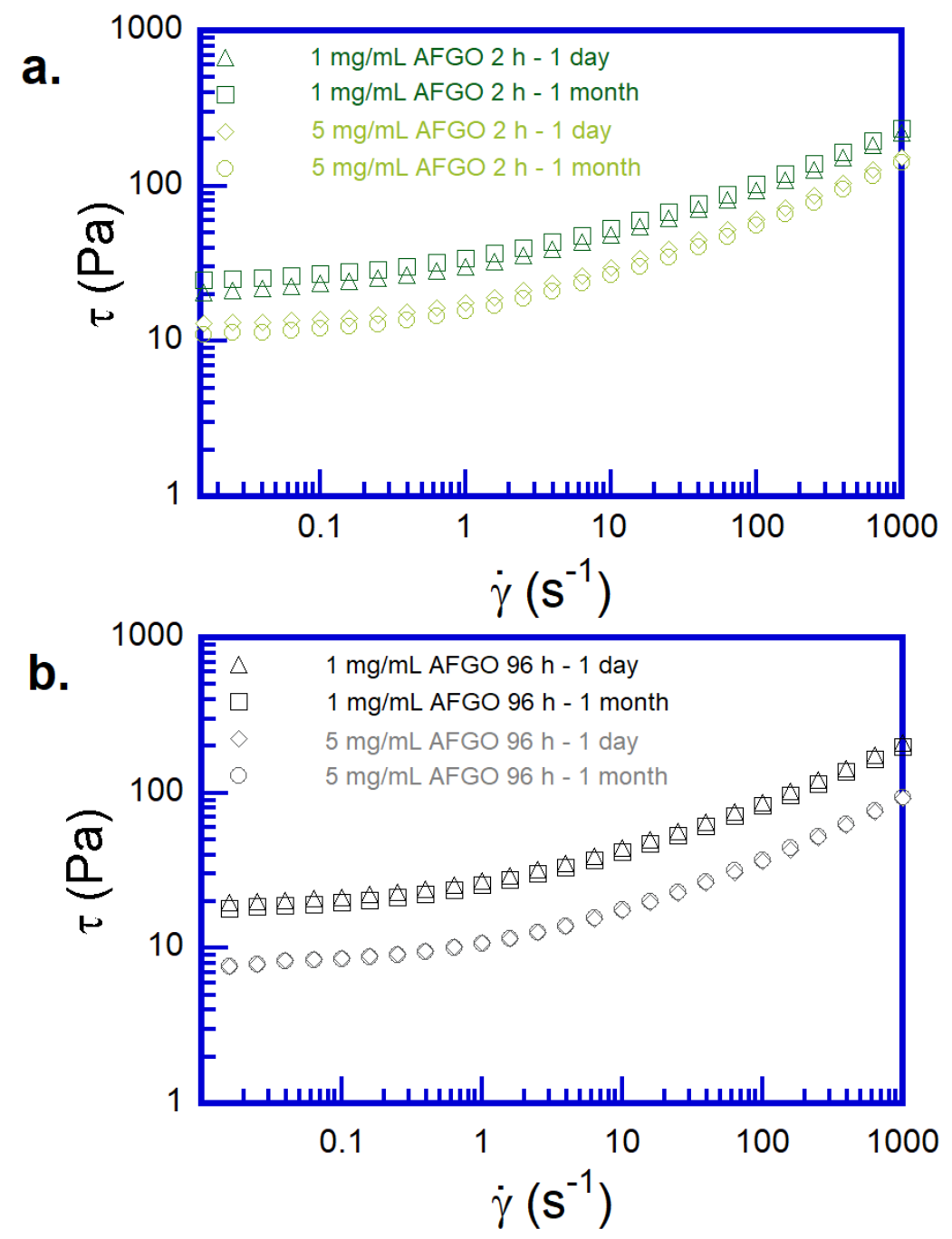

Figure 4.28: Flow curves stability of AFGO suspensions with 1 and $5 \mathrm{mg} / \mathrm{mL}$ after one month of ageing. a. AFGO $2 \mathrm{~h}$ suspensions and b. AFGO $96 \mathrm{~h}$ suspensions.

Table 4.5: Zeta potential values of Carbopol dispersion and AFGO 2 h and 96 h suspensions

\begin{tabular}{c|cc} 
System & $\mu(\mu \mathrm{m} . \mathrm{cm} / \mathrm{Vs})$ & $\zeta(\mathrm{mV})$ \\
\hline Carbopol & -9.2 & -174.0 \\
AFGO 2 h & -3.8 & -48.4 \\
AFGO 96 h & -3.1 & -39.5 \\
Carbopol + AFGO 2 h & -6.3 & -116.2 \\
Carbopol + AFGO 96 h & -5.6 & -108.0
\end{tabular}

potential modulus greater than $30 \mathrm{mV}$, which indicates that the solids involved in the formation of the fluid are stable and do not tend to promote clusters. However, perhaps the most important information in the Table 4.5 be the fact that all particles have negative $\zeta$. In other words, even with the 
presence of the amine groups, the synthesized AFGO nanosheets became negatively charged when suspended on the Carbopol dispersion. The XPS results indicated the formation of covalent bonds between GO and TETA through the formation of amides, but also indicated the permanence of carboxylated groups. As a consequence of the presence of both functional groups on the nanosheets, when the material is suspended in a neutral medium, between protonations and deprotonations, the resulting charge net is negative. As observed for GO suspensions, the introduction of AFGO nanosheets in the Carbopol dispersion decreases the zeta potential of the system, from $-174.0 \mathrm{mV}$ to $-116.4 \mathrm{mV}$, for the AFGO $2 \mathrm{~h}$ suspension, and $-108 \mathrm{mV}$ for the AFGO $96 \mathrm{~h}$ one. In other words, the presence of the nanosheets reduces the level of electrostatic repulsion between the solid particles that make up the system, a fundamental characteristic of the Carbopol hydrogel formation. The result of the lowest repulsion force between the particles is the formation of a fluid with weaker microstructure and lower yield stress, viscosity and elasticity. The increase in the concentration of the nanosheets reduces the suspension structuring even more, because what was previously a system of strong repulsion between extremely charged macromolecules becomes a system of interactions between macromolecules-nanosheets (of lower $\zeta$ ) and nanosheets-nanosheets. An illustration is shown in Figure 4.29.

a.

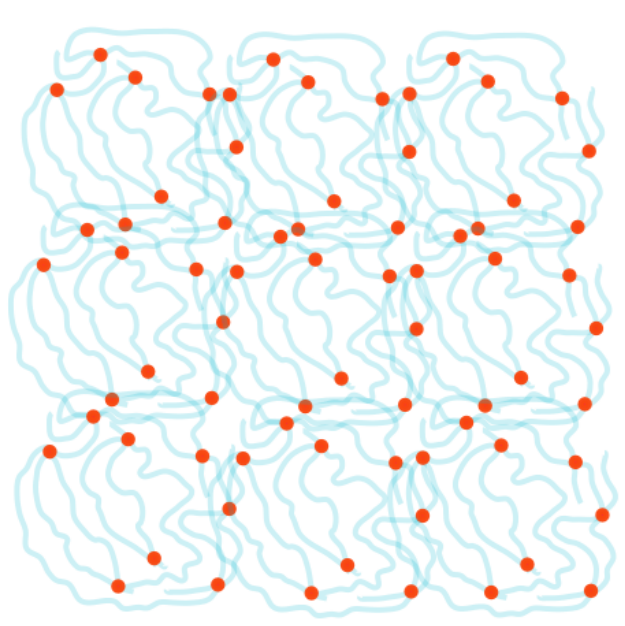

b.

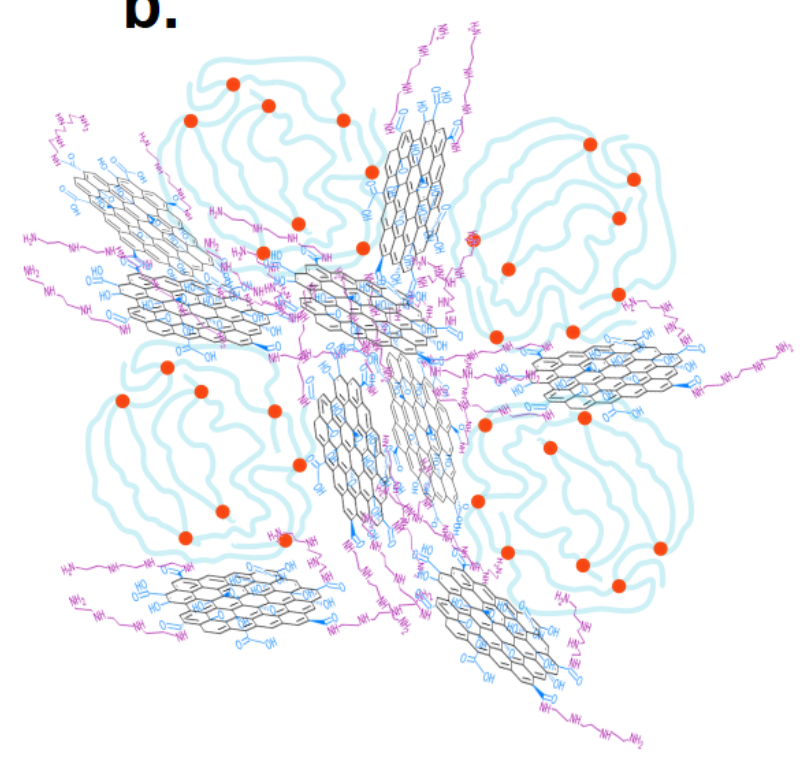

Figure 4.29: a.The structure of Carbopol aqueous dispersion and b. The structure of AFGO Suspensions on Carbopol.

The results of TGA and DTG help to complement the analysis. The thermographic curves indicated that the AFGO $96 \mathrm{~h}$ has a higher percentage 
by mass of amine groups. The values of $\zeta$ indicate that the AFGO $96 \mathrm{~h}(-39.5$ $\mathrm{mV})$ has a less negative character than the AFGO $2 \mathrm{~h}(-48.4 \mathrm{mV})$. In other words, this information indicates that the increase in the amount of amine groups tends to introduce positive charges on the surface of the nanosheets, in this case reducing the magnitude of the negative net charge. In response, the electrostatic repulsion promoted by the AFGO $96 \mathrm{~h}$ nanosheets is weaker than the repulsion generated by the AFGO $2 \mathrm{~h}$, resulting in the suspension with a lower magnitude of zeta potential $(-108 \mathrm{mV})$. This is the probable reason why the suspension with $5 \mathrm{mg} / \mathrm{mL}$ of AFGO $96 \mathrm{~h}$ has lower yield stress, viscosity and elasticity than the suspension made of AFGO $2 \mathrm{~h}$. 


\section{5}

\section{Final Remarks}

The rheological behavior of graphene oxide and amine-functionalized graphene oxide suspensions in the aqueous dispersion of Carbopol® was investigated. The modified Hummers method adopted culminated in the effective oxidation of the graphite particles while the graphene oxide functionalization with triethylenetetramine through microwave assisted reaction promoted covalent attachment of the amine elements on the GO nanosheet. The use of a longer oxidation process time resulted in a GrO with greater interplanar distance and higher number of oxidized groups. These defects incorporated on the sheet surface, which is a characteristic that facilitated the exfoliation, and promotes the achievement of a GO with fewer layers. The GO prepared from the more oxidized GrO produced an AFGO with higher amination degree. All nanosheets synthesized in this work are highly stable when suspended at neutral media.

As for the pure Carbopol® dispersions, the suspensions of GO and AFGO were also modeled by Herschel-Bulkley equation, meaning that the material continues to behave as a yield stress fluid. However, the addition of these nanosheets in the Carbopol® dispersion, have led to the development of a weaker gel, with the decrease in shear viscosity and yield stress. This behavior was suggested as a result from the weaker repulsive electrostatic interactions between the nanosheets and Carbopol, which have caused the perturbation of the hydrogel network. Moreover, the increase in concentration could result in micro-phase separation, turning in a weaker gel. The viscoelastic properties were also investigated, and it was observed that elasticity also decreases as an influence from GO and AFGO incorporation, with the crossover of G' and G" occurring at lower frequencies.

The influence of GO oxidation degree in Carbopol suspensions was studied, by analyzing two different oxidations times, $2 \mathrm{~h}$ and $96 \mathrm{~h}$. The lower oxidation time leads to higher decrease in shear viscosity, yield stress and elasticity, which suggests a competition between interactions that affects the rheological behavior of the Carbopol with different oxidation degree of GO. The increase in oxygenated groups seems to lead the hydrogel with GO $96 \mathrm{~h}$ to be a tougher gel, when compared to the suspension with the GO oxidized 
for $2 \mathrm{~h}$.

The effect of AFGO amination degree on the rheological properties of the suspensions was investigated as well. Being a little more aminated, AFGO $96 \mathrm{~h}$ promoted a weaker gel when at the highest concentration, with lower rheological parameters. Due to the amine groups, the net charge of AFGO nanosheets become less negative, which reduces the electrostatic repulsion between the solid particles in the suspension, weakening the jammed structure of the hydrogel. In fact, the rheological behavior of the AFGO suspensions reiterates the discussions elaborated for the GO suspensions.

Finally, hysteresis curves were performed, and a time-dependent response was observed only for the suspension with $5 \mathrm{mg} / \mathrm{mL}$ of GO $96 \mathrm{~h}$, mostly due to the presence of more oxygenated groups and higher interactions between the hydrogel and GO. The increase in oxidation time have led to increase the interplanar distance between the GO sheets, and the obtaining of less stacked layers, increasing the dispersion. Thus, a better interaction with the hydrogel, would have required a different time to the reorganization of the developed microstructure during the flow.

The results obtained have shown the influence of the negative charges on the rheological behavior of the GO and AFGO suspensions in Carbopol. However, more formulations and more studies should be performed with the aim to understand the fundamental chemical and physical interactions between the functionalized graphene and the fluid.

\section{Future Works}

There being still many gaps about the effects of the graphene derivatives characteristics on the microstructure and rheology of their suspensions on complex fluids, interesting approaches for future work are:

1. To investigate the rheological effects of a functionalized graphene with positive superficial net charge on Carbopol dispersions.

2. To evaluate the structural and rheological effects of functionalized graphenes suspensions on other model complex fluids, such as clay suspensions, linear polymer solutions, and emulsions.

3. To analyze the rheological impact of other graphene derivatives characteristics, such as nanosheets aspect ratio and shape.

4. To use other characterization techniques to analyze the suspensions microstructure, such as scanning electron cryomicroscopy. 


\section{6 \\ Bibliography}

1 RODUNER, E. Size matters: why nanomaterials are different. Chemical

Society Reviews, Royal Society of Chemistry, v. 35, n. 7, p. 583-592, 2006.

2 RAFIQUE, $M$. et al. History and fundamentals of nanoscience and nanotechnology. In: Nanotechnology and Photocatalysis for Environmental Applications. [S.I.]: Elsevier, 2020. p. 1-25.

3 THOMPSON, D. Michael faraday's recognition of ruby gold: the birth of modern nanotechnology. Gold Bulletin, Springer, v. 40, n. 4, p. 267-269, 2007.

4 KHAN, I.; SAEED, K.; KHAN, I. Nanoparticles: Properties, applications and toxicities. Arabian journal of chemistry, Elsevier, v. 12, n. 7, p. 908-931, 2019.

5 DREADEN, E. C. et al. The golden age: gold nanoparticles for biomedicine. Chemical Society Reviews, Royal Society of Chemistry, v. 41, n. 7, p. 2740-2779, 2012.

6 CLYVEDON, P. The royal society \& the royal academy of engineering. In: Nanoscience and Nanotechnologies, workshop, Science Policy Section. [S.I.: s.n.]. p. 6-9.

7 BHUSHAN, B. Introduction to nanotechnology. In: Springer handbook of nanotechnology. [S.I.]: Springer, 2017. p. 1-19.

8 ZARBIN, A. J.; OLIVEIRA, M. M. Carbon nanostructures (nanotubes and graphene): Quo vadis? Química Nova, SciELO Brasil, v. 36, n. 10, p. 1533-1539, 2013.

9 NOVOSELOV, K. et al. Room-temperature electric field effect and carrier-type inversion in graphene films. arXiv preprint cond-mat/0410631, 2004.

$10 \mathrm{ZHU}, \mathrm{Y}$. et al. Graphene and graphene oxide: synthesis, properties, and applications. Advanced materials, Wiley Online Library, v. 22, n. 35, p. 3906-3924, 2010.

11 NAIR, R. R. et al. Fine structure constant defines visual transparency of graphene. Science, American Association for the Advancement of Science, v. 320, n. 5881, p. 1308-1308, 2008.

$12 \mathrm{BUNCH}$, J. S. et al. Impermeable atomic membranes from graphene sheets. Nano letters, ACS Publications, v. 8, n. 8, p. 2458-2462, 2008.

13 BALANDIN, A. A. et al. Superior thermal conductivity of single-layer graphene. Nano letters, ACS Publications, v. 8, n. 3, p. 902-907, 2008. 
14 MOROZOV, S. et al. Giant intrinsic carrier mobilities in graphene and its bilayer. Physical review letters, APS, v. 100, n. 1, p. 016602, 2008.

15 BOLOTIN, K. I. et al. Ultrahigh electron mobility in suspended graphene. Solid state communications, Elsevier, v. 146, n. 9-10, p. 351-355, 2008.

16 LEE, C. et al. Measurement of the elastic properties and intrinsic strength of monolayer graphene. science, American Association for the Advancement of Science, v. 321, n. 5887, p. 385-388, 2008.

17 SHINOHARA, H.; TIWARI, A. Graphene: an introduction to the fundamentals and industrial applications. [S.I.]: John Wiley \& Sons, 2015.

18 RAY, S. Applications of graphene and graphene-oxide based nanomaterials. [S.I.]: William Andrew, 2015.

19 HUANG, X. et al. Graphene-based materials: synthesis, characterization, properties, and applications. small, Wiley Online Library, v. 7, n. 14, p. 1876-1902, 2011.

20 SEGUNDO, J. V.; VILAR, E. O. Grafeno: Uma revisão sobre propriedades, mecanismos de produção e potenciais aplicações em sistemas energéticos. Revista eletrônica de materiais e processos, v. 11, n. 2, 2016.

21 SINGH, V. et al. Graphene based materials: past, present and future. Progress in materials science, Elsevier, v. 56, n. 8, p. 1178-1271, 2011.

22 GUPTA, A.; SAKTHIVEL, T.; SEAL, S. Recent development in 2d materials beyond graphene. Progress in Materials Science, Elsevier, v. 73, p. 44-126, 2015.

23 TALEBIAN, S. et al. Nanotechnology-based disinfectants and sensors for sars-cov-2. Nature nanotechnology, Nature Publishing Group, v. 15, n. 8, p. 618-621, 2020.

24 CHAKRABORTY, S. et al. High yield synthesis of amine functionalized graphene oxide and its surface properties. Rsc Advances, Royal Society of Chemistry, v. 6, n. 72, p. 67916-67924, 2016.

25 BOUKHVALOV, D.; KATSNELSON, M. Chemical functionalization of graphene. Journal of Physics: Condensed Matter, IOP Publishing, v. 21, n. 34, p. $344205,2009$.

26 LAYEK, R. K.; NANDI, A. K. A review on synthesis and properties of polymer functionalized graphene. Polymer, Elsevier, v. 54, n. 19, p. 5087-5103, 2013.

27 SONG, M.; CAI, D. Graphene functionalization: a review. Polymer-Graphene Nanocomposites, Royal Society of Chemistry, v. 26, n. 26, p. 1-51, 2012.

28 YANG, G.-h. et al. Functionalization of graphene and applications of the derivatives. Journal of Inorganic and Organometallic Polymers and Materials, Springer, v. 27, n. 5, p. 1129-1141, 2017. 
29 KUILA, T. et al. Chemical functionalization of graphene and its applications.

Progress in Materials Science, Elsevier, v. 57, n. 7, p. 1061-1105, 2012.

30 FERREIRA, F. V. et al. Functionalization of graphene and applications. In: Functionalizing graphene and carbon nanotubes. [S.I.]: Springer, 2016. p. $1-29$.

31 DIDEIKIN, A. T.; VUL, A. Y. Graphene oxide and derivatives: the place in graphene family. Frontiers in Physics, Frontiers, v. 6, p. 149, 2019.

32 ZHAO, J.; LIU, L.; LI, F. Graphene oxide: physics and applications. [S.I.]: Springer, 2015. v. 1.

$33 \mathrm{KIM}$, J.; COTE, L. J.; HUANG, J. Two dimensional soft material: new faces of graphene oxide. Accounts of chemical research, ACS Publications, v. 45, n. 8 , p. 1356-1364, 2012.

34 LI, F. et al. Graphene oxide: a promising nanomaterial for energy and environmental applications. Nano energy, Elsevier, v. 16, p. 488-515, 2015.

35 RANI, S. et al. Characterization and dispersibility of improved thermally stable amide functionalized graphene oxide. Materials Research Bulletin, Elsevier, v. 60, p. 143-149, 2014.

$36 \mathrm{HU}, \mathrm{Y}$. et al. Amino-functionalization of graphene sheets and the fabrication of their nanocomposites. Polymer composites, Wiley Online Library, v. 31, n. 12, p. 1987-1994, 2010.

37 WANG, S. et al. Ethylenediamine modified graphene and its chemically responsive supramolecular hydrogels. Industrial \& Engineering Chemistry Research, ACS Publications, v. 53, n. 33, p. 13205-13209, 2014.

$38 \mathrm{MEI}$, L. et al. Amino-functionalized graphene oxide for the capture and photothermal inhibition of bacteria. ACS Applied Nano Materials, ACS Publications, v. 2, n. 5, p. 2902-2908, 2019.

39 LIU, S. et al. Antibacterial activity of graphite, graphite oxide, graphene oxide, and reduced graphene oxide: membrane and oxidative stress. ACS nano, ACS Publications, v. 5, n. 9, p. 6971-6980, 2011.

40 SINGH, D. P. et al. Graphene oxide: An efficient material and recent approach for biotechnological and biomedical applications. Materials Science and Engineering: C, Elsevier, v. 86, p. 173-197, 2018.

41 YE, S. et al. Antiviral activity of graphene oxide: how sharp edged structure and charge matter. ACS applied materials \& interfaces, ACS Publications, v. 7 , n. 38, p. 21571-21579, 2015.

42 GIUDICE, F. D.; SHEN, A. Q. Shear rheology of graphene oxide dispersions. Current opinion in chemical engineering, Elsevier, v. 16, p. 23-30, 2017.

43 DIMIEV, A. M.; EIGLER, S. Graphene oxide: fundamentals and applications. [S.I.]: John Wiley \& Sons, 2016. 
44 VALLÉS, C. et al. The rheological behaviour of concentrated dispersions of graphene oxide. Journal of Materials Science, Springer, v. 49, n. 18, p. 6311-6320, 2014.

45 JALILI, R. et al. Organic solvent-based graphene oxide liquid crystals: a facile route toward the next generation of self-assembled layer-by-layer multifunctional 3d architectures. Acs Nano, ACS Publications, v. 7, n. 5, p. 3981-3990, 2013.

$46 \mathrm{XU}, \mathrm{Z}$. et al. Highly electrically conductive ag-doped graphene fibers as stretchable conductors. Advanced Materials, Wiley Online Library, v. 25, n. 23, p. 3249-3253, 2013.

47 ZHANG, W. L.; CHOI, H. J. Graphene oxide based smart fluids. Soft Matter, Royal Society of Chemistry, v. 10, n. 35, p. 6601-6608, 2014.

48 TESFAI, W. et al. Rheology and microstructure of dilute graphene oxide suspension. Journal of nanoparticle research, Springer, v. 15 , n. 10, p. 1-7, 2013.

49 NAFICY, S. et al. Graphene oxide dispersions: tuning rheology to enable fabrication. Materials Horizons, Royal Society of Chemistry, v. 1, n. 3, p. 326-331, 2014.

50 KUMAR, P. et al. Rheological properties of graphene oxide liquid crystal. Carbon, Elsevier, v. 80, p. 453-461, 2014.

51 SOARES, Y. C. F. et al. Influence of oxidation degree of graphene oxide on the shear rheology of poly (ethylene glycol) suspensions. Fluids, Multidisciplinary Digital Publishing Institute, v. 5, n. 2, p. 41, 2020.

52 LIU, S.; BASTOLA, A. K.; LI, L. A 3d printable and mechanically robust hydrogel based on alginate and graphene oxide. ACS applied materials \& interfaces, ACS Publications, v. 9, n. 47, p. 41473-41481, 2017.

53 LING, S. et al. Highly concentrated graphene oxide ink for facile $3 \mathrm{~d}$ printing of supercapacitors. Nano Materials Science, Elsevier, v. 1, n. 2, p. 142-148, 2019.

54 GARCÍA-TUÑÓN, E. et al. Graphene oxide: an all-in-one processing additive for 3d printing. ACS applied materials \& interfaces, ACS Publications, v. 9, n. 38, p. 32977-32989, 2017.

55 FU, K. et al. Graphene oxide-based electrode inks for 3d-printed lithium-ion batteries. Advanced Materials, Wiley Online Library, v. 28, n. 13, p. 2587-2594, 2016.

56 LI, H.; LIU, S.; LIN, L. Rheological study on 3d printability of alginate hydrogel and effect of graphene oxide. International Journal of Bioprinting, Whioce, v. 2, n. 2, 2016.

57 ZHONG, J. et al. 3d printing strong and conductive geo-polymer nanocomposite structures modified by graphene oxide. Carbon, Elsevier, v. 117, p. 421-426, 2017. 
58 KOSYNKIN, D. V. et al. Graphene oxide as a high-performance fluid-loss-control additive in water-based drilling fluids. ACS applied materials \& interfaces, ACS Publications, v. 4, n. 1, p. 222-227, 2012.

59 LIU, S. et al. Effect of graphene and graphene oxide addition on lubricating and friction properties of drilling fluids. Nanoscience and Nanotechnology Letters, American Scientific Publishers, v. 9, n. 4, p. 446-452, 2017.

60 SALEH, T. A.; RANA, A.; ARFAJ, M. K. Graphene grafted with polyethyleneimine for enhanced shale inhibition in the water-based drilling fluid. Environmental Nanotechnology, Monitoring \& Management, Elsevier, v. 14, p. $100348,2020$.

$61 \mathrm{LEI}, \mathrm{L}$. et al. Preparation and properties of amino-functional reduced graphene oxide/waterborne polyurethane hybrid emulsions. Progress in organic coatings, Elsevier, v. 97, p. 19-27, 2016.

62 HAGHDADEH, P. et al. The role of functionalized graphene oxide on the mechanical and anti-corrosion properties of polyurethane coating. Journal of the Taiwan Institute of Chemical Engineers, Elsevier, v. 86, p. 199-212, 2018.

63 POURHASHEM, S. et al. Excellent corrosion protection performance of epoxy composite coatings filled with amino-silane functionalized graphene oxide. Surface and Coatings Technology, Elsevier, v. 317, p. 1-9, 2017.

64 SUN, T. et al. Achieving high-performance epoxy nanocomposites with trifunctional poly (oxypropylene) amines functionalized graphene oxide. High Performance Polymers, SAGE Publications Sage UK: London, England, v. 31, n. 5, p. 557-569, 2019.

65 WAN, Y.-J. et al. Mechanical properties of epoxy composites filled with silane-functionalized graphene oxide. Composites Part A: Applied Science and Manufacturing, Elsevier, v. 64, p. 79-89, 2014.

66 RYU, S. H.; SIN, J.; SHANMUGHARAJ, A. Study on the effect of hexamethylene diamine functionalized graphene oxide on the curing kinetics of epoxy nanocomposites. European polymer journal, Elsevier, v. 52, p. 88-97, 2014.

67 MISSALA, T. et al. Study on tribological properties of lubricating grease with additive of graphene. In: Progress in Automation, Robotics and Measuring Techniques. [S.I.]: Springer, 2015. p. 181-187.

68 KINOSHITA, $\mathrm{H}$. et al. Tribological properties of monolayer graphene oxide sheets as water-based lubricant additives. Carbon, Elsevier, v. 66, p. 720-723, 2014.

69 FAN, $\mathrm{X}$. et al. Multilayer graphene as a lubricating additive in bentone grease. Tribology Letters, Springer, v. 55, n. 3, p. 455-464, 2014.

70 CHENG, Z.-L.; QIN, X.-X. Study on friction performance of graphene-based semi-solid grease. Chinese Chemical Letters, Elsevier, v. 25, n. 9, p. 1305-1307, 2014. 
71 RAWAT, S. S. et al. Effect of graphene-based nanoadditives on the tribological and rheological performance of paraffin grease. Journal of Materials Engineering and Performance, Springer, v. 29, n. 4, p. 2235-2247, 2020.

$72 \mathrm{YI}, \mathrm{S}$. et al. Performance and mechanisms of graphene oxide suspended cutting fluid in the drilling of titanium alloy ti-6al-4v. Journal of Manufacturing Processes, Elsevier, v. 29, p. 182-193, 2017.

73 LEE, J. et al. Graphene oxide nanoplatelets composite membrane with hydrophilic and antifouling properties for wastewater treatment. Journal of membrane science, Elsevier, v. 448, p. 223-230, 2013.

74 ZHAO, C. et al. Highly effective antifouling performance of pvdf/graphene oxide composite membrane in membrane bioreactor ( $\mathrm{mbr}$ ) system. Desalination, Elsevier, v. 340, p. 59-66, 2014.

75 SHAO, W. et al. Fabrication of ph-sensitive thin-film nanocomposite nanofiltration membranes with enhanced performance by incorporating amine-functionalized graphene oxide. Applied Surface Science, Elsevier, v. 487, p. 1209-1221, 2019.

76 SHANG, Y. et al. Effect of graphene oxide on the rheological properties of cement pastes. Construction and Building Materials, Elsevier, v. 96, p. 20-28, 2015.

77 WANG, M. et al. Chemically functionalized graphene oxide as the additive for cement-matrix composite with enhanced fluidity and toughness. Construction and Building Materials, Elsevier, v. 150, p. 150-156, 2017.

$78 \mathrm{HU}, \mathrm{M}$. et al. Dispersion of triethanolamine-functionalized graphene oxide (tea-go) in pore solution and its influence on hydration, mechanical behavior of cement composite. Construction and Building Materials, Elsevier, v. 216, p. 128-136, 2019.

79 CURRAN, S. et al. Properties of carbopol solutions as models for yield-stress fluids. Journal of food science, Wiley Online Library, v. 67, n. 1, p. 176-180, 2002.

80 BRODIE, B. C. Xiii. on the atomic weight of graphite. Philosophical transactions of the Royal Society of London, The Royal Society London, n. 149 , p. $249-259,1859$.

81 GEIM, A. Graphene prehistory. Physica Scripta, IOP Publishing, v. 2012, n. T146, p. 014003, 2012.

82 WALLACE, P. R. The band theory of graphite. Physical review, APS, v. 71, n. 9 , p. 622, 1947.

83 DREYER, D. R.; RUOFF, R. S.; BIELAWSKI, C. W. From conception to realization: an historial account of graphene and some perspectives for its future.

Angewandte Chemie International Edition, Wiley Online Library, v. 49, n. 49, p. 9336-9344, 2010. 
84 ZHONG, Y.; ZHEN, Z.; ZHU, H. Graphene: Fundamental research and potential applications. FlatChem, Elsevier, v. 4, p. 20-32, 2017.

85 BOEHM, H.-P. et al. Das adsorptionsverhalten sehr dünner kohlenstoff-folien. Zeitschrift für anorganische und allgemeine Chemie, Wiley Online Library, v. 316, n. 3-4, p. 119-127, 1962.

86 BOEHM, H.; SETTON, R.; STUMPP, E. Nomenclature and terminology of graphite intercalation compounds. report by a subgroup of the international committee for characterization and terminology of carbon and graphite on suggestions for rules for the nomenclature and terminology of graphite intercalation compounds. Synthetic metals, Elsevier, v. 11, n. 6, p. 363-371, 1985.

87 BOEHM, H. P.; SETTON, R.; STUMPP, E. Nomenclature and terminology of graphite intercalation compounds (iupac recommendations 1994). Pure and Applied Chemistry, De Gruyter, v. 66, n. 9, p. 1893-1901, 1994.

88 GERSTNER, E. Nobel prize 2010: Andre geim \& konstantin novoselov. Nature Physics, Nature Publishing Group, v. 6, n. 11, p. 836-836, 2010.

89 NOORDEN, R. V. Production: Beyond sticky tape. Nature, Nature Publishing Group, v. 483, n. 7389, p. S32-S33, 2012.

90 RANDVIIR, E. P.; BROWNSON, D. A.; BANKS, C. E. A decade of graphene research: production, applications and outlook. Materials Today, Elsevier, v. 17, n. 9 , p. 426-432, 2014.

91 NOVOSELOV, K. S.; GEIM, A. The rise of graphene. Nat. Mater, v. 6, n. 3, p. 183-191, 2007.

92 ZHANG, $H$. Ultrathin two-dimensional nanomaterials. ACS nano, ACS Publications, v. 9, n. 10, p. 9451-9469, 2015.

93 BIRÓ, L. P.; NEMES-INCZE, P.; LAMBIN, P. Graphene: nanoscale processing and recent applications. Nanoscale, Royal Society of Chemistry, v. 4, n. 6, p. 1824-1839, 2012.

$94 \mathrm{SHU}, \mathrm{G}$; $\mathrm{CHOU}, \mathrm{F}$. Surface conduction and pi-bonds in graphene and topological insulator bi2se3. arXiv preprint arXiv:1212.5982, 2012.

95 TIWARI, S. K. et al. Magical allotropes of carbon: prospects and applications. Critical Reviews in Solid State and Materials Sciences, Taylor \& Francis, v. 41 , n. 4 , p. $257-317,2016$.

96 NETO, A. C. et al. The electronic properties of graphene. Reviews of modern physics, APS, v. 81, n. 1, p. 109, 2009.

97 PERES, N. Graphene, new physics in two dimensions. Europhysics News, EDP Sciences, v. 40, n. 3, p. 17-20, 2009.

98 PIRZADO, A. A. et al. The electrical property of large few layer graphene flakes obtained by microwaves assisted exfoliation of expanded graphite. Current Microwave Chemistry, Bentham Science Publishers, v. 3, n. 2, p. 139-144, 2016. 
99 ZHEN, Z.; ZHU, H. Structure and properties of graphene. In: Graphene. [S.I.]: Elsevier, 2018. p. 1-12.

100 STANKOVICH, S. et al. Graphene-based composite materials. nature, Nature Publishing Group, v. 442, n. 7100, p. 282-286, 2006.

101 STOLLER, M. D. et al. Graphene-based ultracapacitors. Nano letters, ACS Publications, v. 8, n. 10, p. 3498-3502, 2008.

$102 \mathrm{GHOSH}$, S. et al. Heat conduction in graphene: experimental study and theoretical interpretation. New Journal of Physics, IOP Publishing, v. 11, n. 9, p. 095012, 2009.

103 TIWARI, S. K. et al. Graphene research and their outputs: Status and prospect. Journal of Science: Advanced Materials and Devices, Elsevier, v. 5, n. 1, p. 10-29, 2020.

104 ALLEN, M. J.; TUNG, V. C.; KANER, R. B. Honeycomb carbon: a review of graphene. Chemical reviews, ACS Publications, v. 110, n. 1, p. 132-145, 2010.

105 YANG, G. et al. Structure of graphene and its disorders: a review. Science and technology of advanced materials, Taylor \& Francis, v. 19, n. 1, p. 613-648, 2018.

106 JING, N. et al. Effect of defects on young's modulus of graphene sheets: a molecular dynamics simulation. Rsc Advances, Royal Society of Chemistry, v. 2, n. 24, p. 9124-9129, 2012.

107 PENG, Y.; WANG, Z.; ZOU, K. Friction and wear properties of different types of graphene nanosheets as effective solid lubricants. Langmuir, ACS Publications, v. 31, n. 28 , p. $7782-7791,2015$.

108 DASARI, B. L. et al. Graphene and derivatives-synthesis techniques, properties and their energy applications. Energy, Elsevier, v. 140, p. 766-778, 2017.

109 TIWARI, S. K. et al. Evolution of graphene oxide and graphene: from imagination to industrialization. ChemNanoMat, Wiley Online Library, v. 4, n. 7, p. 598-620, 2018.

110 BHUYAN, M. S. A. et al. Synthesis of graphene. International Nano Letters, Springer, v. 6, n. 2, p. 65-83, 2016.

111 LIANG, A. et al. Recent developments concerning the dispersion methods and mechanisms of graphene. Coatings, Multidisciplinary Digital Publishing Institute, v. 8, n. 1, p. $33,2018$.

112 LI, D. et al. Processable aqueous dispersions of graphene nanosheets. Nature nanotechnology, Nature Publishing Group, v. 3, n. 2, p. 101-105, 2008.

113 GEORGAKILAS, V. et al. Functionalization of graphene: covalent and non-covalent approaches, derivatives and applications. Chemical reviews, ACS Publications, v. 112, n. 11, p. 6156-6214, 2012. 
114 KHAN, A. et al. Graphene Functionalization Strategies. [S.I.]: Springer, 2019.

115 STURALA, J. et al. Chemistry of graphene derivatives: Synthesis, applications, and perspectives. Chemistry-A European Journal, Wiley Online Library, v. 24, n. 23, p. 5992-6006, 2018.

116 FRAGA, T. J. et al. Functionalized graphene-based materials as innovative adsorbents of organic pollutants: A concise overview. Brazilian Journal of Chemical Engineering, SciELO Brasil, v. 36, n. 1, p. 1-31, 2019.

117 BOTTARI, G. et al. Chemical functionalization and characterization of graphene-based materials. Chemical Society Reviews, Royal Society of Chemistry, v. 46, n. 15, p. 4464-4500, 2017.

118 YAN, L. et al. Chemistry and physics of a single atomic layer: strategies and challenges for functionalization of graphene and graphene-based materials. Chemical Society Reviews, Royal Society of Chemistry, v. 41, n. 1, p. 97-114, 2012.

119 HU, Y.; SUN, X. Chemically functionalized graphene and their applications in electrochemical energy conversion and storage. Advances in graphene science, InTech, p. 161-189, 2013.

120 IONIT Ă, M. et al. Graphene and functionalized graphene: Extraordinary prospects for nanobiocomposite materials. Composites Part B: Engineering, Elsevier, v. 121, p. 34-57, 2017.

121 JOHNS, J. E.; HERSAM, M. C. Atomic covalent functionalization of graphene. Accounts of chemical research, ACS Publications, v. 46, n. 1, p. 77-86, 2013.

122 DANIEL, R. D. et al. The chemistry of graphene oxide. Chemical Society Reviews, v. 39, n. 1, p. 228-240, 2010.

123 PARK, S.; RUOFF, R. S. Chemical methods for the production of graphenes. Nature nanotechnology, Nature Publishing Group, v. 4, n. 4, p. 217-224, 2009.

124 STAUDENMAIER, L. Verfahren zur darstellung der graphitsäure. Berichte der deutschen chemischen Gesellschaft, Wiley Online Library, v. 31, n. 2, p. 1481-1487, 1898.

125 HUMMERS, W.; OfFEMAN, R. J am chem soc 80: 1339. J. Amer. Chem. Soc, v. 80, 1958.

126 MUZYKA, R. et al. Oxidation of graphite by different modified hummers methods. New Carbon Materials, Elsevier, v. 32, n. 1, p. 15-20, 2017.

127 RAO, C. N. R.; SOOD, A. K. Graphene: synthesis, properties, and phenomena. [S.I.]: John Wiley \& Sons, 2013.

128 ADETAYO, A.; RUNSEWE, D. et al. Synthesis and fabrication of graphene and graphene oxide: a review. Open journal of composite materials, Scientific Research Publishing, v. 9, n. 02, p. 207, 2019. 
$129 \mathrm{YU}, \mathrm{W}$. et al. Progress in the functional modification of graphene/graphene oxide: a review. RSC Advances, Royal Society of Chemistry, v. 10, n. 26, p. 15328-15345, 2020.

130 CHEN, D.; FENG, H.; LI, J. Graphene oxide: preparation, functionalization, and electrochemical applications. Chemical reviews, ACS Publications, v. 112, n. 11, p. 6027-6053, 2012.

131 KIM, F.; COTE, L. J.; HUANG, J. Graphene oxide: surface activity and two-dimensional assembly. Advanced Materials, Wiley Online Library, v. 22, n. 17, p. 1954-1958, 2010.

132 CRACIUN, M. et al. Properties and applications of chemically functionalized graphene. Journal of Physics: Condensed Matter, IOP Publishing, v. 25, n. 42, p. 423201, 2013.

$133 \mathrm{KIM}$, J. et al. Graphene oxide sheets at interfaces. Journal of the American Chemical Society, ACS Publications, v. 132, n. 23, p. 8180-8186, 2010.

134 KONKENA, B.; VASUDEVAN, S. Understanding aqueous dispersibility of graphene oxide and reduced graphene oxide through $\mathrm{p} \mathrm{k}$ a measurements. The journal of physical chemistry letters, ACS Publications, v. 3, n. 7, p. 867-872, 2012.

135 WANG, M. et al. The dispersion and aggregation of graphene oxide in aqueous media. Nanoscale, Royal Society of Chemistry, v. 8, n. 30, p. 14587-14592, 2016.

$136 \mathrm{LOH}, \mathrm{K}$. P. et al. Graphene oxide as a chemically tunable platform for optical applications. Nature chemistry, Nature Publishing Group, v. 2, n. 12, p. 1015, 2010.

137 KRISHNAMOORTHY, K. et al. The chemical and structural analysis of graphene oxide with different degrees of oxidation. Carbon, Elsevier, v. 53, p. 38-49, 2013.

138 LIU, L. et al. Amorphous structural models for graphene oxides. Carbon, Elsevier, v. 50, n. 4, p. 1690-1698, 2012.

139 GILJE, S. et al. A chemical route to graphene for device applications. Nano letters, ACS Publications, v. 7, n. 11, p. 3394-3398, 2007.

140 LIU, L. et al. Mechanical properties of graphene oxides. Nanoscale, Royal Society of Chemistry, v. 4, n. 19, p. 5910-5916, 2012.

141 SUK, J. W. et al. Mechanical properties of monolayer graphene oxide. ACS nano, ACS Publications, v. 4, n. 11, p. 6557-6564, 2010.

142 ZHENG, Q. et al. Effects of functional groups on the mechanical and wrinkling properties of graphene sheets. Carbon, Elsevier, v. 48, n. 15, p. 4315-4322, 2010.

143 GÓMEZ-NAVARRO, C.; BURGHARD, M.; KERN, K. Elastic properties of chemically derived single graphene sheets. Nano letters, ACS Publications, v. 8, n. 7, p. 2045-2049, 2008. 
144 DIKIN, D. A. et al. Preparation and characterization of graphene oxide paper. Nature, Nature Publishing Group, v. 448, n. 7152, p. 457-460, 2007.

145 HUANG, X.-M. et al. Physical properties and device applications of graphene oxide. Frontiers of Physics, Springer, v. 15, n. 3, p. 33301, 2020.

146 CHEN, J.; LI, L. Effect of oxidation degree on the thermal properties of graphene oxide. Journal of Materials Research and Technology, Elsevier, v. 9, n. 6 , p. $13740-13748,2020$.

147 CLARK, S. P. Handbook of physical constants. [S.I.]: Geological Society of America, 1966. v. 97.

148 HO, C. Y.; POWELL, R. W.; LILEY, P. E. Thermal conductivity of the elements. Journal of Physical and Chemical Reference Data, American Institute of Physics for the National Institute of Standards and ..., v. 1, n. 2, p. 279-421, 1972.

149 PERREAULT, F. et al. Antimicrobial properties of graphene oxide nanosheets: why size matters. ACS nano, ACS Publications, v. 9, n. 7, p. 7226-7236, 2015.

$150 \mathrm{GAO}, \mathrm{Y}$. et al. Impact of graphene oxide on the antibacterial activity of antibiotics against bacteria. Environmental Science: Nano, Royal Society of Chemistry, v. 4, n. 5, p. 1016-1024, 2017.

151 SAWANGPHRUK, M. et al. Synthesis and antifungal activity of reduced graphene oxide nanosheets. Carbon, Elsevier, v. 50, n. 14, p. 5156-5161, 2012.

152 HUANG, J. et al. Graphene oxide as a functional excipient in buccal films for delivery of clotrimazole: Effect of molecular interactions on drug release and antifungal activity in vitro. International Journal of Pharmaceutics, Elsevier, v. 589, p. 119811, 2020.

153 CAI, N.; LARESE-CASANOVA, P. Application of positively-charged ethylenediamine-functionalized graphene for the sorption of anionic organic contaminants from water. Journal of environmental chemical engineering, Elsevier, v. 4, n. 3, p. 2941-2951, 2016.

154 PARASKAR, P.; BARI, P.; MISHRA, S. Influence of amine functionalized graphene oxide on mechanical and thermal properties of epoxy matrix composites. Iranian Polymer Journal, Springer, v. 29, n. 1, p. 47-55, 2020.

155 JANG, J. et al. Graphene oxide nanocomposite membrane cooperatively cross-linked by monomer and polymer overcoming the trade-off between flux and rejection in forward osmosis. Journal of Membrane Science, Elsevier, v. 598, p. $117684,2020$.

156 ZHANG, W. et al. Preparation of amino-functionalized graphene oxide by hoffman rearrangement and its performances on polyacrylate coating latex. Progress in Organic Coatings, Elsevier, v. 94, p. 9-17, 2016.

157 FERREIRA, F. et al. Functionalized graphene oxide as reinforcement in epoxy based nanocomposites. Surfaces and Interfaces, Elsevier, v. 10, p. 100-109, 2018. 
158 LU, B.-Y. et al. Functionalized graphene oxide nanosheets with unique three-in-one properties for efficient and tunable antibacterial applications. Nano Research, Springer, v. 14, n. 1, p. 185-190, 2021.

159 RIBEIRO, $\mathrm{H}$. et al. Multifunctional nanocomposites based on tetraethylenepentamine-modified graphene oxide/epoxy. Polymer Testing, Elsevier, v. 43, p. 182-192, 2015.

160 OUELLETTE, R.; RAWN, J. Amines and amides. In: Organic Chemistry Study Guide. [S.I.: s.n.], 2015. p. 465-494.

161 OUELLETTE, R. J.; RAWN, J. D. Amines and amides. In: Organic Chemistry. [S.I.]: Elsevier, 2018. p. 763-800.

162 BARNES, H. A. A handbook of elementary rheology. [S.I.]: University of Wales, Institute of Non-Newtonian Fluid Mechanics Aberystwyth, 2000. v. 1.

163 LARSON, R. G. The structure and rheology of complex fluids. [S.I.]: Oxford university press New York, 1999. v. 150.

164 CHHABRA, R. P. Non-newtonian fluids: an introduction. In: Rheology of complex fluids. [S.I.]: Springer, 2010. p. 3-34.

165 BRANNICK, J.; KIRSHTEIN, A.; LIU, C. Dynamics of multi-component flows: diffusive interface methods with energetic variational approaches. Reference Module in Materials Science and Materials Engineering, p. 1-7, 2016.

166 BIRD, R. B.; ARMSTRONG, R. C.; HASSAGER, O. Dynamics of polymeric liquids. vol. 1: Fluid mechanics. 1987.

167 COUSSOT, P. Introduction to the rheology of complex fluids. In: Understanding the rheology of concrete. [S.I.]: Elsevier, 2012. p. 3-22.

168 IRGENS, F. Rheology and non-newtonian fluids. [S.I.]: Springer, 2014. v. 190 .

169 KRISHNAN, J. M.; DESHPANDE, A. P.; KUMAR, P. S. Rheology of complex fluids. [S.I.]: Springer, 2010.

170 BARNES, H. A.; HUTTON, J. F.; WALTERS, K. An introduction to rheology. [S.I.]: Elsevier, 1989. v. 3.

171 REINER, M. Rheology. In: Elasticity and Plasticity/Elastizität und Plastizität. [S.I.]: Springer, 1958. p. 434-550.

172 DALWADI, D. H. et al. Rheology: an important tool in ink development. American Laboratory, THE ROYAL SOCIETY OF CHEMISTRY, v. 37, n. 23, p. $18,2005$.

173 NELSON, A. Z.; EWOLDT, R. H. Design of yield-stress fluids: A rheology-to-structure inverse problem. Soft matter, Royal Society of Chemistry, v. 13, n. 41, p. 7578-7594, 2017. 
174 NELSON, A. Z. et al. Designing and transforming yield-stress fluids. Current Opinion in Solid State and Materials Science, Elsevier, v. 23, n. 5, p. 100758, 2019.

175 BHATTACHARJEE, T. et al. Writing in the granular gel medium. Science advances, American Association for the Advancement of Science, v. 1, n. 8, p. e1500655, 2015.

176 COUSSOT, P.; BERTRAND, F.; HERZHAFT, B. Rheological behavior of drilling muds, characterization using mri visualization. Oil \& gas science and technology, EDP Sciences, v. 59, n. 1, p. 23-29, 2004.

177 APPEL, E. A. et al. Self-assembled hydrogels utilizing polymer-nanoparticle interactions. Nature communications, Nature Publishing Group, v. 6, n. 1, p. 1-9, 2015.

178 HERSCHEL, W. H.; BULKLEY, R. Konsistenzmessungen von gummi-benzollösungen. Kolloid-Zeitschrift, Springer, v. 39, n. 4, p. 291-300, 1926.

179 GAVRILOV, A. A.; FINNIKOV, K. A.; PODRYABINKIN, E. V. Modeling of steady herschel-bulkley fluid flow over a sphere. Journal of Engineering Thermophysics, Springer, v. 26, n. 2, p. 197-215, 2017.

180 BARNES, $\mathrm{H}$. A. The yield stress-a review or ' $\pi \alpha \nu \tau \alpha \rho \varepsilon \iota^{\prime}$-everything flows? Journal of Non-Newtonian Fluid Mechanics, Elsevier, v. 81, n. 1-2, p. 133-178, 1999.

181 MØLLER, P. C.; MEWIS, J.; BONN, D. Yield stress and thixotropy: on the difficulty of measuring yield stresses in practice. Soft matter, Royal Society of Chemistry, v. 2, n. 4, p. 274-283, 2006.

182 MOLLER, P. et al. An attempt to categorize yield stress fluid behaviour. Philosophical Transactions of the Royal Society A: Mathematical, Physical and Engineering Sciences, The Royal Society Publishing, v. 367, n. 1909, p. 5139-5155, 2009.

183 BARNES, H.; WALTERS, K. The yield stress myth? Rheologica acta, Springer, v. 24, n. 4, p. 323-326, 1985.

184 NGUYEN, Q.; BOGER, D. Measuring the flow properties of yield stress fluids. Annual Review of Fluid Mechanics, Annual Reviews 4139 El Camino Way, PO Box 10139, Palo Alto, CA 94303-0139, USA, v. 24, n. 1, p. 47-88, 1992.

185 DINKGREVE, M. et al. On different ways of measuring "the" yield stress. Journal of non-Newtonian fluid mechanics, Elsevier, v. 238, p. 233-241, 2016.

186 MENDES, P. R. de S. et al. Flow of viscoplastic liquids through axisymmetric expansions-contractions. Journal of Non-Newtonian Fluid Mechanics, Elsevier, v. 142, n. 1-3, p. 207-217, 2007.

187 LIU, T.; SOONG, D.; KEE, D. D. A model for structured fluids. Chemical Engineering Communications, Taylor \& Francis, v. 22, n. 5-6, p. 273-286, 1983. 
188 STOKES, J.; TELFORD, J. Measuring the yield behaviour of structured fluids. Journal of Non-Newtonian Fluid Mechanics, Elsevier, v. 124, n. 1-3, p. 137-146, 2004.

189 CRAIG, D. Q. et al. An investigation into the structure and properties of carbopol 934 gels using dielectric spectroscopy and oscillatory rheometry. Journal of controlled release, Elsevier, v. 30, n. 3, p. 213-223, 1994.

190 BARRY, B.; MEYER, M. The rheological properties of carbopol gels i. continuous shear and creep properties of carbopol gels. International journal of pharmaceutics, Elsevier, v. 2, n. 1, p. 1-25, 1979.

191 CARBOPOL ${ }^{\circledR}$ polymer excipients - homopolymers, copolymers \& interpolymers - lubrizol. Disponível em: <https://www.lubrizol.com/Health/ Pharmaceuticals/Excipients/Carbopol-Polymer-Products $>$.

192 PANZADE, P.; PURANIK, P. K. Carbopol polymers: A versatile polymer for pharmaceutical applications. Research Journal of Pharmacy and Technology, rjpt, Raipur, v. 3, n. 3, p. 672-675, 2010.

193 MURAMATSU, M. et al. Application of carbopol ${ }^{\circledR}$ to controlled release

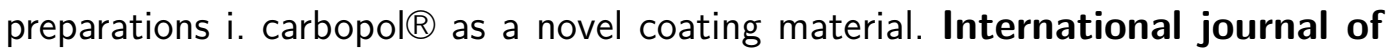
pharmaceutics, Elsevier, v. 199, n. 1, p. 77-83, 2000.

194 DUCHĚNE, D.; TOUCHARD, F.; PEPPAS, N. Pharmaceutical and medical aspects of bioadhesive systems for drug administration. Drug development and industrial pharmacy, Taylor \& Francis, v. 14, n. 2-3, p. 283-318, 1988.

195 WANG, S.; KISLALIOGLU, M.; BREUER, M. The effect of rheological properties of experimental moisturizing creams/lotions on their efficacy and perceptual attributes. International journal of cosmetic science, Wiley Online Library, v. 21, n. 3, p. 167-188, 1999.

196 NAGARAJAN, M. K.; AMBUTER, H. Polymeric stabilizers for liquid detergents. Surfactant science series, p. 129-178, 1996.

197 ELLIOTT, J. E. et al. Structure and swelling of poly (acrylic acid) hydrogels: effect of ph, ionic strength, and dilution on the crosslinked polymer structure. Polymer, Elsevier, v. 45, n. 5, p. 1503-1510, 2004.

198 KETZ, R.; PRUD'HOMME, R.; GRAESSLEY, W. Rheology of concentrated microgel solutions. Rheologica acta, Springer, v. 27, n. 5, p. 531-539, 1988.

199 NAVICKIS, L.; BAGLEY, E. Yield stresses in concentrated dispersions of closely packed, deformable gel particles. Journal of Rheology, The Society of Rheology, v. 27, n. 6, p. 519-536, 1983.

200 GUTOWSKI, I. A. et al. Scaling and mesostructure of carbopol dispersions. Rheologica acta, Springer, v. 51, n. 5, p. 441-450, 2012.

201 GUTOWSKI, I. A. The effects of $\mathbf{p H}$ and concentration on the rheology of Carbopol gels. Tese (Doutorado) - Science: Department of Physics, 2010. 
202 MARCANO, D. C. et al. Improved synthesis of graphene oxide. ACS nano, ACS Publications, v. 4, n. 8, p. 4806-4814, 2010.

203 CHEN, J. et al. An improved hummers method for eco-friendly synthesis of graphene oxide. Carbon, Elsevier, v. 64, p. 225-229, 2013.

204 LUBRIZOL. Neutralizing Carbopol Pemulen in Aqueous Hydroalcoholic Systems - TDS-237. [S.I.], 2009.

205 VARGES, P. R. et al. Rheological characterization of carbopol ${ }^{\circledR}$ dispersions in water and in water/glycerol solutions. Fluids, Multidisciplinary Digital Publishing Institute, v. 4, n. 1, p. 3, 2019.

206 ORTH, E. S. et al. pka determination of graphene-like materials: Validating chemical functionalization. Journal of colloid and interface science, Elsevier, v. 467 , p. 239-244, 2016.

207 AGNIHOTRI, S. M. et al. Electrophoretic mobility of colloidal gold particles in electrolyte solutions. Langmuir, ACS Publications, v. 25, n. 8, p. 4804-4807, 2009.

208 VEČĚ̌, M.; POSPÍŠIL, J. Stability and rheology of aqueous suspensions. Procedia Engineering, Elsevier, v. 42, p. 1720-1725, 2012.

209 OLIVEIRA, Y. D. de et al. The role of physical structure and morphology on the photodegradation behaviour of polypropylene-graphene oxide nanocomposites. Polymer, Elsevier, v. 176, p. 146-158, 2019.

210 KUDIN, K. N. et al. Raman spectra of graphite oxide and functionalized graphene sheets. Nano letters, ACS Publications, v. 8, n. 1, p. 36-41, 2008.

211 MALARD, L. et al. Raman spectroscopy in graphene. Physics reports, Elsevier, v. 473, n. 5-6, p. 51-87, 2009.

212 FERRARI, A. C. Raman spectroscopy of graphene and graphite: Disorder, electron-phonon coupling, doping and nonadiabatic effects. Solid state communications, Elsevier, v. 143, n. 1-2, p. 47-57, 2007.

213 SOCRATES, G. Infrared and Raman characteristic group frequencies: tables and charts. [S.I.]: John Wiley \& Sons, 2004.

214 SMITH, B. C. Infrared spectral interpretation: a systematic approach. [S.I.]: CRC press, 2018.

215 LUCEÑO-SÁNCHEZ, J. A. et al. Synthesis and characterization of graphene oxide derivatives via functionalization reaction with hexamethylene diisocyanate. Nanomaterials, Multidisciplinary Digital Publishing Institute, v. 8, n. 11, p. 870, 2018.

216 RIBEIRO, $H$. et al. Glass transition improvement in epoxy/graphene composites. Journal of materials science, Springer, v. 48, n. 22, p. 7883-7892, 2013. 
217 NIYOGI, S. et al. Solution properties of graphite and graphene. Journal of the American Chemical Society, ACS Publications, v. 128, n. 24, p. 7720-7721, 2006.

218 WAN, Y.-J. et al. Improved dispersion and interface in the graphene/epoxy composites via a facile surfactant-assisted process. Composites science and technology, Elsevier, v. 82, p. 60-68, 2013.

219 SILVA, W. M. et al. Surface properties of oxidized and aminated multi-walled carbon nanotubes. Journal of the Brazilian Chemical Society, SciELO Brasil, v. 23, n. 6, p. 1078-1086, 2012.

220 XUE, Y. et al. Functionalization of graphene oxide with polyhedral oligomeric silsesquioxane (poss) for multifunctional applications. The journal of physical chemistry letters, ACS Publications, v. 3, n. 12, p. 1607-1612, 2012.

221 ARAUJO, M. H. de et al. Nanohybrid material based on carbazole-thiophene-functionalized mwcnt and grafted poly (3-hexylthiophene): Preparation, characterization and spectroelectrochemistry. Synthetic Metals, Elsevier, v. 266, p. 116418, 2020.

$222 \mathrm{XIA}, \mathrm{W}$. et al. Surface characterization of oxygen-functionalized multi-walled carbon nanotubes by high-resolution x-ray photoelectron spectroscopy and temperature-programmed desorption. Applied surface science, Elsevier, v. 254, n. 1, p. 247-250, 2007.

223 AL-GAASHANI, R. et al. Xps and structural studies of high quality graphene oxide and reduced graphene oxide prepared by different chemical oxidation methods. Ceramics International, Elsevier, v. 45, n. 11, p. 14439-14448, 2019.

224 MA, P.-C. et al. Dispersion, interfacial interaction and re-agglomeration of functionalized carbon nanotubes in epoxy composites. Carbon, Elsevier, v. 48, n. 6, p. $1824-1834,2010$.

225 OPPONG, F. K. et al. Microrheology and structure of a yield-stress polymer gel. Physical Review E, APS, v. 73, n. 4, p. 041405, 2006.

$226 \mathrm{KIM}$, J.-Y. et al. Rheological properties and microstructures of carbopol gel network system. Colloid and Polymer Science, Springer, v. 281, n. 7, p. 614-623, 2003.

227 ISLAM, M. T. et al. Rheological characterization of topical carbomer gels neutralized to different ph. Pharmaceutical research, Springer, v. 21, n. 7, p. 1192-1199, 2004.

228 PIAU, J. Carbopol gels: Elastoviscoplastic and slippery glasses made of individual swollen sponges: Meso-and macroscopic properties, constitutive equations and scaling laws. Journal of non-newtonian fluid mechanics, Elsevier, v. 144, n. 1, p. 1-29, 2007.

229 BORREGA, R. et al. Concentration dependence of the low-shear viscosity of polyelectrolyte micro-networks: From hard spheres to soft microgels. EPL (Europhysics Letters), IOP Publishing, v. 47, n. 6, p. 729, 1999. 
230 COUSSOT, P. et al. Macroscopic vs. local rheology of yield stress fluids. Journal of Non-Newtonian Fluid Mechanics, Elsevier, v. 158, n. 1-3, p. 85-90, 2009.

231 OPPONG, F.; BRUYN, J. D. Mircorheology and jamming in a yield-stress fluid. Rheologica acta, Springer, v. 50, n. 4, p. 317-326, 2011.

232 GIUSEPPE, E. D. et al. Characterization of carbopol ${ }^{\circledR}$ hydrogel rheology for experimental tectonics and geodynamics. Tectonophysics, Elsevier, v. 642, p. 29-45, 2015.

233 SAEZ, V. et al. Graphene quantum dots nanoparticles changed the rheological properties of hydrophilic gels (carbopol). Journal of Molecular Liquids, Elsevier, v. 287, p. 110949, 2019.

234 SAMANTA, S. K. et al. Composites of graphene and other nanocarbons with organogelators assembled through supramolecular interactions. Chemistry-A European Journal, Wiley Online Library, v. 18, n. 10, p. 2890-2901, 2012.

235 FAGHIHI, S. et al. Graphene oxide/poly (acrylic acid)/gelatin nanocomposite hydrogel: experimental and numerical validation of hyperelastic model. Materials Science and Engineering: C, Elsevier, v. 38, p. 299-305, 2014.

236 MEWIS, J.; WAGNER, N. J. Thixotropy. Advances in colloid and interface science, Elsevier, v. 147, p. 214-227, 2009.

237 VASU, K. et al. Yield stress, thixotropy and shear banding in a dilute aqueous suspension of few layer graphene oxide platelets. Soft Matter, Royal Society of Chemistry, v. 9, n. 25, p. 5874-5882, 2013.

238 LARSSON, M.; HILL, A.; DUFFY, J. Suspension stability; why particle size, zeta potential and rheology are important. Annual transactions of the Nordic rheology society, v. 20, n. 2012, p. 6, 2012.

239 CLOGSTON, J. D.; PATRI, A. K. Zeta potential measurement. In: Characterization of nanoparticles intended for drug delivery. [S.I.]: Springer, 2011. p. 63-70.

240 MALVERN. Zeta Potential: An Introduction in 30 Minutes. [S.I.], 2015. 